Portland State University

PDXScholar

Spring 5-18-2015

\title{
The Scholarship of Student Affairs Professionals: Effective Writing Strategies and Scholarly Identity Formation Explored through a Coaching Model
}

Lisa Janie Hatfield

Portland State University

Follow this and additional works at: https://pdxscholar.library.pdx.edu/open_access_etds

Part of the Educational Leadership Commons, and the Teacher Education and Professional Development Commons Let us know how access to this document benefits you.

\section{Recommended Citation}

Hatfield, Lisa Janie, "The Scholarship of Student Affairs Professionals: Effective Writing Strategies and Scholarly Identity Formation Explored through a Coaching Model" (2015). Dissertations and Theses. Paper 2311.

https://doi.org/10.15760/etd.2308

This Dissertation is brought to you for free and open access. It has been accepted for inclusion in Dissertations and Theses by an authorized administrator of PDXScholar. For more information, please contact pdxscholar@pdx.edu. 
The Scholarship of Student Affairs Professionals:

Effective Writing Strategies and Scholarly Identity Formation

Explored through a Coaching Model

by

Lisa J. Hatfield

A dissertation submitted in partial fulfillment of the requirements for the degree of

Doctor of Education

in

Educational Leadership: Curriculum and Instruction

\author{
Dissertation Committee: \\ Karen Haley, Chair \\ Dannelle Stevens \\ Micki Caskey \\ James Hook
}

Portland State University

2015 
(C) 2015 Lisa J. Hatfield 


\begin{abstract}
Student affairs professionals work directly with university students in various programs that provide services to these students. From these experiences, they collect daily valuable insights about how to serve students successfully. Yet, in general, they are not publishing about their work even though dissemination of such knowledge through publication could positively impact programs and services across many institutions. My dissertation explored what happens when mid-level student affairs professionals pursue scholarly writing during a structured program intended to help participants produce manuscripts for publication. In working with five professionals in student services at a large urban institution in the Pacific Northwest region of the United States, I learned about participants' identities as scholars as well as which writing strategies they found effective. I worked with participants using case study and action research methodologies and used writing coaching as an intervention to support the tenets of autonomy, competence, and relatedness as defined by Self-Determination Theory. Participants viewed strategies that created a habit of practice that fostered writing to be the most effective. Participants varied in how they viewed themselves professionally along the scholar-practitioner continuum. Leadership can create environments to foster scholarship among student affairs professionals. I give recommendations not only for senior student affairs officers but also for graduate programs in higher education as well as national student affairs organizations to promote research and writing in the profession. Lastly, I share recommendations for further research.
\end{abstract}




\section{Acknowledgments}

The work I do is not possible without the many people who help me daily. My doctoral work is no exception. The people I want to acknowledge and thank first are my participants. They committed to spend hours with me, hours they could have been serving students, completing reports, or addressing a myriad of other high priorities, including spending precious time with their families. They also trusted that I would give honest and fair voice to their words through my writing. I did not take that responsibility lightly and hope I have characterized them with integrity. I want to thank them also for staying with me until the end when it would have been easier and understandable that they not.

My committee members have been invaluable. I wish to thank my adviser Karen Haley for being so supportive, pointed in her feedback, and incredibly timely in all that she does. I admire her astute organizational skills and commitment to me as a learner. She is extremely knowledgeable about the work of student affairs practitioners and is an ally of the profession. For nearly three years now, Dannelle Stevens and Micki Caskey have given me immense guidance as they have served as my doctoral community of practice leaders. I am a better writer because of them, and they are the reason I identify as a scholar. Lastly, I wish to thank Jim Hook for his support as my Office of Graduate Studies representative. He is the kind of faculty member and administrator who seeks to understand the larger picture of the students we serve, and I appreciate his commitment to 
SCHOLARSHIP IN STUDENT AFFAIRS

them. I want to thank all my committee members for dedicating the time and energy to be engaged with my dissertation. Like my participants, I know they have many other priorities, including those that are not work-related, and so I am extremely grateful for their commitment to my work.

Many other people have helped me along the way. My doctoral cohort members have caused me to think hard; they have provided me with a safe and thoughtful community. Faculty members in the Graduate School of Education have also challenged my thinking and have made me want to do more both for them and for myself. My former supervisor Dan Fortmiller also deserves my gratitude for his constant support of both my work and studies as I tried to tackle both concurrently though sometimes not so elegantly.

I wish to thank my family and apologize to them for all that I have missed during my doctoral program, including two Halloweens and countless events. I thank especially my husband, John, who cut short several bike rides so I could do schoolwork. I also thank our daughter, Yunji, for asking only a few times, "When are you going to be done?" I feel as though these past three years have flown by, but I understand if they do not. Finally, I wish to thank my mother, Yon Sun Hong, who cleaned my floors and regularly watched Yunji throughout my studies. My mother never attended elementary school, and so she decided 41 years ago to immigrate to the United States to give her two young children the educational opportunities she never had. The work put into a doctoral program does not begin to compare to what she has endured during her seven decades. Earning this degree is the least I can do to show my gratitude. 


\section{Table of Contents}

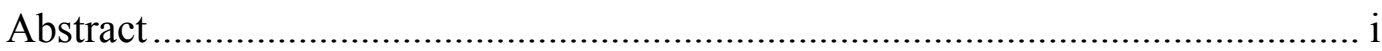

Acknowledgements ....................................................................................... ii

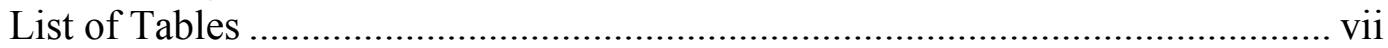

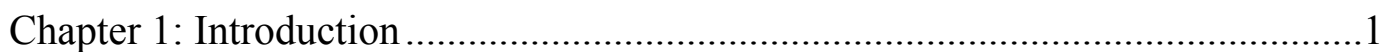

Statement of the Research Problem .......................................................4

Significance of the Research Problem .......................................................4

Presentation of Research Question and Methods..................................... 7

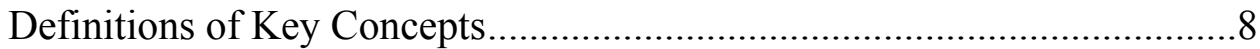

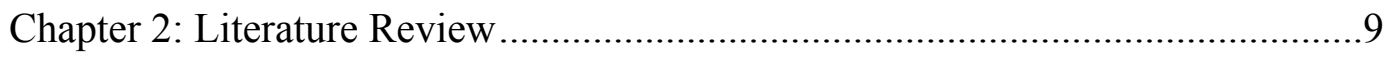

Conceptual Framework: Self-Determination Theory …..........................10

Critique of Self-Determination Theory........................................12

Conceptual Framework: Coaching as a Model for Creating Scholarship..14

Critique of Coaching ...............................................................17

Review of the Research Literature.........................................................18

Brief History of Student Affairs as a Distinct Profession.............19

Divergence between Academic Units and Student Affairs............20

The Push for Scholarship in Student Affairs ..............................22

Publishing Issues in the Workplace ............................................24

Writing as a Block to Publishing .............................................28

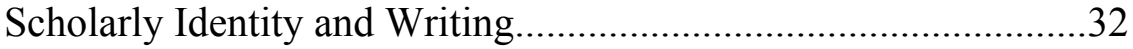

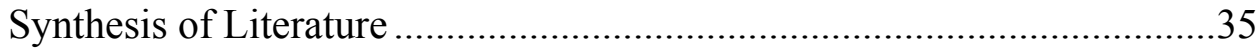

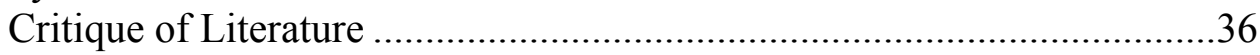

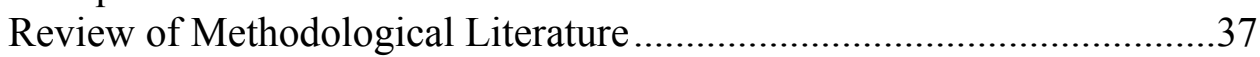

Critique of Case Study and Action Research...............................39

Summary of the Research Literature and Application to the Study ..........39

Chapter 3: Methods ..................................................................................4 40

Research Methods .........................................................................4 40

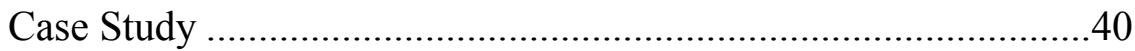

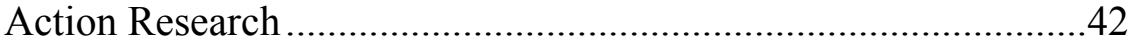

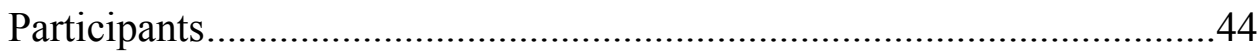

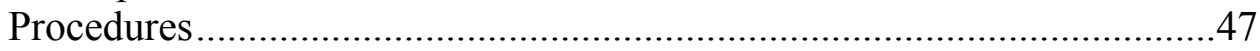

Data and Analysis .......................................................................48

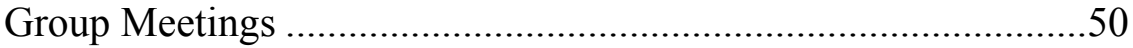

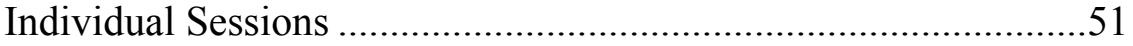

Methods of Analysis ...........................................................52

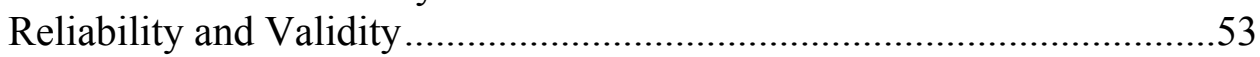

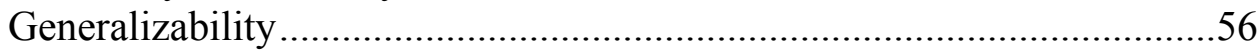

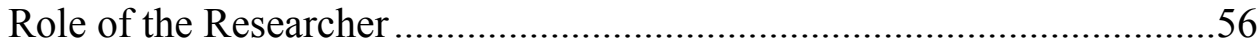

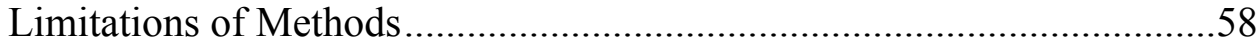

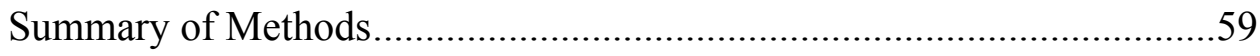




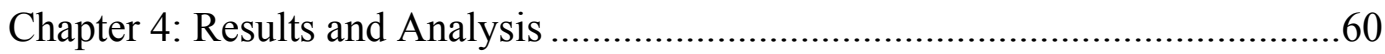

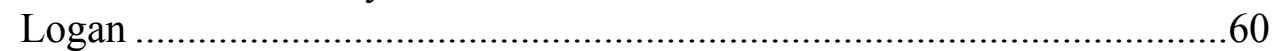

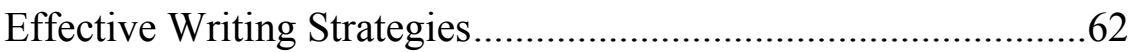

Scholarly Identity Formation ......................................................66

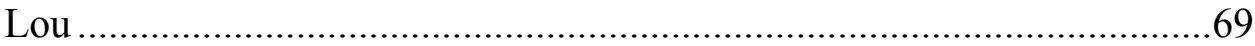

Effective Writing Strategies.......................................................72

Scholarly Identity Formation .......................................................76

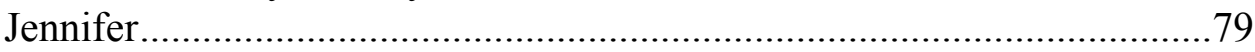

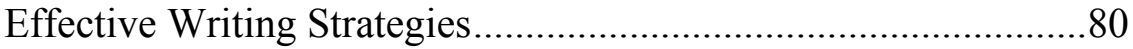

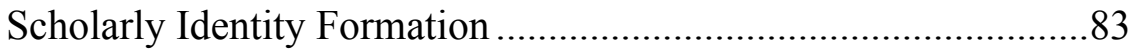

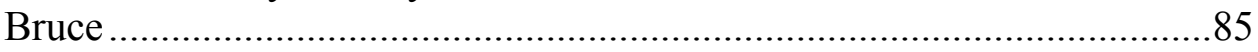

Effective Writing Strategies.......................................................... 87

Scholarly Identity Formation .......................................................90

Diana ……....................................................................................92

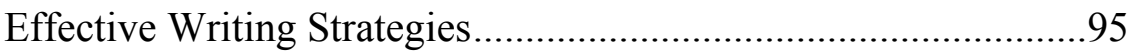

Scholarly Identity Formation .....................................................100

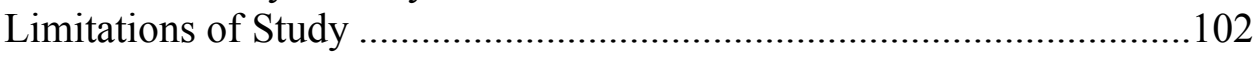

Chapter 5: Discussion and Implications …………….......................................104

Interpretation of Findings across Participants..........................................104

Effective Writing Strategies........................................................107

Scholarly Identity Formation ......................................................111

Synthesis of Findings in Relation to Conceptual Frameworks

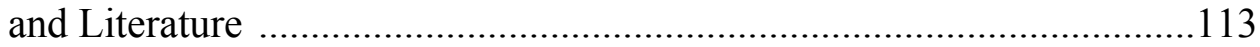

Reflections of Action Research ...........................................................116

Implications and Recommendations ....................................................117

Student Affairs Divisions..........................................................117

Create organizational expectations

and supportive structures ................................................118

Model and mentor ..........................................................121

Graduate Programs in Higher Education .....................................123

National Student Affairs Organizations........................................123

Conclusion

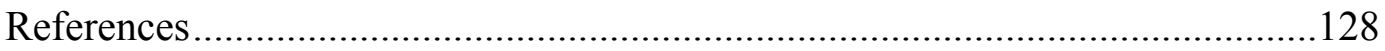

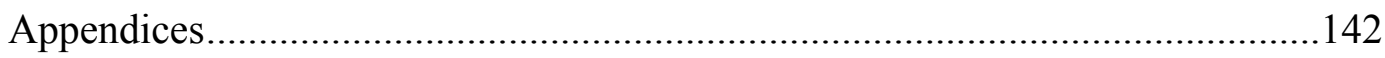

A. Informed Consent Form ...............................................................142

B. Background Questions .....................................................................143

C. Interview Protocol: Guiding Questions and Rationales .......................144

D. Parent, Children, and Grandchildren Codes in Alphabetical Order....145

E. Group Slides Session 1 ...............................................................147

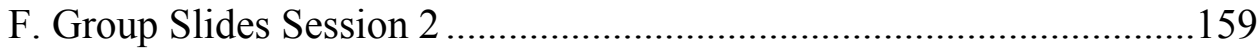

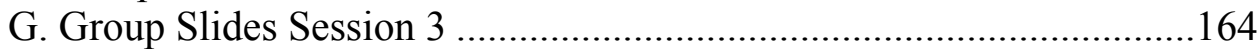

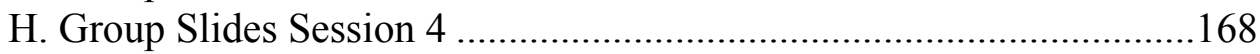


SCHOLARSHIP IN STUDENT AFFAIRS

I. Lou's Organizational Mind Map ...................................................173

J. Diana's Organizational Mind Map.................................................174 
SCHOLARSHIP IN STUDENT AFFAIRS

\section{List of Tables}

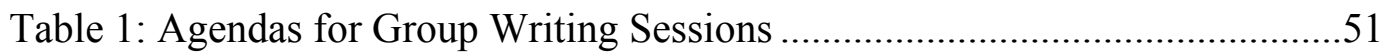




\section{CHAPTER 1: INTRODUCTION}

I am the director of a learning center at a large urban university; my department provides academic support services such as tutoring in many academic disciplines as well as college success courses. One morning as I arrived at work, a graduate student was lamenting that all she needed was someone with whom to talk through her assignment. Almost in tears and visibly frustrated, she relayed that she had been bounced around from office to office, and no one had been able to help her. Before I could take off my coat or put my lunch away, I ushered her in to my office and asked her to take a seat. It was likely that at the same time my colleague in the registrar's office was also tackling a student concern such as figuring out how to create a field for preferred names in the student information system because students identified as transgender had requested this change. As the clock barely reached 9 a.m. the Veterans services director in the building across the quad probably had been on hold for the past half hour with the federal government trying to access a student's GI benefits. I have worked in student affairs for more than a decade, so I know that this array of work is the life of student affairs professionals on private and public college and university campuses across the United States.

It would be helpful if student affairs professionals knew more about what colleagues at their own institutions, not to mention at others, have done in similar situations as those described above. How do such professionals learn from the experiences of their colleagues? The topics of journal articles and discussions sponsored by the two largest national student affairs organizations suggest that scenarios such as 
SCHOLARSHIP IN STUDENT AFFAIRS

these are not isolated to my individual campus (ACPA, 2014; NASPA, 2014a).

Unfortunately, student affairs professionals are not publishing scholarship to share such information (Carpenter, 2001; Fey \& Carpenter, 1996; Saunders \& Cooper, 1999; Semersheim \& Keim, 2005).

Student affairs professionals are not sharing what they know through scholarship. Why? Researchers have identified a number of reasons. Studies show that student affairs practitioners are given little incentive by supervisors for scholarship (Fey \& Carpenter, 1996; Saunders \& Cooper, 1999). Saunders and Cooper (1999) found that chief student affairs officers rated writing articles for publication, developing procedures for research studies, and maintaining scholarly backgrounds in their discipline as skills least important for doctoral graduates in mid-management positions. Mid-level managers in student affairs also appear not to value research and evaluation (Semersheim \& Keim, 2005). Lastly, Saunders et al. (2000) concluded that the profession of student affairs has seen a decrease in scholarship by administrators. If research and scholarship are not valued by supervisors, and staff are not encouraged to participate in such work, it is not surprising that there would be little motivation or incentive to engage in scholarly activities (Schroeder \& Pike, 2001). Add to this the "tyranny of the urgent" (Sriram, 2011, p. 1), which refers to the almost daily fires that need to be addressed immediately when working with students, and the result is that student affairs professionals do not pursue scholarship resulting in publications.

In addition to not feeling supported in creating scholarship as well as the lack of incentive to do so, another reason for not pursuing scholarship could lie outside the 
SCHOLARSHIP IN STUDENT AFFAIRS

functional work areas (e.g., residence life or admissions) of the profession. AbbateVaughn (2012) found graduate students often lack confidence in either writing skills or the publication process. Bair and Mader (2013) concurred and concluded it is commonly accepted that graduate students find academic writing difficult and stressful. Many of my colleagues in student affairs have shared that even though they have graduate degrees and have written theses or even dissertations, they still lack confidence in their writing abilities. Lack of confidence in writing may also impact professional identity. As people who work in universities and colleges, student affairs professionals may view themselves quite unlike their faculty colleagues in that the latter are expected to publish scholarship. Student affairs professionals thus may not view themselves as scholars.

To encourage engagement in scholarly writing, the two largest student affairs professional organizations in the United States, the American College Personnel Association (ACPA) and National Association of Student Personnel Administrators (NASPA), have advocated research and publication. Since 2001, these two organizations and their respective journals have explored topics on scholarship in student affairs and have called for more of such scholarship. For example, in 2006, NASPA held a Summit on Scholarship (Jablonski, Mena, Manning, Carpenter, \& Siko, 2006). In addition, ACPA and NASPA (2010) jointly approved Professional Competency Areas for Student Affairs Practitioners that include using theory to inform practice and contributing to the field through reflections. However, the reality seems to be that scholarship production is not happening widely (Saunders \& Cooper, 1999; Fey \& Carpenter, 1996; Sermershein \& Keim, 2005). 


\section{Statement of the Research Problem}

The problem is student affairs professionals are not widely publishing scholarly work and thus limiting the sharing of practices that could help the students they interact with every day. This lack of publication also impacts professional identity as student affairs practitioners often do not see themselves as contributors to the body of knowledge created on college campuses and universities even though they may understand best how practices and programs work. Unless such professionals, who often work closely with students throughout their entire undergraduate and graduate careers in various support services, take the time to share effective practices, they will not be able to contribute to positive changes to the field. In my study, I sought to understand how a structured writing program could facilitate the publication process so that work can be shared with others and how professional identity is impacted in the process.

\section{Significance of the Research Problem}

Not sharing knowledge about effective practices through scholarship could ultimately impact students negatively. Examples of possible impact on practices can be as life-changing as how best to respond to the traumatic psychological aftermath of an active shooter on campus to the more mundane of creating better online registration processes. A campus may continue to operate just as it always has because faculty and staff are not aware of other practices even though such practices may be more helpful to students. Students would likely benefit if more student affairs professionals were aware of more effective practices taking place on campuses. 
Not knowing how to share research about effective practices or lack of confidence to do so is also an issue of social justice. Student affairs professionals work daily with students, and the landscape of students in higher education is rapidly changing. Enrollment in degree-granting institutions in the United States rose by 37\% from 2000 and 2010 to 21 million students (National Center for Education Statistics, n.d.). Unfortunately, though enrollment increased for Black students during this time, graduation rates for Black students still lag 20\% below their White peers (Lynch \& Engle, 2010a). Graduation rates for Hispanic students are nearly 15\% behind those of White students, and only $13 \%$ of young adult Hispanics hold bachelor's degrees compared with $39 \%$ of Whites and $21 \%$ of Blacks (Lynch \& Engle, 2010b). Pacific Islander students as well as many Southeast Asian students also are far behind their peers in college obtainment (National Commission on Asian American and Pacific Islander Research in Education, 2011). Many student affairs professionals work closely with these student populations through student clubs, the residence halls, student government, and programs such as the federally-funded TRIO programs that support underrepresented students (U.S. Department of Education, 2014). These student affairs professionals have intimate knowledge of what can positively or negatively impact these students' academic success; the practices of such professionals can contribute to creating a more just society.

Exploring scholarship in student affairs also touches on professional identity development, and the process of producing scholarship could impact identity. "Writing is one of the primary sites where scholarly identity is formed and displayed," noted Rose 
and McClafferty (2001, p. 30). Unfortunately, in a survey of senior student affairs officers at 50 colleges and universities, Herdlein (2004) found that participants consistently wanted "vast improvements in writing skills of professional staff" (p. 65). The more student affairs professionals write, the more they may see themselves as scholar practitioners and as contributors to the academy both in practice and in knowledge production. Kidder (2010) defined a scholar practitioner as a person who "engages in research and scholarly endeavors" (p. 1) while continuing in an administrative role. Kram, Wasserman, and Yip (2012) suggested a scholar-practitioner continuum on which professionals place themselves when their roles include generating new knowledge as well as improving practice.

Lastly, an indirect benefit of exploring this problem may be its impact on faculty who create graduate programs in higher education. Carpenter (2001) wrote about the preparation of graduate students in student affairs:

Even students from some of our best programs are inadequately trained in research, evaluation, and assessment. Even when they are rudimentarily trained, they frequently lack a conception of the values of scholarship and their obligation to consume and contribute to research in the field. (p. 187)

Faculty who teach in higher education graduate programs may want to learn more about the writing and research experiences of student affairs practitioners and how these practitioners approached writing in their respective graduate programs. This may inform how faculty choose to teach writing in their own courses. Sriram and Oster (2012) suggested that graduate programs in higher education could assess their own required 
research courses and determine how these programs meet the needs of future professionals to promote more assessment, evaluation, and research in their curricula.

\section{Presentation of Research Questions and Methods}

The purpose of my study was to explore participants' identities as scholars as well as their effective strategies for writing. My research questions were: (a) What writing strategies do student affairs professionals find effective when producing manuscripts to submit for publication in academic or practitioner journals? and (b) How does scholarly identity change during a structured writing program specifically intended to foster professional writing?

Although I believe scholarship presented at conferences or symposia is valuable, my study focused on helping student affairs professionals create manuscripts intended for publication to create broader impact. I define scholarship as publishing about practice and/or research. I also use the terms student affairs professionals and practitioners interchangeably. In my study, I worked individually with five student affairs professionals via the integration of action research and case study methods to explore participants' professional identity and writing goals. I worked with participants using the intervention of coaching, which promotes collaborative and experiential learning to meet goals, and I explored participants' scholarly writing through Self-Determination Theory. Although I worked mainly one-on-one with participants, I also created opportunities for participants to meet and work together as a group. My data consist of individual conversations and interviews, group conversations, journal entries from participants, notes and reflections from my own research journal, and artifacts that include manuscript 
SCHOLARSHIP IN STUDENT AFFAIRS

drafts, outlines, and other tangible items that have to do with participants' writing processes.

\section{Definitions of Key Concepts}

Academic journal: Publications intended for professionals in a certain content area or interest and have guidelines for publication as well as a peer-review process.

Coaching: A model of working together that promotes collaboration in helping the participant reach his or her goals.

Practitioner journal: Publications intended for professionals in a certain content area or interest; they may have guidelines for publication and may have a review process but also publish effective practices that are not necessarily research-based.

Scholarly identity: How people view themselves in their ability to contribute to knowledge creation, including researching and writing about one's work Scholarship: Contributions of knowledge about one's practice and/or research for academic and practitioner journals. Although scholarship includes contributions at conferences and presentations, for my study's purpose, I looked at contributions to journals only.

Student Affairs professional/practitioner: Professionals who work on college campuses and universities in non-academic units or in schools and colleges that support students outside of the academic classroom. Examples include residence life, student health and counseling, and advising. 


\section{CHAPTER 2: LITERATURE REVIEW}

As noted in the previous chapter, the purpose of my study was to explore participants' identities as scholars as well as their effective strategies for writing. My research questions were (a) What writing strategies do student affairs professionals find effective when producing manuscripts to submit for publication in academic or practitioner journals? and (b) How does scholarly identity change during a structured writing program specifically intended to foster professional writing?

To situate my study conceptually, I begin this section with two theoretical frameworks that guided my research: Self-Determination Theory (SDT), which I applied to my participants' identity formation in producing a manuscript, and coaching, a model I used with my study's participants. I provide rationales for using these frameworks in the next section. SDT has been applied to a multitude of settings, including education; because I want to explore SDT in general, I present research tied directly to the theory's main tenets of autonomy, relatedness, and motivation, which are defined below. Because my study is located in a university, I include coaching research largely situated in educational contexts though I give a brief introduction to its beginnings in the business sector.

I then present a brief history of student affairs as a profession to give context for the fairly recent push for scholarship in the profession. Unfortunately, though there has been a call to pursue scholarly work, many professionals are not doing so for a multitude of reasons. I share what the literature suggests why this is happening, which include obstacles in the workplace as well as writing preparation in graduate programs. Most of the literature I review deals directly with student affairs professionals in higher education. 
However, I also present a few studies in business settings because of their application to a large system such as a university or college. Writing for publication can affect professional identity; therefore, I then discuss this issue. I explore literature about professional identity in educational organizations as well research about writing in graduate programs and how this may affect identity.

As noted in Chapter 1, student affairs professionals are not widely publishing even though their professional organizations are advocating for them to do so. My study, therefore, contributes to the field by exploring what strategies are effective in creating a publishable manuscript. In other words, I explored what works in fulfilling the professional push for scholarship. It is my intent that my findings in part can be transferable to student affairs professionals elsewhere so that they may be able to better share their important work. This may positively impact the thousands of students whom these practitioners serve as well as the scholarly or professional identities of the practitioners themselves.

\section{Conceptual Framework: Self-Determination Theory}

In exploring strategies for successful completion of scholarly manuscripts and possible changes to professional identity, I used Self-Determination Theory (SDT) as a theoretical framework in which to situate my study. In this section, I give a summary of SDT and its main tenets. Although SDT is associated with motivation, as explained below, the theory can be applied to identity because if a person is motivated to work toward a goal of creating scholarly writing and successfully uses writing strategies to meet this goal, that person may view himself or herself differently for having gone through an intervention such as facilitated writing coaching. 
SCHOLARSHIP IN STUDENT AFFAIRS

Developed by Deci and Ryan (2002) at the University of Rochester, SDT

represents a broad framework for understanding human motivation and personality. SDT posits that conditions supporting a person's autonomy, competence, and relatedness foster high quality motivation and engagement as well as psychological well-being within a social context. Autonomy is defined here not as being independent but instead "to the feeling of volition that can accompany any act, whether dependent or independent, collectivist or individual" (Ryan \& Deci, 2000b, p. 74). Competence is another term for efficacy or the perceived ability to be able to accomplish a task, and relatedness has to do with a sense of belongingness and connectedness to persons, group, or culture disseminating a goal (Ryan \& Deci, 2000a).

Ryan and Deci (2002) assert that the three needs of autonomy, competence, and relatedness are universal, and that social environments can facilitate, forestall, or fragment these processes. According to Vansteenkiste, Williams, and Resnicow (2012), SDT is characterized "by a sense of parsimony and elegance, as a minimum set of concepts is used to explain a wide variety of phenomena across age groups, life domains, and cultures" (p. 2). Using coaching as the framework of a social environment that can facilitate writing development, I explored how my participants' views of their autonomy and competence in writing as well as their relatedness to the other participants and to me impacted identity and writing growth.

SDT consists of several mini-theories, including those having to do with internal and external motivation. Vallerand and Ratelle (2002) cited one study of a component of SDT in which positive feedback led participants to feel more competent, which led to them to be more intrinsically motivated. Researchers of studies of K-12 and college 
students concluded that intrinsic goal framing "resulted in superior performance"

(Vansteenkiste et al., 2006, p. 24) in various activities over the short and long terms. If intrinsic goal framing produces more positive results, such positive outcomes could impact how people perceive themselves. In feeling more autonomous and competent in one's writing abilities, a person may view himself or herself differently than if feeling a lack of competence to accomplish a task.

SDT suggests that people are oriented differently in how they regulate their behavior and that these orientations can be largely described as autonomy oriented, control oriented, and impersonally oriented (Gagnė \& Deci, 2005). Autonomy orientation reflects a general tendency to be autonomy-supportive and self-determined; control orientation reflects a general tendency to experience social contexts as controlling and to be controlled; and impersonal orientation reflects the general tendency to be amotivated. Autonomy orientation has also been associated with enhanced selfregulation, higher self-esteem, and self-actualization (Baard, Deci, \& Ryan, 2004).

\section{Critique of Self-Determination Theory}

SDT asserts that all humans, "regardless of culture or gender, need to feel both related and autonomous in order to be healthy" (Deci \& Ryan, 2002b, p. 435). I question this notion of universality, as I adhere, like many qualitative researchers, to the ontological perspective of multiple realities. To counter those who critique the assertion of universality of SDT, Deci and Ryan (2002b) responded:

We maintain that, in spite of being a unique and controversial aspect of SDT, the idea of universal needs that are differentially expressed and satisfied as a function of differing social contexts is consistent with the recent work in evolutionary psychology and genetics. (p. 435) 
However, the very fact that western researchers developed SDT has inherent bias. In the above statement Deci and Ryan have foregrounded the sciences of evolution and genetics, which are empirically-based. Smith (2005), in discussing corporate layers of research, discussed the very Western notion of research that defines its methodologies and classification systems based in disciplines of knowledge that are historically embedded in imperialism and the development of science.

I also question SDT's assumption that the concepts of autonomy, competence, and relatedness themselves exist in all cultures. This is more than a simple translation issue. Although Ryan and Deci (2000b) explained that autonomy does not necessarily mean individuals must accomplish something by themselves but rather that they feel they have the agency to do so, without exhaustively exploring even the term and how it is perceived or defined by other cultures, the universality of SDT remains an assumption.

Lastly, many studies of SDT in education and industry are quantitative in nature and use quantitative instruments that have been validated previously for specific populations and in specific contexts. I have intentionally sought qualitative studies and have not been able to find one. Although SDT looks closely at motivation of people, individual voices are absent. What is heard instead are the researchers' voices. This is highly ironic in that SDT has to do with individuals. "Research is not just a highly moral and civilized search for knowledge; it is a set of very human activities that reproduce particular social relations of power," wrote Smith $(2005$, p. 88$)$. The power in the SDT research remains clearly with the authority of the researcher. 


\section{Conceptual Framework: Coaching as a Model for Creating Scholarship}

One model that is useful to promote more scholarship by student affairs professionals is that of coaching. I used coaching as an intervention with my participants; in this sense, coaching can be considered a method. However, because the three tenets of autonomy, competence, and relatedness of SDT can be facilitated by the model of coaching, I consider coaching to be a conceptual framework as well. Coaching, like SDT, is one way to organize my research in exploring the case of scholarship in student affairs. Like other theories that help explain behavior or ways of understanding reality, coaching also is undergirded by general tenets and beliefs through which to view a situation, in this case sessions that facilitate writing for publication.

A significant increase in coaching literature has appeared in the past decade, with more than half of the scholarly articles about coaching published in this relatively short time period and mostly in executive or business roles (Gardiner \& Kearns, 2012). Coaching has been defined as a professional relationship in which coaches and clients work together with the former facilitating experiential learning often in the context of working toward the latter's specific goals (Biswas-Diener, 2009). However, though largely used in industry, coaching has been a method of professional development that has been used by teachers and faculty from primary grades to higher education (Goldman, Wesner, \& Karnchanomai, 2013).

In education, coaching has been described as encouraging "persistence and completion by helping students find ways to overcome both academic and 'real-life' barriers and to identify strategies for success" (Bettinger \& Baker, 2011, p. 10). Coaching has also been looked at as moving a teacher "to a higher level of 
competence, confidence, performance, or insight ... Coaching is all about change" (Reiss, 2007, p. 11). Instructional coaching of teachers should be seen as a non-evaluative, learning relationship that fosters real change (Knight, 2006). These ideas of coaching can benefit those who desire to write in their professional roles (Gardiner \& Kearns, 2012), and all of these views can be applied to coaching student affairs professionals to create scholarly work for publication in an appropriate journal.

Coaching, whether one-on-one or in a group, can foster the relatedness component of Self-Determination Theory (SDT) (Ryan \& Deci, 2006). Ryan and Deci (2000b) wrote that the groundwork for facilitating internalization that leads to motivation has to do with relatedness, which is described as providing a sense of belongingness and connectedness to the person, group, or culture disseminating a goal. They went on to state that perceived competence, another component of SDT, can be supported through offering optimal challenges and appropriate feedback. Both of these are offered in coaching models. Optimal challenges can also be described as scaffolding, which provides structure in a zone of proximal development (Vygotsky, 1978). According to Vygotsky (1978), this is the distance between the actual developmental level as determined by independent problem solving and the level of potential development as determined through problem solving under adult guidance or in collaboration with more capable peers such as a coach, in this case.

Another way to view a coaching relationship is that of mentoring. Smith (2013) conceded that though a universal definition of mentoring does not exist in educational settings, common themes of mentoring in higher education include guidance in socialization and furthering "the development and refinement of the protégé's skills, 
abilities, and understanding" (p. 4). In a study of 15 faculty members who served as mentors for graduate students, Lechuga (2011) identified three roles mentors played: allies, ambassadors, and master-teachers. The faculty were allies in that they focused on individual needs, both academic and otherwise, of their students; they served as ambassadors of the profession by acculturating students to academe and by instilling a sense of professional responsibility; and they were master-teachers in an apprentice model that developed students into expert researchers. Mentors, like coaches, are seen as providing scaffolds to facilitate professional growth.

Vansteenkiste, Lens, and Deci (2006) found that people who were provided scaffolding in autonomy-supportive structures such as coaching or mentoring evidenced deep processing and persistence in learning. Autonomy support refers to the degree in which socializing agents encourage problem solving, choice, and participation in decisions; structure refers to the consistency of guidelines and expectations. Effective coaches can be such socializing agents who can provide both autonomy support and flexible structure. In education, autonomy-supportive teachers, like coaches, are responsive, supportive, and motivate through interest (Reeve, 2002). Coaches can debunk the perception that writing is an "enormous, solitary task" (Wadsworth, Halfman, \& Upton, 2002), a myth created largely due to an overemphasis on the final product rather than the writing process, which Wadsworth, Halfman, and Upton said often leads to writers experiencing feelings of inadequacy.

In higher education, the term "writing coach" can create many images. These images can vary from what writing tutors typically do at campus writing centers to a person who literally walks a student through the many intricate steps of completing a 
dissertation. Miami University offers what it calls entrepreneurial consultants, who situate themselves in particular discourse communities "to continually 'sell' writing and rhetoric to both faculty and students" (Shaver, Bowles, \& Beemer, 2009, p. 62). Specifically for faculty, a university may offer writing support through a designated department such as one that promotes faculty development.

Vallerand and Ratelle (2002) concluded that individuals, in this case writing coaches, can have a substantial impact on creating or completing a task. A structured writing program that promotes work with an individual coach may move participants along in creating actual products, including manuscripts for publication. Working individually, however, does not preclude working together as a small group. Often, coaching writing can be a combination of working individually with one participant and together will all participants. Small writing groups that meet regularly often can be helpful in fostering growth for each individual group member (Elbow, 1998). Writing groups that are directly linked to a field of practice within a local setting, such as student affairs professionals at one institution, can enhance peer relationships as well as strengthen scholarly identity (Lee \& Boud, 2003).

\section{Critique of Coaching}

The metaphor of a coach can bring memories of being encouraged to rise to an occasion, being mentored by a more experienced colleague, or getting help knowing how to speak or act in a certain situation. If coaching can create all these images, then, what exactly is coaching? Therein lies one problem with coaching-the term is difficult to define and depends largely on context. Knight (2007) wrote when working with instructional coaches that he uses the term coach cautiously because it has become 
SCHOLARSHIP IN STUDENT AFFAIRS

associated with "images of belligerent coaches throwing chairs across the court after a loss" (p. 15). Adding to the confusion of multiple definitions is the variety of power in relationships within coaching situations. For many, first experiences with coaches are in athletic relationships where a power differential absolutely exists. In K-12 education, teachers are often coached by other teachers, perhaps on special assignment as a reading or math specialist, and so there is much less difference in power than in athletic situations.

Also, is coaching genuine if one is coached to act a certain way such as a politician who may be coached to use certain words or gestures to appeal to the greatest number of constituents? An organization does exist to provide some semblance of common ethics and training for coaches (International Coach Federation, 2014); however, it offers help for coaches who want to work with people in a broad range of categories such as relationships, business, health and fitness, and many more areas. The definition of a coach can be confusing because of so many specializations.

In my study, I tried to be especially thoughtful in how I defined myself as a coach and was explicit with participants about my role. Also, I was acutely aware of my positionality in terms of power. Although I worked with peers, I may have been seen by some participants as having more power in terms of my knowledge of writing and experience with the publication process. In Chapter 3, I will address more fully issues of power and my role as a researcher.

\section{Review of the Research Literature}

To explore why student affairs professionals may not be publishing, it will be helpful to first understand the historical context in which student affairs work was 
SCHOLARSHIP IN STUDENT AFFAIRS

created. I give a brief history of student affairs as a profession, including the advocacy for scholarship within the profession. Although there has been more importance placed on scholarship in recent years, obstacles still remain for such work to be done.

\section{Brief History of Student Affairs as a Distinct Profession}

Since the founding of Harvard College in 1638 and through the early 1800s, college presidents and faculty were not only responsible for educating students in the classroom but also for administering dormitories and disciplining students, which today typically fall under the purview of student affairs divisions (Dungy \& Gordon, 2011). As colleges began to diversify into liberal arts institutions in the mid to late $19^{\text {th }}$ century, "so too did the need to employ educators who could handle student unrest, discipline issues, housing administration, and other duties that the college president and faculty could not" (Dungy \& Gordon, 2011, p. 63). Also, as colleges moved to more elective and diverse areas of study rather than a single prescriptive program, there was greater need for academic advising, which is often done by student affairs professionals today.

According to Nuss (2003), the student personnel movement, or what is now known as student affairs, came into its own in the $20^{\text {th }}$ century. College administrators wondered how to best build upon student activities outside the classroom and thus became more concerned with the whole student rather than just their intellectual lives. The National Association of Student Personnel Administrators (NASPA) and the American College Personnel Association (ACPA), currently the two largest national student affairs professional organizations, were founded in the early part of the $20^{\text {th }}$ century; several other functional professional organizations, or those that are specific to 
SCHOLARSHIP IN STUDENT AFFAIRS

one component of student affairs such as residence life or student leadership, have been created since.

\section{Divergence between Academic Units and Student Affairs}

Kimbrough (2007) suggested one reason $85 \%$ of chief student affairs officers and nearly $48 \%$ of deans of students had terminal degrees may be due to a "climate in higher education that has discounted the importance of student affairs work" (p. 278). Earning that degree connotes, to a point, a metaphorical membership in the academic community, a community from which many student affairs professionals with masters' degrees may feel excluded. Kuh and Banta (2000) noted cultural-historical barriers to a perceived lack of respect for student affairs professionals that grew, in part, from historically being given tasks that faculty did not want to do, many of which were non-curricular in nature. This resulted in faculty spending more time on research and scholarship and less time on what is now considered the realm of student affairs. College faculty were "scholars who felt it was demeaning to their professional dignity to serve as petty disciplinarians keeping attendance records and checking up on the conduct of students outside the classroom" (Brubacher \& Rudy, 1997, p. 124). Love and Love (1995) concurred when they discussed the historical underlying assumptions about just who is to teach what: student affairs professionals dealt solely with social and emotional development, and academic faculty dealt solely with intellectual development. Happenings outside the classroom, though part of students' experiences, were deemed by many to be less important and even trivial compared with what was occurring inside the classroom.

Student affairs professionals often state they work in co-curricular areas, which acknowledges that learning occurs outside of the traditional classroom such as in student 
leadership positions or in the residence halls. Curricular learning is typically associated with academic departments. However, Appleton (2010) advocated for discarding the prefix "co" altogether as it suggests something ancillary to the validated curriculum being offered by academic departments. O'Connor (2012) suggested the notion of co-curricula may tacitly imply a lesser curriculum, which can result in a divide between academic and student affairs. This divide may also result from the "incorrect perceptions and lack of knowledge about each other's jobs, the alienating and consuming jargon, the increased specialization and the financial competition between these two groups" (Kellogg, 1999, p. 2). Bresciani (2012) called for student affairs professionals to articulate that they are "uniquely prepared" (p. 40) to make contributions to the academy as few faculty have scholarly or professional preparation in the areas such as student development. According to Bresciani (2012):

Student affairs work does not simply complement and extend the skills and contributions of academic and business affairs colleagues ... Student affairs leaders must communicate the profession's unique contributions to more productively differentiate and insulate student affairs from concerns about redundancy and elevate the irreplaceable nature of the field. (p. 40)

Currently, student affairs leaders are advocating collaboratively working together with their colleagues in academic departments to create a "whole-systems approach to learning" (Dungy \& Gordon, 2011, p. 75) rather than the bifurcated model used earlier in the history of the profession. Carpenter and Stimpson (2007) concurred when they concluded that the separation between student affairs and academic affairs may be lessening due to a renewed emphasis on student learning both inside and outside the classroom. In a questionnaire sent to chief student affairs officials at 81 institutions that offered graduate programs in higher education, Herdlein (2004) found that one of the 
main qualities respondents felt necessary for successful work in the profession was understanding the importance of collaboration across divisional boundaries.

\section{The Push for Scholarship in Student Affairs}

According to Allen (2002), scholarship is leadership and moves student affairs professionals from practice to influencing the entire field because it identifies emergent theories and practices in creating "connective wisdom for the field" (p. 150). I define scholarship here as contributions of knowledge about one's practice and/or research for publication in academic or practitioner journals. Although I believe that presentations at conferences or symposia are also worthy scholarship, for my research I focused on written scholarship only. Many student affairs organizations offer national, regional, and local conferences. Unlike conferences of some traditional academic disciplines, calls for proposals for student affairs conferences typically require completion of a short proposal form and not a submission of a paper or manuscript (however, some student affairs conferences do offer research paper sessions). In my experience, then, student affairs professionals who desire to pursue scholarship first do so by presenting at conferences. This is considered by many of my colleagues to be a less intimidating foray into sharing practices and research. Student affairs professionals are widely attending and presenting at conferences; they are not, however, widely publishing in journals.

Allen's (2002) notion of connectivity between people as well as in applying theory to practice is also echoed by Boyer (1990), who is widely cited in the literature having to do with scholarship in student affairs. Although Boyer (1990) was referring to academic faculty in his book Scholarship Reconsidered, his work is directly applicable to student affairs professionals: "The work of the scholar means stepping back from one's 
investigation, looking for connections, building bridges between theory and practice, and communicating one's knowledge effectively to students" (p. 16). Moreover, Boyer offered a view of scholarship that calls for us to think of research beyond creation or discovery, but to that of integration, application, and teaching. Student affairs professionals often do all these things when working with students. Carpenter (2001) extended Boyer's work to student affairs and included the "scholarship of practice" (p. 183), calling on student affairs practitioners to use theory and scholarship in their daily interactions.

Because many student affairs professionals work directly with students, they may be in the best positions to determine what really works for college students to have access to higher education, persist through their programs of study, and ultimately graduate. These professionals experience daily how some policies, though well intended, do not always translate successfully to students. As "street-level bureaucrats" (Marshall \& Gerstl-Pepin, 2005, p. 53), student affairs professionals, through their regular interactions with students, live daily the grounding for the conclusions they can draw upon of what works. In other words, they have much to share and offer in how program and policy makers can improve higher education. Without scholarship, without writing and sharing, these stories and voices are lost. Dungy and Gordon (2011) wrote that student affairs professionals must "continually educate themselves, conduct research, and produce scholarship concerning the profession we hold so dear" (p. 77). 
SCHOLARSHIP IN STUDENT AFFAIRS

\section{Publishing Issues in the Workplace}

What keeps student affairs professionals from writing when such scholarship could directly help students and add to the body of knowledge in the field? The literature provides several reasons as to why such professionals may not pursue scholarship.

Unlike tenure-track faculty, student affairs practitioners do not have the same pressure to publish. Studies show that supervisors of student affairs practitioners give little incentive for scholarship (Fey \& Carpenter, 1996; Saunders \& Cooper, 1999). This may be due to managers in student affairs who underutilize or undervalue assessment and research skills (Saunders \& Cooper, 1999; Fey \& Carpenter, 1996; Sermershein \& Keim, 2005). NASPA, one of the leading national student affairs organizations mentioned previously, does not address the topic of scholarship in its book The Mid-Level Manager in Student Affairs (Ackerman, 2007). Although the organization advocates scholarship as noted previously, it omits the topic in a book directed toward mid-level administrators whose job is to supervise and mentor new and experienced professionals. This omission speaks volumes as to the true importance of scholarship for mid-level managers (NASPA defines this as people who have worked in the field for at least five years and supervise other professionals).

Carpenter and Stimpson (2007) suggested that because scholarship and research are often unfamiliar tasks to many student affairs practitioners, these tasks may not be considered as enjoyable or even necessary as planning a program, advising, or "any of thousands of other tasks confronting busy student affairs workers" (p. 272). The demands of daily responsibilities may give little time not only to write for publication but 
also to even read academic or practitioner journals that may contribute to knowledge.

Carpenter (2001) wrote:

Any student affairs professional not reading the literature, not becoming knowledgeable of research and theory, is not acting ethically. Students have a right to expect that student affairs professionals are knowledgeable of appropriate theories, current research, and proven best practices. (p. 311)

Research provides practitioners with a more solid foundation for developing and improving programs and services. It takes professionals beyond anecdotal knowing to knowing that has been examined, and it adds legitimacy and intention to such work. It also provides a necessary foundation to begin scholarly writing.

Not supporting scholarship through reading or writing can be detrimental because advocating continuous improvement of professional positions can benefit an entire organization. For example, in a longitudinal study over 18 months of a family-owned company in the United Kingdom, Parker (1998) found that employees' perceived capability of carrying out more proactive work that extended beyond job requirements resulted in greater self-efficacy in those employees. Self-efficacy refers to how people perceive their ability to perform a particular task; it is concerned with the effective judgments in given situations, not the particular tasks (Bandura, 1986).

This continuous improvement within and beyond job responsibilities can come in the form of professional development. Because of varied and time-sensitive responsibilities, student affairs professionals may desire professional development that focuses not on scholarship but rather on activities and skills that directly address work skills. Professional development has been defined in many ways for student affairs professionals ranging from training for mastery of work requirements to activities tied to 
supervision skills to the career-long process of professional improvement (Carpenter \& Stimpson, 2007). It is ironic, however, that though quick tips addressing immediate work needs may be helpful in the very short term, more thoughtful and intentional changes in practice that can be brought about by scholarship may render the need for such quick tips unnecessary.

Conferences offer one popular form of professional development. Unfortunately, national, regional, and local student affairs organizations seem not to emphasize scholarship in the profession. In reviewing the hundreds of sessions and workshops offered at the 2014 NASPA national conference, only two sessions had to do with producing scholarship (NASPA, 2014b). One was a longer workshop and the other was a roundtable session presented by the same people who had conducted the workshop, so, in actuality, only one group of presenters focused specifically on producing scholarship. At the 2015 ACPA national conference, three sessions addressed submitting papers to the organization's journals, and one session hosted a panel of senior student affairs officers who have continued to publish throughout their careers (ACPA, 2015). At the state level, the Oregon Council of Student Services Administrators holds an annual conference. Its program in 2014 had no sessions having to do with scholarship (Oregon Council of Student Services Administrators, 2014). At an institutional level at my university, no professional development opportunities for student affairs professionals have specifically addressed scholarship in the nearly 30 years that the former Interim Vice President for Enrollment Management and Student Affairs has been at the university (D. Fortmiller, personal communication, Feb. 11, 2014). If local, regional, and national student affairs divisions and organizations are not offering research and scholarship as professional 
development topics, student affairs practitioners would not be expected to be aware of or interested in pursuing the topic. They are tacitly being told that scholarship does not matter, which is ironically directly contrary to earlier calls for scholarship by NASPA and ACPA.

Many of the sessions at national and regional conferences noted previously, however, had to do with assessment, which ACPA and NASPA (2010) deemed as an essential area of knowledge for student affairs professionals (combined with evaluation and research) in their jointly-published Professional Competency Areas for Student Affairs. One component of assessment can be research and thus can be connected to scholarship. However, few sessions directly addressed how to go on to the next step of producing scholarship from the assessment work being done.

Lastly, the organization of the institution itself may contribute to lack of scholarship by student affairs professionals. The university has become more fragmented (Boyer, 1990), which can lead to a lack of coherence in students' educational experiences. To foster a holistic student journey, rather than a "miscellaneous heap of separate bits of experience" (Dewey, 1902, p. 5), educators across the university need to be intentional in student learning. College, therefore, can be more of an accumulation of inextricably linked experiences and not separate, discrete entities. This intentionality can only occur when educators actually talk with each other. Community often is a precursor to scholarship, which can help prevent departments and people within them from becoming silos and thus disconnected from the rest of the university.

According to Davis and Berdrow (2008), silos occur in organizations that have hierarchical structures separated by functional areas. Although the authors were referring 
to integrating service science with the traditional areas of marketing, accounting, and so on found in business schools, the parallel to student affairs work on university campuses is striking. These silos both in business schools and in student affairs have led to a division of labor of very specialized areas. Only at the highest levels of the organization does integration take place. At the university level, vice presidents from academic affairs, student affairs, development, finance, and other key areas usually meet together with the president. Unfortunately, integration at lower levels is not typical though many advocate for just this to create a more holistic experience for students (Kellogg, 1999; O’Connor, 2012; Sanchez, 2013).

Some student affairs practitioners find it difficult to collaborate even within their own division. Carpenter and Stimpson (2007) stated that if the growth, learning, and success for all students are the primary goal for those in student affairs, then student affairs professionals must collaborate and consult with each other. Referring to student affairs as a profession, they wrote, "We need to be more available to one another in nonjudgmental, but constructively critical ways ... we claim that our field, at a minimum, is professional in practice; but we are not always taking the attendant responsibilities seriously" (p. 280). Student affairs professionals must intentionally leave their silos and seek collaborations among their own divisions.

\section{Writing as a Block to Publishing}

Many factors in the daily professional lives of student affairs professionals may inhibit or encourage producing scholarship. Integral to research and writing is what professionals bring to their work - that of experience, comfort, and ability in writing. 
This section looks at how these areas associated with writing may affect writing for publication and scholarly identity.

Students at both the master's and doctoral levels typically are required to do a great deal of writing, and the expectation is that these students already know how to write well when they enter graduate programs (Sallee, Hallett, \& Tierney, 2011). After all, they are college graduates and have done well enough in their undergraduate programs to tackle the rigor of graduate school. However, the quality of writing at this level is largely criticized, both outside and inside the academy while, at the same time, universities seem to do little to address the quality of writing in a systemic way (Rose \& McClafferty, 2001). Graduate students often cite a lack of confidence in either writing skills or the publication process (Abbate-Vaughn, 2012); Bair and Mader (2013) wrote that graduate students find academic writing difficult and stressful.

Professional skills in reading and doing research are needed for scholarly writing. However, graduate student affairs programs may not be consistent in educating practitioners how to research, write, and publish; some programs may not even feel these skills are important to include. Referring to the continuing dialog about the purpose of graduate programs in student affairs or higher education, Jablonski, Mena, Manning, Carpenter and Siko (2006) wrote:

Should the master's programs focus solely on preparing our practitioners to work in our field, or should they be educated to conduct assessment and research? Some of our doctoral programs are research-based, and others are more practiceoriented. What should we expect in terms of knowledge and skill sets from a person who has completed a doctoral program? (p. 197)

Conversely, student affairs professionals who have been out of their graduate programs for a length of time may feel too distant from research skills, especially with changing 
technology, and see themselves as less competent in their ability to do research and publish (Saunders, Register, Cooper, Bates, \& Doddona, 2000; Schroeder \& Pike, 2001). Sriram and Oster (2012) found in a study about student affairs and scholarship at a large private university that graduate students actually were the most engaged in research rather than full-time student affairs professionals. The authors defined engagement as a phenomenon that results from professionals' attitudes toward research and their actions in reviewing research. Also, after creating an intervention of a newsletter targeted to professionals that presented accessible research in a concise way, Sriram and Oster (2012) concluded that though professionals often cite time and access as reasons for not engaging with scholarship, lack of engagement could be "more of a cultural problem than a practical one" (p. 390).

How graduate students feel about their writing and how faculty and administrators view the skill may be a product in part of how writing is taught. Graduate students are taught writing via two main methods: embedding instruction within an existing course and creating a separate course that looks specifically to improve writing. An example of the former is the Scholarly Writing Project, or SWP (Cafarella \& Barnett, 2000), which is embedded in the first doctoral core course required for all doctoral students in the educational leadership program at one unnamed institution in North America. Students are expected to complete the SWP in conjunction with learning about leadership. Sallee, Hallett, and Tierney (2011) offered another example of embedded writing instruction in a required course in a student affairs master's program. Although the authors argued that writing needs to be an explicit part of the graduate curriculum, they cited the unrealistic possibility of creating a stand-alone writing course due to the lack of flexibility of the 
program and not wanting to extend length of time to degree. Instead, the authors focused on writing in an introductory qualitative research course in this program.

The second model for writing instruction is a course that focuses on writing. One such course is offered at the University of California, Los Angeles (UCLA) and involves students from a variety of disciplines (Rose \& McClafferty, 2001). In 1996, one of the authors instituted such a course in professional writing, housing it in the Social Research Methodology Division of UCLA's Graduate School of Education \& Information Studies. Since then, several faculty have taught the course and have been given the freedom to teach it a bit differently as long as they maintain a writing workshop structure. Another course at UCLA was Belcher's (2009), who taught a 10-week class called Writing and Publishing the Academic Article. Open to faculty and doctoral students, the course gave students practical experience in getting their research published. These experiences ranged from helping students create feasible work schedules, articulate arguments, and work with editors. The goal of the course was to "develop the habits of productivity that lead to confidence, helping (students) to overcome anxiety about academic publishing" (p. 192). However, according to Abbate-Vaughn (2012), overall, "little has been researched about promoting writing skills at the graduate level through specific course work focused on writing" (p. 53). It appears that writing at the graduate level remains embedded in other courses or assumed to have been mastered by students at this level.

At my institution, although individual departments and colleges are offering writing instruction at the graduate level, no university-wide graduate writing effort exists (M. Everett, personal communication, November 13, 2013). According to Everett (personal communication, November 13, 2013), there is a need for learning the 
SCHOLARSHIP IN STUDENT AFFAIRS

conventions of academic writing within disciplines because graduate students most likely had never been taught how to write toward a certain journal or the standard conventions of academic prose and format. Everett also suggested translating the faculty mentoring and writing retreat opportunities to graduate students as other possibilities for writing instruction (personal communication, November 13, 2013). If student affairs graduate programs allow for opportunities such as including students in writing retreats as well as explicitly show that scholarship production is important and valued, graduates moving on to professional roles in student affairs may view themselves more as scholar practitioners and thus have more of a scholarly identity.

\section{Scholarly Identity and Writing}

Professional identity refers to how a person perceives himself or herself in a career, and identity development is "movement toward complete conceptualization of a desired future self" (Hardré, 2013, p. 54). Individual identities are often associated with labels as roles, and these labels convey behavioral expectations (Colbeck, 2008). According to Colbeck (2008), who studied identity development in doctoral students, roles such as teaching assistant, postdoc, or writing specialist instantly convey various expectations, and these expectations become internalized to become part of a person's identity. Also, people live and work in social systems, so people may identify with several groups and roles.

Professions are characterized by autonomy and expertise in a distinct body of knowledge (Colbeck, 2008). Given the history of the separation of academic and student affairs as discussed previously, some student affairs professionals may feel less important than academic faculty because they do not identify as scholars in a singular area of 
SCHOLARSHIP IN STUDENT AFFAIRS

expertise, saving this role for their colleagues in academic departments. If many student affairs professionals in a department or institution do not identity as scholars, then there may be little inclination for others to do so. Ellemers, De Gilder, and Haslam (2004) called this phenomena social identification, which makes individuals perceive group features as self-descriptive and thus adopt such features for themselves. This adoption of group norms, not pursuing scholarship in this case, perpetuates this behavior. However, Sutherland and Markauskaite (2012) concluded in a study of professional identity of preservice teachers in Australia that identity is not stagnant; rather, it develops over time and is "prone to change" (p. 748). Change in identity can occur dependent on the context and the value people place upon characteristics of a particular identity, stated Rhodes (2006) when exploring professional identity construction in school learning mentors in the United Kingdom. Mentors are learning support assistants who help students in both primary and secondary grades. If identity can be changed based on context and value, then student affairs professionals who had not viewed themselves as scholars may be able to do so in the right environment.

Blimling (2001) created a schema of four communities of practice through which student affairs professional view their work that describes their professional identities: student learning, student development, student services, and student administration. Blimling (2001) considered the first two as falling under an educational framework and the latter two falling under a management framework. Brown and Duguid (2000) differentiated a community of practice from a network of practice as a subgroup of a larger network of people that "continually negotiate with, communicate with, and coordinate with each other directly in the course of work" (p. 143). According to 
SCHOLARSHIP IN STUDENT AFFAIRS

Blimling (2001), if student affairs professionals viewed their work through an educational lens, they were more concerned with student learning and development. If student affairs professionals viewed their work through the management lens, they saw themselves more as managers and administrators for transactional purposes. Learning and human development theories guide the former, and management and organizational theories guide the latter. Such perspectives may impact where professionals see themselves on the scholar-practitioner continuum (Kram, Wasserman, \& Yip, 2012).

Addressing writing practices, whether in graduate programs or in the workplace, may help create the environment in which student affairs practitioners see themselves as scholars. In the workplace, Lee and Boud (2003) found that educational faculty at an Australian university strengthened their scholarly identities while involved in writing groups over a three-year period. This also held true for groups of doctoral students in the United Kingdom working together in what they called thesis writing groups (Ferguson, 2009). These groups of three to six social science students voluntarily met fortnightly for a semester; Ferguson (2009) concluded these students not only developed concrete strategies in writing but also experienced attitudinal shifts of increased confidence in their writing abilities and thus their ability to be scholars. Through the entire process of writing, graduate students and faculty alike develop and morph their identities as scholars. According to Carter (2012), graduate students improve writing by increasing the intensity and writing on a schedule with demands, participating in peer review groups, analyzing research articles to evaluate how other researchers frame arguments, and soliciting and responding to faculty feedback. Carter, a doctoral student in 
educational inquiry, measurement, and evaluation, concluded this while studying the process of her own writing through action research.

Looking specifically at feedback, more integration of feedback in the teaching of academic writing needs to occur because many undergraduate and graduate students have negative feelings about feedback, especially if they do not have previous experience with giving and receiving feedback (Poverjuc, Brooks, \& Wray, 2012). One reason to become more comfortable with feedback, besides improving writing skills, is that such a process mirrors the expectations (and perhaps the angst) of peer review and so can acculturate graduate students to the norms of scholarship (Ferguson, 2009; Lee \& Boud, 2003). The process of giving and receiving feedback with peers can increase one's knowledge and ability to think critically, which also may impact identity (Maher et al, 2008). This process of feedback was mirrored in the coaching process that I used in my study. Because best practice in education dictates that students should receive feedback about their performance on tasks if they are to improve in their performance and understanding of the materials (Bruning, Schraw, \& Ronning,1995; Upcraft \& Schuh, 1996; Wiggins, 1998), feedback is essential to learning (Wiggins, 1998).

\section{Synthesis of Literature}

The profession of student affairs has evolved since its beginnings in the early part of the last century. Although student affairs work may have historically been seen by some as secondary to the work in classrooms, this thinking has evolved to notions of cocurricular learning happening in student affairs functional areas, with some people advocating that all learning in a university is curricular, classroom or no. Student affairs leaders also are encouraging collaborative work with academic departments; the good 
news is that though this has been advocated before, more recent research suggests this is actually taking place.

Part of the profession's evolution has to do with creating scholarship about the work being done. The two main student affairs organizations have in the past decade pushed for more research and scholarship though the people producing such scholarship are mainly graduate students and faculty of higher education programs. Student affairs practitioners themselves are not creating much of this work. This is due to various reasons, including not being expected to do so as well as confidence in how to produce scholarship, including confidence in one's writing abilities. What needs to occur for more scholarship is not just a call for valuing this work but actual practices that support it. Chief student affairs officers can provide this support through professional development opportunities that promote not only scholarship but also conversations across departments and divisions, as well as explicit expectations of scholarship for appropriate positions.

\section{Critique of Literature}

Although the literature suggests why student affairs professionals do not publish, it omits this important question: What has worked for those practitioners who do publish? These professionals may have the same constraints on their time and writing blocks as their non-publishing peers, but what makes these people successful at publishing while their peers are not? Also, the literature shows a disconnect between theory and practice: the two main student affairs organizations NASPA and ACPA are both encouraging professionals to write but may not be providing the most support in sharing ways to do so. 
Lastly, there is a dearth of literature about how graduate programs in higher education are creating a sense of responsibility for scholarship. This can affect the scholarly identity of student affairs practitioners as does the lack of professional development offered on the topic. For the past century, student affairs as a profession has focused on the student, all for good reasons; it is now time, however, to turn that focus on the practitioners who serve these students to create a more reflexive profession.

\section{Review of Methodological Literature}

I used an integrated method of case study and action research because I wanted to gain an in-depth understanding of a real-life phenomenon, that of my participants' professional identity and writing goals, and wanted to explore these understandings holistically (Yin, 2014). I used an intervention, which is a component of action research, through coaching that may have facilitated my participants' production of an article for publication (Herr \& Anderson, 2005). My qualitative study was situated in the context of a large, urban university campus; there was not one specific variable that could have been manipulated to impact my study and thus it cannot be generalizable in the empirical sense of the term (Merriam, 1998). My study relied on direct observation and conversations and a variety of evidence, including my own memos and writings in my research journal, participants' journal entries, and the writing participants produced as well as other documents related to their writing processes.

Patton (1990) wrote that qualitative inquiry allows for dynamic and developmental perspectives as "staff learn, as clients move in and out, and as conditions of delivery are altered" (p. 52). This perspective fits nicely with my study as I was an active participant as a writing coach; my participants and I negotiated our interactions 
depending on my participants' needs. Although all of my participants work in student services at one institution, they were from different functional areas, wrote for different journals, and had different backgrounds and experiences. Thus, each participant's context going into this research was somewhat different.

I chose not to do a quantitative study because I wanted to explore in depth my participants' identities as well as understand what strategies worked well for them to meet their writing goals. Bargal (2008) wrote that traditional positivist approaches to research, which include many quantitative methods, are not interested in developing interventions like action research does. Moreover, qualitative studies allow for a description of "the multiple realities encountered at any given site ... it is adaptable to demonstrating the investigator's interaction with the site" (Lincoln \& Guba, 1985, p. 4243). I regularly interacted with my participants, and so case study and action research seemed the most appropriate methods as opposed to other common methods used in qualitative research such as ethnography or grounded theory. Ethnographic research has to do with studying groups and people as they go about their daily lives (Emerson, Freztz, \& Shaw, 1995). In ethnography, the researcher describes and interprets shared and learned patterns of values and behaviors and is immersed in day-to-day activities (Creswell, 2013). Although I studied a group of people who may have similar values and behaviors, my intent was not to immerse myself in their daily comings and goings. Rather, my research questions were based in a structured process. Also, I as the researcher was an interactive and intentional participant. Similar to grounded theory methods, I focused on a process that occurs over time (Creswell, 2013). However, my goal was not to develop a theory to explain a phenomenon; also, my time was bound 
SCHOLARSHIP IN STUDENT AFFAIRS

from the beginning, and the format of my study was structured in weekly sessions as I

discuss more in the next chapter. I was dissuaded from using grounded theory because of these limits.

\section{Critique of Case Study and Action Research}

In exploring the case of scholarship in Student Affairs, I worked with multiple participants. As I turned my attention to more than one participant, I as a researcher tried to be extremely cognizant of equitably and earnestly giving time for individual voices during my study as well as in the analysis of data produced from these voices. Ontologically, case study and action research allow for participants' multiple realities, in addition to my own reality as the researcher. As I was responsible for interpreting my participants' data, I used systematic strategies, such as member checking, to come as close to actual intended meaning as possible. I will speak more to these strategies in Chapter 3.

\section{Summary of the Research Literature and Application to the Study}

I have given a brief history of student affairs as a profession and how scholarship has fit into this history. I then shared how writing experiences may impact student affairs professionals' ability to create scholarship. To promote scholarship, which may impact professional identity, as viewed through the lens of autonomy, competence, and relatedness, my research used a coaching model that gave participants opportunities for individual and small group learning. I did this through case study and action research methods, which I explain in detail in the next chapter. In conducting my research, I intended to contribute to and advocate for student affairs professionals sharing their work so their professional identities and interactions with students will be positively impacted. 
SCHOLARSHIP IN STUDENT AFFAIRS

\section{CHAPTER 3: METHODS}

The purpose of my study was to explore participants' identities as scholars as well as their effective strategies for writing. My research questions were: (a) What writing strategies do student affairs professionals find effective when producing manuscripts to submit for publication in academic or practitioner journals? and (b) How does scholarly identity change during a structured writing program specifically intended to foster professional writing? I used an integration of case study and action research methods with multiple participants because I wanted to gain an in-depth understanding of my participants' views of identity and use of writing strategies throughout my research process, which included the intervention of coaching.

\section{Research Methods}

As further explained in detail below, combining the qualitative methods of case study and action research was appropriate to my study. These two methods complement each other because my study explored in depth the case of scholarship in student affairs within a localized context. However, I also facilitated an intervention. I took a current situation, namely student affairs professionals who wished to publish their writing, and created a structure for change to occur. I then explored how this change impacted their professional identity and perceptions of writing strategies. My participants guided how I facilitated my interventions, and so they largely determined our processes.

\section{Case Study}

The qualitative method of case study is one appropriate method for my study because issues studied by case study reflect complex, situated, problematic relationships of ordinary experiences in natural settings (Stake, 2006). According to Creswell (2013), 
the investigator conducting a case study explores a real-life, contemporary bounded system (a case) over time through detailed in-depth data collection involving multiple sources of information, and reports a case description and case themes. Yin (2014) added that case study is a comprehensive research strategy and is especially useful when the boundaries between the phenomenon and context are not clearly evident. In other words, the researcher needs to use the case study method because he or she wants to include contextual conditions because they might be highly pertinent to the phenomenon of study. Case study is used to gain an in-depth understanding of a situation and its meaning for those involved. Case study method allows for a description of "the multiple realities encountered at any given site ... it is adaptable to demonstrating the investigator's interaction with the site" (Lincoln \& Guba, 1985, pp. 42-43). According to Merriam (1998), the researcher using case study is interested in the "process rather than outcomes, in context rather than a specific variable, in discovery rather than confirmation" (p. 19). The insights researchers learn from case study are often pragmatic and can influence policy, practice, and future research (Merriam, 1998).

In multicase, or multiple case, studies, researchers can study one issue or concern through multiple participants experiencing the case to illustrate the issue (Creswell, 2013). My research issue or case was the phenomenon of scholarship of student affairs professionals, and I used data collected from five participants. Yin (2014) stated that multiple case studies are often more compelling because of common evidence to explain a phenomenon.

According to Yin, Bateman, and Moore (1983), who studied 53 case studies in seven public services including education, quality case studies that seek to contribute to 
both practice and theory should have the following attributes: (a) relate previous theories to the issues being investigated, (b) use relevant cases, (c) create an operational procedure for selecting the cases or participants, and (d) have a formal data procedure. I explored in Chapter 2 the attribute of the theoretical constructs I applied to my study. In the next section, I explain how I addressed the other enumerated attributes.

\section{Action Research}

Because I facilitated an intervention in my role of a coach, I used elements of action research, which is used when addressing the needs of people in specific settings (Herr \& Anderson, 2005). According to Herr and Anderson (2005), the main goal of action research is to generate local knowledge that is given back to the setting. Reason and Bradbury (2006) defined action research as a participatory, democratic process that is concerned with developing practical knowledge applicable to people's everyday lives; they also advocated using the metaphor of participation as the lens through which to look when using action research. From a teaching perspective, McNiff (1991) called action research a powerful method of bridging the gap between theory and practice in the classroom by reflecting upon actions and then changing them accordingly to work toward a desired outcome. On a small scale, my participants and I generated knowledge during our group and individual sessions, and this new knowledge as well as reflection informed what happened in the subsequent session. Action research was an appropriate method for my research because it demands some form of intervention or created change. This intervention was in the form of practical suggestions to writing questions my participants experienced, which facilitated effective writing strategies as they tried to produce manuscripts for publication by the end of our time together. 
SCHOLARSHIP IN STUDENT AFFAIRS

According to Kemmis and McTaggart (2000), action research is a social process that is participatory, practical, and collaborative. Participants are either in control of the research or are participants in the design and methodology of the research. In my research, participants were a little of both. They were not in control of the process because I was coaching them through a process that we pursued; however, participants did have some control because they guided what I did as a coach in discussing writing strategies. In that sense, they impacted the research design.

The ideas of emancipation and empowerment are common in action research (Bargal, 2008; Kemmis \& McTaggart, 2000; Reason \& Bradbury, 2006) because the method "is rooted in the democratic philosophy of promoting individual welfare in a humanistic way" (Bargal, 2008, p. 18). Action research can be traced to Lewin's (1948) work looking at inter-group relationships and his belief that "research that produces nothing but books will not suffice" (p. 203). Lewin believed in the "centrality and importance of the facilitators as change agents" (Bargal, 2008, p. 24), especially when involved with social action. The notion of liberation is especially prevalent when action research is guided by critical theory, which often can be seen in large social movements (Kemmis, 2006). Although some of my participants felt more empowered after having gone through my research process, my research was only with five participants and so was on a much smaller scale than those often referenced as examples of action research such as Friere's work with the poor in Brazil (Borda, 2006; Herr \& Anderson, 2005; Reason \& Bradbury, 2006). However, the process my participants and I shared was meaningful to each of us individually as well as collectively. 


\section{Participants}

The term "participants" is commonly used in qualitative research to describe the individuals being studied and is preferred over other terms describing these people because it connotes inclusion and willing cooperation (Merriam, 1998). This is contrary to the term "subjects" used in experiments where investigators seek to control environments or "respondents" often used in survey research methods; in these two environments, as well as when researchers use historical archives only, investigators seek to control closely data collection (Yin, 2014). The term participants also serves as a litmus test concerning ethics because if subjects is more appropriate, then the researcher may conclude that qualitative methods is not appropriate for his or her study (Merriam, 1998). In my study, I use the term participants for those who chose willingly to actively engage in my study.

My research consisted of working with five professionals employed in student services and developing a case study around professional identity and writing strategies. For geographical and logistical convenience, participants were employees of one large urban university in the Pacific Northwest who work in student services. I also am employed at this institution. Herr and Anderson (2005) wrote that participants in action research are often concurrently subordinates in the organizational setting as well as participants. Although I do not consider my participants as subordinates, they may have felt that my role as their coach elevated me while subordinating them in our relationship. I will speak more to this positionality in the section regarding my roles as a researcher.

I obtained written informed consent from each of the participants; this is standard procedure for research involving humans (see Appendix A). Because all participants 
work at my institution and are familiar with the context of higher education in the United States, informed consent was not an issue of cultural understanding (Smith, 2005). I maintained digital data on my desktop and laptop computers, which are both password protected. I maintained written data in a locked cabinet in my office, which also remains locked when I am not in it. I used pseudonyms for my participants to better protect their identities for privacy, and so I kept data confidential. Because I wanted my participants to collaborate as much as possible in the research process to support action research and coaching tenets, I asked if participants wanted to choose their own pseudonyms, which they did.

I used purposeful sampling by asking prospective participants who had expressed interest in publishing scholarship during previous conversations or who had heard of my proposed research. Maxwell (2013) defined purposeful sampling as choosing deliberately settings, persons, or activities that provide information particularly relevant to the researcher's questions and goals. Because my participants had already expressed an interest, this suggests they may have been motivated to participate in my research. Purposeful sampling increases the scope or range of data collected, increases the likelihood that a more full array of multiple realities will be uncovered, and maximizes the investigator's ability to adequately account for local conditions and values (Lincoln \& Guba, 1985). Participants had varying experiences with publishing scholarship. However, participants' previous experiences with publishing scholarship was not relevant for my study as I explored individual identity change and effective strategies for current writing and not whether the same type of participant had similar or dissimilar experiences. Because all participants were employees of the same division or had 
worked closely with various university student services offices, they did share a common ethos for their work in terms of division leadership or other leaders in student services. However, their individual supervisors may have had varying viewpoints of where scholarship fits with their work.

One subset of purposeful sampling is homogenous sampling, which is used to describe a particular subgroup in depth (Patton, 1990). Because several hundred employees work in student services at my institution, I narrowed my sample to that of mid-level managers. ACPA (2013), a national student affairs organization, defines midlevel professionals as those who have been in the student affairs field for five or more years. NASPA (2013), another national student affairs organization, also defines midlevel professionals with the same time frame but adds that such professionals should be responsible for the direction and oversight of one or more student affairs functions and supervise one or more professional staff members. I chose mid-level managers because they have had enough experience in student affairs to understand student needs and how programs operate; these experiences may have lent themselves well as topics for articles to write. New student affairs professionals may not have felt as comfortable committing to pursuits outside of the job descriptions, and senior administrators may not have been able to commit to the entire duration of my research.

As I stated previously, I worked with five participants. According to Patton (1990), no rule exists for the right sample size in qualitative inquiry. The number of participants depends on what the researcher wants to know, the purpose of the inquiry, what will be useful, what will have credibility, and what can be done with the available time and resources. In-depth information from a small group of people can be very 
valuable, especially if the cases are information rich; less depth from a larger number of participants can be helpful in exploring a phenomenon and trying to document diversity or understand variation. In a multicase study, Stake (2006) suggested no fewer than four and no more than 10 cases should be used. Stake (2006) stated that fewer than four cases would not show enough interactivity between each case, and large numbers of cases would create more unique interactivity than the researcher may be able to understand. To balance the practicalities of time commitment for everyone involved in my study (including me) as well as my desire for a quality multicase study, I chose to study five participants.

\section{Procedures}

As I discussed in Chapter 2, I worked with participants using a coaching model, which is one that promotes the obtainment of a participant's goals through collaborative and experiential learning. I conducted my research over 13 weeks and met individually with my participants nine times and as a group four times (group meeting, three individual meetings, group meeting, three individual meetings, and so on, ending with a group meeting at the 13th week). I held the first group meeting in mid-October 2014 and concluded the 13 -week process in mid-January 2015. My participants and I intentionally did not meet the second half of December due to the winter holidays.

My research process was iterative in nature, and each individual and group session produced more data on which I reflected and from which I created strategies for the next session (McNiff, 1991). I kept a research journal, which is "vital" (Herr \& Anderson, 2005, p. 77) to action research. In this journal, I chronicled my interactions, questions, and feelings. McNiff (1991) suggested approaching action research in a 
SCHOLARSHIP IN STUDENT AFFAIRS

systematic way that includes a cycle of evaluation after a solution is implemented, which will re-formulate the problem, which will then inform the next steps. According to Herr and Anderson (2005), "Action research is a messy, somewhat unpredictable process, and a key part of the inquiry is a recording of decisions made in the face of this messiness" (p. 78). Yin (2014) suggested being prepared for unanticipated events in qualitative research. For example, my participants missed appointments or group meetings or did not do any writing. I did note attendance in my research journal and reflected upon how such rescheduling, as well any other unanticipated events, affected my study.

\section{Data and Analysis}

The researcher in qualitative inquiry is the primary instrument for gathering and analyzing data (Lincoln \& Guba, 1985; Merriam, 1998). Thus, I am limited to being human — that is, the following characterized my study: "mistakes are made, opportunities are missed, personal biases interfere" (Merriam, 1998, p. 20). Because human instruments are fallible as with any other instrument, I needed to have the personal characteristics and skills that Merriam (1998) recommended - sensitivity to context and all variables within my study, sensitivity to information revealed, and sensitivity to personal biases and their potential. I will talk more about my biases and role as the researcher below.

To understand the background of my participants as writers, I sent them a survey via Google Forms a week before our initial group meeting (see Appendix B). Maxwell (2013) suggested pilot-testing interview guides with people similar to planned participants; I considered my survey similar to an interview in that I had created questions to ask my participants though in a written rather than verbal format. I did this 
by sending it to two colleagues who work in student services. I used their feedback, which included confusion about wording, to create the final form. I reviewed participants' responses before the first group meeting.

To address my research questions, I also used five guiding questions in an interview format. According to Seidman (2013), interviews are appropriate when the researcher seeks to understand the "lived experience of other people and the meaning they make of that experience" (p. 9), which was my intent in determining participants' effective writing strategies and scholarly identity formation. I asked the same five questions during the first, fifth, and last individual sessions (the last session number varied among the participants) to determine change, if any, over time. I did not conduct the interviews during group meetings because I did not want participants' responses to be impacted by that of their peers' answers. These five questions as well as my rationale for asking them are listed in Appendix C. The questions explored my research questions of identity through the notions of autonomy, competence, and relatedness as well as effective strategies for writing through a coaching model. These questions comprised a semi-structured interview protocol and my one formal instrument. I recorded the interviews with participants' permission, transcribed the recordings, and then sent each participant transcripts to confirm accuracy of my interpretation; this use of member checking constitutes a systematic solicitation of feedback about data from the participants I am studying and thus an important way of ruling out the possibility of misinterpreting participants' understandings of what is happening (Maxwell, 2013).

My data consisted of my transcripts from the interviews, journal entries from participants, free-writes from group sessions, the aforementioned survey that asked 
background questions, and artifacts that included manuscript drafts, outlines, and other tangible items that had to do with participants' writing processes. I also used documents that I had generated such as my own research journal entries about my interactions with participants and my reflections on our processes. I created these researcher-generated documents after the study began to learn more about what I was investigating, which added to the iterative process of qualitative inquiry and, in my study, of the case study method in particular (Merriam, 1998).

\section{Group Meetings}

As stated previously, I began my research with a group meeting involving all five participants; the group met again after three individual sessions though not every participant attended these subsequent group meetings. This pattern continued until the last group meeting, which was the $13^{\text {th }}$ session overall, with four group meetings altogether. We met on campus in an available meeting room that I had scheduled for the study. We met in the same room for all four group meetings. We discussed the topics noted in Table 1 during the four group meetings, which lasted 60-90 minutes each. I used my background knowledge of writing for publication as well as participants' responses to the survey I had sent them before the first group meeting to create an agenda for the first meeting. However, I did not plan the second through fourth group meetings in advance; rather, because I employed action research, I created agendas for these meetings based on participants' needs and requests. The presentation slides for each group session, which I created in Google Presentations, are shown in Appendices E-H. 
Table 1

Agendas for Group Writing Sessions

Session Agenda

1 Introductions; share research questions, methods and conceptual framework of my research; confidentiality; research schedule; discussion of journals for publication, the publication process, goal setting for first individual session

2 Updates and check-in on progress, share journal selection; writing strategies and creating habit; my observations on impact of environment; the abstract; goal setting for next individual session

3 Updates and check-in; use of rubrics; writers' workshop; sharing of resources, schedule reminders

4 Final verbal sharing on process; reminders of research questions; housekeeping; what's next

\section{Individual Sessions}

Because I have experience teaching writing, working in writing groups, and working individually with students in writing centers, I had some sense of writing needs, including idea generation, organization of ideas, and researching for content support. However, my participants and I worked together to create agendas for individual sessions that would be most helpful for them to meet their individual goals; this collaborative process aligns with the ethos of action research. Each week, my participants created weekly goals for their writing that would work best for their individual circumstances. I met with participants five to nine times depending on the participant, and our meetings lasted 30-60 minutes. We scheduled our individual meetings at the beginning of the 
study, and they recurred at the same time and day each week; all individual meetings took place in participants' private offices.

\section{Methods of Analysis}

During and after collecting my data, I used the qualitative capabilities of the mixed-methods web-based research software Dedoose to determine patterns, categories, or correspondence in my data. Taylor and Bogdan (1984) wrote that researchers need to construct categories or themes that capture recurring patterns or concepts across "the preponderance" (p. 139) of data. Stake (2006) used the term correspondence to describe when things are happening together, when the researcher notices among a large number of happenings, variables, and contexts that some ideas are similar in nature. This method of noticing similarities among variables is also known as the constant comparative method (Merriam, 1998); I used this method to analyze my data. In this method, incidents and participants' responses are continually compared with each other, and units of data are sorted into groupings that have something in common. A unit of data is any meaningful (or potentially meaningful) segment of data. Patton (1990) called this method content analysis, which is the process of identifying, coding, and categorizing primary patterns and then creating typologies. According to Patton (1990), the qualitative researcher works back and forth between data and classification systems to verify the meaningfulness and accuracy of the categories and the placement of data in categories.

I looked for categories individually within each participant's case and then across all five participants' data. After initially creating and assigning categories for all my data, I combed through the data again to confirm that I had coded the categories 
correctly. I created parent codes such as "motivation" and "professional identity" as well as children and grandchildren codes when appropriate. Parent codes are larger categories, children codes are subsets of those larger categories, and grandchildren codes are subsets of the children categories (Dedoose, 2013). Examples of children codes for the parent codes motivation and professional identity are "helping students" and "wants to be a scholar," respectively. An example of a grandchild code is "visual" under the child code "outline," which was under the parent or larger code of "writing strategies." For a list of my codes, please see Appendix D.

In addition to addressing my research questions specifically, the categories that I determined were exhaustive, meaning I was able to place all the data that I decided as important or relevant to the study in a category or subcategory; mutually exclusive so one unit of data fit into one category only; sensitizing in that an outsider would be able to read the categories and gain some sense of their nature; and conceptually congruent so the same levels of abstraction would characterize all of my categories (Merriam, 1998).

\section{Reliability and Validity}

Reliability refers to the extent to which research findings can be replicated (Merriam, 1998; Yin, 2014). Ontologically, reliability in research design is based on the assumption that there is a single reality and that studying it repeatedly will yield the same results (Merriam, 1998). This notion of replication is problematic in the social sciences because human behavior is never static. Qualitative research, unlike its quantitative counterpart, is not conducted so laws of human behavior can be explained. Rather, as I have noted previously, researchers seek to describe and explain the world as those in the world experience it. Because there are many interpretations of what is happening, there 
is no benchmark by which to take repeated measures and establish reliability in the traditional empirical sense (Merriam, 1998). To be considered reliable, a qualitative study needs to minimize errors and biases (Yin, 2014). This can be done by documenting procedures, using a case study protocol, developing a case study database, making as many steps as operational as possible, and acting as if someone were looking always over your shoulder (Yin, 2014). Merriam (1998) added that just as a quantitative researcher refines instruments and uses statistical techniques to ensure reliability, the human instrument can become more reliable through training and practice. I have been trained in qualitative research by taking coursework and have been involved as a researcher in previous qualitative studies.

Also, I used member checking to improve reliability. Member checking occurs when the researcher takes data and tentative interpretations back to the people from whom they were derived and asks them if the results are plausible (Merriam, 1998). I shared my notes of transcripts and my interpretations of participants' journals with participants to ensure common meaning and understanding. Member checking can also provide additional data and contribute to the iterative process of interpreting data.

Because case study inquiry deals with distinct and contextual situations in which there will be many more variables of interest than data points, it must rely on multiple sources of evidence, with data needing to be triangulated (Yin, 2014). Stake (2006) defined triangulation as each important finding having three or more confirmations and assurances that key meanings are not being overlooked. Merriam (1998) wrote that triangulation occurs in qualitative research by using multiple investigators, multiple sources of data, or multiple methods to confirm findings. Using such multiple sources of 
evidence in triangulating data will create construct validity, which occurs when measures reflect what they purport to be measuring such as the change that is being studied (Yin, 2014). I collected different forms of data from group and individual meetings over 13 weeks. This long-term contact also added to the validity of my data (Merriam, 1998). For action research, Herr and Anderson (2005) described validity in terms of (a) outcome validity, which is the extent to which outcomes occur; (b) process validity, which is the extent problems are framed and solved in a manner that allows for ongoing learning of the individual or system and includes the quality of relationships that are developed with participants; (c) democratic validity, which is the extent to which research is done in collaboration with all people who have a stake in the problem; (d) catalytic validity, which is how the research process refocuses participants' views of reality; and (e) dialogic validity, which has to do with a peer review process in the interpretation of findings. I was able, through the myriad sources of data I collected, to determine outcome validity and process validity. Because each individual session was tailored for each participant, there was some level of democratic validity; however, it was not a completely democratic experience as I created agendas for the group meetings. I was able to address catalytic validity in terms of changes to identity. Lastly, as I discussed earlier, I used member checking with the participants to address dialogic validity. However, I did not use "critical friends" (Herr \& Anderson, 2005, p. 78), who are described as peers or colleagues willing to debrief with the researcher. Because I work at the same institution as my participants, I did not want to breech confidentiality and share my research experiences with others who likely may know the participants. 


\section{Generalizability}

Some researchers are concerned with instruments and measures ensuring generalizability, which can be defined as the extent that one study can be applied to other situations. Merriam (1998) stated that the question of generalizability has "plagued" (p. 207) qualitative researchers for some time; however, she asserted that part of the problem stems from thinking of generalizability in terms of experimental correlational designs. Stake (2006) wrote that case studies are concerned with "the practical, the concrete, and the achievable" (p. 491) and that researchers using qualitative methods provide perspective rather than generalizations. Merriam (1998) suggested that due to the nature of qualitative inquiry, generalizability should be thought of in terms of reader or user generalizability, which involves the people in those possibly applicable situations to determine the extent to which a study's findings can apply to them. The reader or user of the study, drawing on intuition and experiences, therefore determines what does and does not apply to his or her situation. According to Lincoln and Guba (1985), this dynamic between the researcher and the receiver of the research can be called transferability, which is a direct function of the similarity between contexts. This is true for my study as my findings may or may not be applicable to people in other situations and institutions depending on similarities with my institution and participants. For example, student affairs professionals at large public institutions may determine my findings more applicable to their situations than those at small private ones.

\section{Role of the Researcher}

I used qualitative inquiry because it allows for the researcher to interact with participants and, in doing this, acknowledge the consequent biases that may result 
(Lincoln \& Guba, 1985). This can be problematic because the action researcher is an insider to the organization, the institution in my case. Not only did I interact with my participants, but I also explicitly used tacit knowledge, which Lincoln and Guba (1985) defined as intuitive or felt knowledge and a legitimate form of data in addition to that gathered through written or oral language.

Because I as the researcher was the primary instrument through which data were filtered, to be ethical I was explicit in stating that I interpreted whatever meaning my participants created throughout my study. Data do not speak for themselves as there is always an interpreter or translator (Merriam, 1998). Also, though I consider myself a professional peer to my participants, I was aware of our relationship throughout the research process. Participants may have viewed me in an authoritative role in our coaching relationship though that is not how coaching in education is typically viewed. This may have been due to my having published before and my having a background in writing. To counter this, I was explicit in my role as a coach and purpose as a researcher. I also was explicit in my biases. I love writing and research, and I consider myself a competent writer. Participants have had different experiences with writing and some did not always identify this way. Also, my own supervisor has been supportive in my research and writing, including that done during my doctoral program. Again, participants' own supervisors and experiences may have been different.

My role was not to create a perceived objective study but to acknowledge my biases and assumptions as I interacted with my participants. Researchers can "give up the burden of producing completely objective, unassailable certainties and concentrate on the more immediate task of providing credible, balanced, and useful information to 
SCHOLARSHIP IN STUDENT AFFAIRS

specific decision makers and evaluation users" (Patton 1990, p. 491). As Patton alluded, my role also was to contribute to addressing the gap in the literature about scholarship for student affairs professionals so that such practitioners may be more supported to pursue scholarship.

\section{Limitations of Methods}

Case study and action research can provide rich data in an authentic context. However, studying scholarship of student affairs professionals through these methods can be intensive, lengthy in duration, and, in the end, not transferable. Not enough time spent with my participants may also have been a limitation. My research encompassed 13 weeks - would participants' identities have changed in a different way if I had worked with them throughout an entire year? Conversely, Bargal (2008) wrote that action research designs typically include long-range interventions. Because I was bounded by time, my participants and I may not have experienced all the results of my intervention of coaching that we may have had if the research process were longer in duration.

Action research also typically involves participation from within - those who desire change create a movement that ultimately effects change to the group (Reason \& Bradbury, 2006). McNiff (1991) called this research "with" rather than research "on." In my study, I created change from without; my participants did not come together and seek their own coaching experience. Rather, even though I work with my participants in student services, I remained an outsider because I was imposing this intervention on them.

Lastly, though student affairs professionals at other institutions may find my results helpful or interesting, I cannot know whether my work will transfer to another 
SCHOLARSHIP IN STUDENT AFFAIRS

environment as this will depend on the people at those institutions and their specific situations.

\section{Summary of Methods}

Integrating case study and action research methods was appropriate for this study as I explored identity change as well as effective writing strategies. Case study allowed me to explore in-depth within the context of my participants' professional lives their goals of producing scholarship. Action research complemented this in-depth exploration of identity change by facilitating this change via the intervention of a writing coach. The two research methods worked hand in hand to address my research questions. In using these methods as well as purposeful sampling, multiple data sources, diligent weekly work with my study's participants, and a keen awareness of my own biases, I conducted a study with the intent of benefiting student affairs professionals and the students they serve. 
CHAPTER 4: RESULTS AND ANALYSIS

The purpose of my study was to explore participants' identities as scholars as well as their effective strategies for writing. My research questions were: (a) What writing strategies do student affairs professionals find effective when producing manuscripts to submit for publication in academic or practitioner journals? and (b) How does scholarly identity change during a structured writing program specifically intended to foster professional writing? I used an integration of case study and action research methods with multiple participants because I wanted to gain an in-depth understanding of my participants' views of identity and use of writing strategies throughout my research process, which included the intervention of coaching. I present each participant individually to give each participant the time and space to share their narratives. I share first demographic information, educational levels obtained, and professional context so that the reader may understand a bit more each person's story. I then report on effective writing strategies and professional identity formation throughout our time together. I present my participants in order of years of experience working in student services, from fewest to most. I chose this as simply one logical way to represent my participants.

\section{Logan}

Logan identifies as an African-American male, has worked in student services for five years, and has a master's degree in Sociology. His job entails high contact with students. As an undergraduate student, he co-authored a journal article with his faculty mentor about African-American males in higher education. Although he was a co-author, most of his work on the study consisted of data design, collection, and analysis. He had very little to do with the actual writing of the article. Logan has also presented at various 
conferences. He described his writing as developing, empirically-based, and open to feedback. Although he feels his writing has improved over time, he believes it is "behind" that of his colleagues. He does not yet feel as competent as he would like to be in terms of writing for academic purposes.

Logan greatly enjoys research and wants to conduct research "until the day I die." Although he feels he is a good researcher, he wanted to improve how he conveyed on paper what he gleaned from his research. "I never felt comfortable with my writing," he said, "but I like getting my thoughts on paper." Logan wanted to work on adding to the research he worked on with an undergraduate faculty member. His topic had to do with applying a theory of environmental factors that he asserts contributes to the achievement gap of African-American males in higher education.

Logan decided to write for the American Education Research Association's Open Access Journal. He chose this journal because he found an article in it that specifically addressed the use of path analysis, a research method, which he would like to use in his paper. He mined the reference list of that published article and found four or five articles, which was helpful for his own paper. He read the submission guidelines of the open access journal and understood what was required of him. He did not complete a draft of a manuscript by the end of our study; however, he had a draft of his introduction, which consisted of three double-spaced pages.

Logan and I met individually seven times, and we conducted all three interview protocols. He attended the first two group meetings. He missed the third meeting due to his partner having their first child after which he took one week of family leave. He shared with me before the study began that he was planning to do this, and so we 
anticipated this absence. Logan missed the fourth meeting due to work commitments. I shared with him the slides of our last two group meetings as well as summaries of what happened during those meetings.

Logan cited lack of time as most problematic when it comes to writing, especially since the birth of his son. However, his job, which consists largely of meeting with students and being available for them, also contributed to his lack of writing. "The time constraint has been a beast and more because I've been navigating with little or no sleep," he said. However, he realized how much he can accomplish with a new infant. "I appreciate being pushed to my max. I now expect more from myself. When I do start getting more sleep, I'll expect more from my day," he said. In addition to time, Logan also found it difficult to concentrate on work and on this writing project. "It has been really hard ... to get my mind in the right place," he said. "I have noticed that I get distracted with thinking about other priorities while I am writing."

\section{Effective Writing Strategies}

To combat time and distractions, Logan concluded that being accountable to a coach who expected a certain amount of time to be set aside to produce a paper was an effective writing strategy. "I really enjoyed participating in this study for several reasons. First it helped me set a side time to do something that I like doing," he said. During our individual sessions, Logan often requested time to actually write. We had scheduled an hour together, and he insisted that we use the entire hour. Some of this time included time he actually worked on his paper, such as researching articles or looking up citations, while I did other work. Also, if I left him alone, students may walk in, he said. In this sense, his accessibility to the students he serves that is such an asset for student 
SCHOLARSHIP IN STUDENT AFFAIRS

development hinders his own writing development. This availability to students, which Logan considered a distraction to his writing, was underscored by his desire to shut the door during our sessions so students would not just saunter in (though during one individual session one student did walk right in on us).

Even though meeting weekly in person and communicating about drafts by email on a regular basis were part of our coaching model, Logan wanted even more accountability as we neared the end of the study. He recommended that he send me an email every night before midnight telling me what he did that day, even if it was to tell me he had not done anything. He said, "Instead of checking in weekly I would like to send updates more regularly. Not for feedback but just to keep myself on track. I am honestly having a hard time and wish I could be getting more done.” This was effective for Logan, as he produced a few more paragraphs and, more importantly to him, felt he was making progress, albeit small. Regarding his draft at the end of our study, he said, "I do need to better organize it though. It could flow much better; it is a shitty first draft, but it felt good to make progress."

Because of his work and new infant, we talked about trying different physical places where he could be removed from distractions. This included visiting the campus library several times during his lunch hour to do research even though he could find many of the articles from his computer in his office. He also would steal away to coffee shops during the weekends to write. Working in such physical spaces helped him "get it all out," which he considered vital to processing his thoughts. "I kind of feel like it is a little all over the place," he said of a draft. "This is because I literally wrote like the stream of consciousness." 
Having family members help with his new son so he could physically leave his house was welcomed and appreciated. Also, knowing that he has a supportive family has helped him feel positive about his professional goals. "I feel like my girlfriend is really starting to support me in ways that I didn't know she could. I'm able to have a kid and pursue my dreams at the same time. She was more involved and more supportive in the process this year," he said.

Logan felt receiving feedback was extremely effective in helping him work toward his goal. "I really like feedback. Communication in general is one of the things I want to master," he said. He shared that a tutor at the university's writing center literally taught him how to write. "He really changed my world. We went over my comments, one by one," he said. Logan and I also spent time talking about faculty life, research, and the value of sabbaticals for scholarly production.

Ultimately, Logan is working toward creating a habit of practice for his writing.

He felt that this would be the most effective strategy to produce publishable manuscripts.

I'm really looking forward to the writing practice. I'm going to be writing something everyday, even if it's a paragraph or a sentence. What I really liked about last week [when he made a commitment to email me daily about his progress] is that I'm going to make it a habit to write a little bit everyday. I have to write a little bit or edit. Either way, I just love the idea of forcing myself to do this. I love this idea. Now, I'll go to bed thinking about what I just got done. It gets the wheels flowing. I want it to be a regular thing. If I put in the framework of the logic of practice, I believe I am deliberately trying to make this practice a form of habitus ... I like being held accountable. I like the structure though what's going on here is teaching me to be independently motivated. I need to be able to do this without anybody telling me I need to do it.

Lastly, Logan felt that relatedness to a coach, to our larger group, and to other mentors was vital to his growth. 
This [coaching] process has been really good. This reminded me that this is what I need to be doing, that this is what I love. I feel like you've been on me not in an uncomfortable way but in a productive way ... Coaching is good thing. I feel like it's a form of mentorship. I like it because it gives me structure and expectations. I miss that structure ... It feels like constant reinforcement.

Logan also liked being part of a larger group and believed "surrounding myself with likeminded people contributes to desire to succeed in this realm." He added that though the individual meetings were productive, he appreciated hearing other people's ideas in the larger group meetings and desired for regular group meetings to continue. "I wish this was sustainable, particularly for this group already started," he said.

Mentoring has played a vital role in Logan's academic and professional success, particularly, he said, because he is a first-generation student and comes from a background of poverty. Logan did abysmally in high school and community college (he said he graduated high school with a $1.67 \mathrm{GPA})$. He was admitted into a four-year institution only because his older brother had attended the same institution, he said. To his surprise, one of his professors eventually told him that he needed to pursue graduate education. "My mentor set me on a track to get a Ph.D. The third time I met with him, he set an expectation of [my] getting one. He was mentoring me and showing me how to get there, and publishing was one of [the ways]," Logan said. This concurs with Lechuga's (2011) findings about the faculty role of master to an apprentice in serving as mentors to graduate students. Logan eventually co-authored an article with this professor. Because of this one person, Logan is now interested in doing his own research and publishing his own work. "All it took was one person believing in me and that just changed my whole life, so mentorship is very important to me," he said. 
Interestingly, Logan made a clear distinction between how mentoring was approached in the southern United States where he had gone to school and how it is viewed here in the Pacific Northwest:

What people consider mentorship in general is really different than what I experienced in the South. When I was in the South, people noticed I had something and they started reaching out to me. Here, I feel like I have to seek them out. I feel like good mentorship comes from a person who's interested in mentoring [rather than the person desiring to find a mentor]. I really miss that about the South. If I was still in the South, I would be so much farther than where I am right now. It's a difference in culture ... The lack of genuine mentorship here is really playing a role in where I'm at [professionally].

Logan has reached out to six or seven different people seeking professional mentorship since moving to the Pacific Northwest. However, he said that no one has reached out to him save one person. This suggests that relatedness, regardless of who initiates the relationship, can impact one's feeling of both autonomy and competence in pursuing one's goals.

\section{Scholarly Identity Formation}

Logan clearly identified as a scholar from the beginning of our time together. His definition of scholar is inclusive and reflects on his own time researching as an undergraduate student. During our first session, Logan said this:

I would define myself as a scholar ... I've always defined myself as an intellectual so if they are the same, then yes [I identify as a scholar]. I feel like a scholar can be anybody who's studying or contributing to the educational realm as well. Even if you're a student, I can see you're a scholar as well.

Clearly, Logan believes that a person can contribute to knowledge production even if he or she is not faculty or considered an expert in a field. Logan cited several activities that define being a scholar for him. These include reading journal articles for fun, which he does on the bus; being on listservs or participating in other forms of communication so 
that he constantly has a stream of reading to do; and understanding good research methodology. Most importantly, being a scholar for Logan means being curious:

I can't stop thinking about research all the time. If I'm watching the news, if I see some new phenomena that interests me, I'm constantly thinking about methods and how to best measure that. How's that measured? How many variables? How is that defined? I used to think about these things before, but it wasn't until my mentor in undergrad who gave me labels to what was going on in my mind.

For Logan, it seems that developing expertise rather than having the expertise itself is what defines a scholar.

Scholarship, for Logan, also is about applying what he learns to his practice, especially when it comes to helping under-represented students succeed in higher education.

My research interests are about inequalities. We need a significant number of people in positions of leadership to dictate what we can do to tackle these things or else the people who are looking through privileged lenses are always going to design things through that particular lens ... I felt initially I just love doing research, for one, and, two, I know I wanted to get a PhD. ... More recently, I'm really interested in using research to make change, to benefit everyone.

Scholarly identity has to do with creating a more equitable world. It is not surprising, then, that Logan identified as scholar from the beginning of my study even if he had not published greatly or conducted original research. His professional identify is directly tied to the work he does daily with students.

Perhaps because he identifies as a scholar, Logan felt he has greater competence in his professional life:

I do believe that I am competent and have the ability to successfully navigate this field [of work]. I know how to play the game [of navigating bureaucracy] now a little more, which is better than not knowing how to play the game. I don't like the game at all, but to make the changes I want to make, I have to play the game, so now I have to become the master of that craft. 
Such mastery, he said, involves understanding research and knowing how that research can be applied to his practitioner self.

Although he valued scholarship, Logan felt that the academy generally does not value it when it comes to student affairs professionals. Logan and I met during the lunch hour partly because he wanted to keep his personal goals separate from his work in student services even though his topic for our project would be directly applicable to the students at our university. At the beginning of my study, I asked him if he thought research and publishing should be an expectation of his position, and he did not answer directly. He sees his colleagues as scholars because they are curious and contribute to the profession by trying to figure out what works in helping students navigate higher education. However, he does not consider scholarship through writing or a scholarly identity as essential to his position.

During our last interview protocol, which occurred at our last individual meeting for the study, Logan reconsidered his stance about where scholarship fits into his work. "I wish there was an opportunity for staff to set aside time in their work schedule, that it was part of their job, to work on publishing," he said. "I feel like staff, even though they're not faculty, have a lot of offer. Just like it's written into faculty's positions to publish, it should be written into ours." Logan would like greater autonomy "to build my own scholarship," he said. "I don’t want to be doing work for other people anymore. I've done that, I've done all the grunt work."

Logan has a great desire to produce scholarship because he truly has a curious mind. During our time together I could almost physically see his mind working as we discussed research methods as well as issues in higher education. If Logan were given 
the opportunity in his day to research and write, it seems he would be more fulfilled professionally because he would be contributing to issues of equity and social justice for all students. Logan appreciated my physical presence as a coach because if I were literally present, he could dedicate that time to the work that interests him that is in addition to the responsibilities in his job description.

Because I used action research as one method, Logan was able to reflect on his practice, which informed how he approached this project. He and I decided that given his situation with a new child, selecting a journal and reviewing some literature would suffice for the first month of my study. He had wanted to produce more and apologized for not doing so. We had conversations about what was realistic with his new and sometimes overwhelming responsibilities of fatherhood, and Logan concluded that spending time to research and think about his project was what he could do at that moment. He was happy, however, that he did produce the three pages that he did by the end of our time together.

\section{Lou}

Lou has been working in student services for six years. He identifies as a White male, and his highest degree earned is a master's in student affairs in higher education. He is the only participant with a degree specifically in higher education. He has high contact with students and interacts with many of them on a daily basis. Lou recently has become interested in assessment, and he wanted to write an article about the assessment work he has been doing for his department. He considers himself "someone who can write well" and has published creative writing pieces. He describes his academic writing as "rusty" but his writing overall as "engaging" and "thoughtful." Like Logan, being in 
an environment with mentors who have encouraged him to publish and present has been vital for him, Lou said. He attended all four group sessions and nine individual sessions. By the end of our time together, he completed a manuscript that he was going to submit for publication.

Lou wanted to participate in my study because he felt the time was right for him to contribute to the profession. "I think that it's important to let others know what you're doing. The collective information is better than just one person's," he said. "The more you can add to the body of knowledge, the more other people can improve higher education, create better systems and programs ... I'm at that place where I want to contribute to the conversation."

One factor determining his timing is Lou's current desire to go on to earn a doctorate. During the first six weeks of my study, Lou was applying to several doctoral programs all having to do with higher education work. "It was pretty hard [to work on doctoral applications] at the same time, coming back and forth to personal statements and this project," he said. Lou's strategy for juggling the two priorities was to wake up early in the morning when his mind is most clear. However, he also had to work on his writings in the evenings as well. "Before I started this [study], I was reading scholarly articles in the morning, so I'll probably go back to that and exercise a little bit more," Lou said at the end of our time together. "[Now] I need to start preparing for my Ph.D. interviews. It's always something ... That's what I realized; you'll always have something going on.”

Although it was a relief for Lou to have met the deadline for applications, he still found himself distracted from his writing a paper for publication. In my journal, I wrote: 
Lou has almost completed all his doctoral applications. He is now at the worrying stage - worrying about whether his recommenders have sent in everything, worrying about transcripts getting mailed to his house on time, and so on. We talked about how difficult it is to worry only about things within our control and also to focus on the moment when other priorities are occupying our mind.

For Lou, worrying about his doctoral path seemed to be directly related to his greatest concern, that of supporting a family, which he discussed several times over the duration of this study.

Lou is a first-generation student who was raised in poverty and in the foster care system, ultimately being adopted when he was older. He chose to attend his undergraduate institution — the only one he applied to — because he happened to see a newspaper story about a new financial aid program that would allow him to attend at little cost. For Lou, "moving up the org[anizational] chart to positions that pay more" is extremely important, he said, adding that participating in scholarly work has been secondary to more immediate needs. "For a practitioner, scholarship has taken a back seat to my job, to justify my job," he said, referring to the need he felt to justify that his position should exist. "This has taken precedence over doing original research. They need to. I can't eat on scholarly work."

Lou experienced an emergency during the study when a close family member became unexpectedly ill. He flew to the Midwest to attend to this, and so we rescheduled one meeting. Fortunately, though this family member would need continued care, she eventually was able to leave the hospital. This added to the multiple priorities he juggled during my study. 


\section{Effective Writing Strategies}

Although Lou liked writing, he favored more of the creative sort. His goal for this project was to sound "articulate," "concise," and "scientific." He said he was not concerned about his writing as far as grabbing the reader's attention and saying what he wanted to say. However, he wanted to have more of an academic voice. For Lou, writing for a publication as a representative of higher education required a different style. "Putting pen to paper is not difficult for me," he said. "I need to ensure that I find the balance between creativity and data-driven analysis, between style and content. I need to make sure my writing and research match the journal type.”

Lou and I spent a great deal of time, particularly at the beginning of my study, sorting through journals. It took Lou until our fifth individual meeting to decide which journal would be most appropriate for his paper. He had looked into three journals, and I asked Lou to systematically go through each of their submission guidelines to determine which one would be the best fit for his work; to do this, Lou had to consider what he truly wanted to write about and his motivations behind this decision. Through this reflective process, which is an integral part of action research, Lou not only decided on a publication but he also learned more about academic writing style, expectations of research, and scholarly conventions.

The first journal that caught his interest largely published articles that had to do with original research. Lou decided he could not pull together such research in the 13 weeks of my study. Ultimately, Lou chose one that is published by a national student affairs organization. He determined that his vision of the article he wanted to write was congruent to those he found in previous issues of the journal. He looked at the journal's 
submission and abstract guidelines, and the requirements seemed more feasible. We discussed whether he wanted to inquire with the editor first to determine interest or just submit the entire paper when done. The journal's guidelines did not specify which is preferred or required. Lou decided he wanted to submit the entire paper when done. Having one journal to write toward was useful for Lou and helped him understand how papers published in this journal were written.

I encouraged Lou to create weekly goals such as finding a certain number of articles to support his topic, reading them, and making notes on them. He mined the references lists of these articles and found more publications that were helpful to him. He enjoyed reading: "Writing requires me to read," he said. "I'm synthesizing other people's ideas, connecting them to my thoughts and writing helps squish my thoughts." Although he found some articles easily, Lou did have questions about downloading articles from the university's library website. This suggested to me that not knowing the research tools on our very own campus or not knowing how to use such tools may hinder writing.

Setting weekly goals helped create a habit for Lou, who wrote once in his journal about how his smart phone, which wakes him early every morning so he can write, is not the enemy. In actuality, the phone "helps me arise with a new form of calmness. I am not angry at waking up but alive with knowledge that my little hand-held computer has woken me up at precisely the time I have asked and now I must sit down to write.” Lou learned that though carving out time to write is difficult, he chose to do so because he prioritized it over reading a book or going out for a run in the morning. 
Lou said he prefers to write alone and at home. This is largely due to the physical environment at his work. During one session when he was working on his abstract, I noted this: "He has no privacy as the offices have space above the walls where noise travels. As he was writing, someone from the office next to his spoke over the walls about the computers not working, and Lou interjected a comment." Lou concurred: "My work days flow like an hour. I fill up the space with students 'needs' and questions hurled over the wall ... My office is often more of a chaotic circus of jugglers than a quiet consortium of academics."

While many writers effectively use outlines to help organize their thoughts, Lou utilized other physical organizers in addition to a more traditional outline. Lou kept the work for his project in an electronic folder in his mail program, and he also kept a dedicated physical folder for his hand-written work. He created to-do lists on sticky notes that had not only the items listed but also hand-drawn checkboxes next to the items so he could literally check them off when done. At one point, I showed Lou a mind map of how I wanted to organize my dissertation; a mind map presents a visual depiction rather than a narrative of main ideas and supporting details. He then tried this and created a mind map (Appendix I) when first attempting to organize his thoughts for his paper, including why it is important to ask his question and thoughts about how his suggestions can be applied to other people's work.

During one individual session, I had Lou read each of his draft's paragraphs. After each one, we talked about what worked, what he meant, and so on. He changed some of the writing as we talked about his work and liked doing this while we had the time together. He also had created subheads that followed the submission guidelines, 
which was, in essence, following a rubric that the journal had created for prospective authors. In addition to revising in real time as we talked, Lou wrote three drafts of his paper. Not only did I give him feedback, but he also asked his supervisor as well as a mentor for feedback. On one draft, his supervisor suggested that "it would be good to have someone who does not know how our department currently functions read through this. I would ask them if it flows logically or if it leaves questions unanswered." Lou acted on this and asked his partner to read his work as a lay person not connected to the inner workings of his department. As a bonus, his partner is an editor professionally, and so he had her comment on his writing generally. He said he was grateful for "a partner that pushes me to be make sure that I am actually committed to doing this."

Lou liked working with me as a writing coach because of the individuality of the experience. "I appreciate that it's tailored toward the individual; it's not a one size fits all approach that we get the information that we need," he said. He also appreciated that our weekly meetings were first thing Monday mornings "because I can come in and then focus on doing other things for the rest of the week." However, he admitted that he sometimes felt "frazzled" when we met because he had not gotten to all of the emails that had come in over the weekend. He continued, "It was really good to have someone help with the timelines, to encourage me to start writing, to encourage me not to worry about how it sounds at first but to just start putting it down on a sheet of paper."

In addition to working individually with me, Lou said that what he liked most about the large group meetings was "hearing that other people were having struggles, that they were feeling behind, knowing that people have like-things happen such as family 
emergencies, knowing where other people are at was all good." The large group

normalized all the challenges that Lou had experienced; he realized that he was not alone.

\section{Scholarly Identity Formation}

Lou was "honored" to be a participant in my study because he saw this

participation as my having "the trust and recognition" that he has the experience, the ability, and the knowledge to inform his practice. "It pushed me forward and built confidence ... the fact that someone says you have something to contribute," he said.

Perhaps because of his being raised in poverty with no models of or mentors in higher education, Lou has struggled to freely identify as a member of the formally educated. "I still define myself as an outsider in higher education," he said, recalling his roots. "There's still a part of me that identifies as an imposter. One day I'll be found out as something other than an educator, a professional.” He wrote during one free write:

I do not want the identity from whence I came to be lost in the intelligence of who I am. Intelligence is not valued unless it is used create something which you can hold. A finished basement, perhaps. Intelligence and academic writing mean nothing, except the advancement of thought and the advancement of thought is for only the wealthy, those with time and money to possess and write such thoughts. This is my upbringing. This is my understanding. To battle against such understanding is exhausting and fraught with identity traps that leave even the most examined person down.

The weight of his upbringing bears heavily on Lou as he straddles the world from where he came and this one in which he now lives.

At the beginning of my study, Lou did not identify as a scholar or researcher; however, he could see how this identity might become a part of his person because of his recent work with assessment, he said. "I've been thrust into a position and asked to do things that are more scholarly in nature," he said, " but I'm getting nervous because I 
better research this stuff. I don't consider myself a scholar right now but I think I'm on the fringes of becoming one." He thought he would identify as a scholar after developing expertise, which is determined symbolically through the earned doctoral degree.

I see myself as more of an expert, or as having more experience, having something to contribute. I still think it's probably the Ph.D., the degree, the doctorate, then you've reached the scholar level. You've done a dissertation that's more than a 2,000 or 3,000 word article. I also think there is an age deference. I'm in my early 30's. Realistically I haven't been doing this for 10-15 years ... I think to be a scholar you have to dedicate your life to [a field]. I'm still at an age where I think that I could go into a different field and become an expert in that field still. Five to 10 years down the road, maybe then I can say I'm an expert or a scholar. I will have read more, researched more.

He said he feels more comfortable using the term "scholar practitioner" to describe himself. Lou ultimately wants to do work where he feels he contributes to higher education. He wants to impact higher education on a large scale such as being a vice president, working for a think tank, or being a director of assessment and research.

At one point, we looked at his current abstract, and I had him note where he needed to find sources. I read his abstract out loud, and I asked in which theoretical frameworks was he grounding his work as the guidelines for the journal he had selected required this. Lou responded that he did not have any theory to support what he was writing. However, we then talked about his possible sources again for his abstract, which led him to share the works of several well-known researchers and theorists in student affairs work and with whom he was familiar. Those works constitute enough theoretical grounding, I told him. The concept of theory may seem intimidating to some student affairs professionals as many consider themselves solely as practitioners even if they graduated from higher education programs. However, many of these people, like Lou, 
are knowledgeable about such conceptual frameworks and perhaps are unknowingly applying them every day.

As a student affairs professional, Lou considered himself an "underdog" because people in his division "often defer to people with lesser knowledge of a system because ... of positional power or academic credentials" rather than actual experience working with students. In other words, they often feel intimidated by faculty because of the letters after their names. "It's like you're support staff," he said referring to how he sometimes feel others look at him. "There's a lot to be said. I'm a professional ... I want to share, to give voice to other people and show what we're doing that works and how that impacts student success and how it impacts students," he said.

At the end of my study, Lou was upbeat. He had heard from one of the schools to which he had applied, which wanted to interview him, and he had completed several drafts of his paper and was ready to submit it for publication. In his last free write, he wrote, "I am re-energized. Bring on the Ph.D."

Lou's worlds seemed disparate - that of the poor and the middle-class, that of the formally uneducated and academia, that of the practitioner and the scholar. However, perhaps they are not as far apart as they appear. For example, Lou has developed an interest in assessment to improve his practice; to do assessment well means asking the most appropriate questions and then generating new knowledge. This, then, can be considered scholarly work. His not wanting to identity as a scholar is understandable given his upbringing. However, if Lou viewed scholarly identify as something that is developed rather than obtained as Logan did, perhaps his worlds would not be so incongruent. 


\section{Jennifer}

Jennifer identifies as a bi-racial female and has worked in student services for seven years. Her highest degree is a master's of arts in English literature. Jennifer has regular contact with students though much of her work involves outreach to the community. Jennifer has not published an article; however, she has written a master's thesis, has experience with grant writing, and has presented at various conferences. She identified as her writing strengths experience with cooperative editing and revising as well as the ability to use and explain theoretical frameworks. Currently, her writing for work consists of outlining, organizing and incorporating frameworks, and using peer input. Initially, Jennifer wanted help with creating a focus and writing for a specific audience, one that would read the particular journal in which she would eventually publish.

Jennifer attended the fewest meetings of all the participants due to health and work challenges. She did not complete a draft of a paper to submit for publication. Jennifer attended only the first group meeting; she did not attend three group meetings due to a transportation issue, an illness, and no reason given. I shared with Jennifer the slides from each missed group meeting as well as summaries of what we did. We worked individually five times; we did not meet individually during other planned times due to her work and also once due to miscommunication. We conducted interview protocols 1 and 2 but did not complete the third and final protocol.

Jennifer considers herself a strong writer and initially considered writing a paper for this project that entailed new research. She prefers to be left alone to do her work, including writing, and said that she works best that way. She is personally interested in 
social justice issues and desired to pursue this in her paper. We decided during our second session that creating new writing involving new research would be problematic due to time constraints. We agreed that writing for more of a transactional purpose by creating communication about what her programs offer would be a more manageable writing project. She said many people have asked her how she has created and coordinated various programs, and that writing one piece detailing this information would be helpful in responding to these requests:

There's no reason to reinvent the wheel, if we can share what we're doing with people. That's how I've garnered a lot of my knowledge, through discussion and sharing of ideas and theoretical practices and pedagogy. I want to do the same thing now and put back into the world ... I think it is very important for sharing knowledge so people can reproduce what we are doing and build on that and sharing best practices, more specifically. I also think it's very important to share that knowledge and story both internally and externally.

Writing a paper for publication has been problematic for Jennifer largely because of her other commitments. "I am currently overwhelmed in my personal and professional life so [I] am concerned that I won't be able to accomplish what I have set out to do," she said at the beginning of the study, adding that her workload does not support scholarship as the actual time that it takes to do the work expected of her is not enough. Also, working within a large organizational system such as a university takes great effort and time. In addition to her work expectations, Jennifer has several personal commitments such as volunteering for local organizations and advocating for social justice issues.

\section{Effective Writing Strategies}

Jennifer found that finding an appropriate journal was challenging. During our second individual meeting, Jennifer shared that she felt like a "needy child" at this point because she was not finding a journal that she could write to. I reminded her that initially 
she had wanted to write a paper about the programs she had helped to develop and why they were framed theoretically the way they are. Her supervisor wants to share this information internally as well as with the greater university and public communities, she had said. Jennifer said she felt behind in everything, including her writing, because of her illness. I suggested that we forget about the journal and write a solid piece that begins with some context (such as a framework of diverse cultures from community climate surveys, history of programs and need, and peer mentoring as an integral piece to a program's success) and then talk about each of the programs she coordinates with the theoretical piece as the common thread linking all the programs together. Jennifer agreed that this would be more feasible, and she felt that she could do this on her own.

Initially, Jennifer created an outline of her paper. During our third meeting, we talked through the outline, which really did have a lot of text. I suggested she begin with a narrative hook, a story of one of the students and to get more interviews, which would bring in student voices to tell their stories of the importance of these programs. I also suggested she work in the "needs" section when talking about each program—which need necessitated which program. We talked about planting the seeds of creating a culture of change throughout the piece as well. Jennifer took notes of our conversations. "So far I feel that I have a good framework built but a lot of filling-in-of-the-gaps is needed. Unfortunately, most of the writing needed hinges on interviewing program participants and a recounting of my experiences," she wrote in a free write. Relying on others, such as for an interview, can be problematic in continuing with one's writing particularly if one feels overwhelmed with other responsibilities, like Jennifer. 
In addition to being flexible in what one writes and outlining, Jennifer found several other writing strategies helpful. She appreciated receiving feedback: "Even the little bit we've been able to do with giving feedback on my writing, that makes a huge difference and helps get me out of that fog sometimes of what's next," she said. She liked talking through ideas with me but then wanted to work on her own; she said she writes better alone while listening to music with ear buds.

Jennifer found our coaching process helpful to her writing:

I completely $100 \%$ believe in coaching and mentoring. I think accountability, relationships, guidance keep people motivated and help us move forward with internal motivation, especially with constraints about publishing ... [Coaching has] been very helpful in keeping me on track and focused even though I haven't gotten done as much as I had wanted to. It's actually been an interesting experience for me because I don't usually say I'm going to do something and not do it, that's actually very different for me. So, it's been kind of humbling, too, in a good way ... I feel like collaboration is also the best way to work. I tend to be an individualist when it comes to my work.

Coaching helped Jennifer stay on task; it provided her with a measure of accountability. "I believe this structure would have been the key to my success had I not struggled with physical issues this past term," she said.

In addition to our coaching relationship, Jennifer also appreciated the group meeting for both practical and personal reasons. "The large take-away from our group meeting is how important it is to target the writing to the particular/type of journal you plan to publish in," she said after our first-group meeting where we had talked about the many kinds of journals that exist. To help Jennifer find appropriate journals, I contacted a colleague who works in a similar field as Jennifer to ask about such journals as I was not as familiar with this area. My colleague responded with a list of journals, and I 
shared this information with Jennifer. Also, the large group helped Jennifer realize

something more personal:

I have wrestled with how to keep things moving forward and struggled more with writing development than I have since first starting my thesis project in school. More than working through the writing process, being a part of this writing group has made me gain internal cognizance of my limitations - those all being physical as I've struggled with an injury the past several months.

\section{Scholarly Identity Formation}

From the beginning of our study, Jennifer identified clearly as a scholar, and this did not change during my study. "I base most of my work, my decisions, my outcomes on a current framework, on the work of my colleagues, on scholarly articles, on philosophical and theoretical ideas, so yes [I identify as a scholar]," she said. During our second interview, she added, "I identify more as an intellectual" because she has not had the time to produce her own scholarship.

Mentors seemed to have played an important role in developing Jennifer's identity as a scholar:

[Scholarship] has always been encouraged and pushed since I was in graduate school. As an underrepresented person in higher education, I didn't have a model for that. I remember having conversations with some of my favorite faculty who were women and married and had a whole bookshelf of books they had written and asking them, how the heck did you do this because I didn't know how to do this. It's a totally different way of functioning. That was something I'm just starting to figure out, how to work that in because I didn't see that in models. People would say you needed to do it but there wasn't a lot of help or guidance.

Partly because of such faculty mentors, Jennifer developed a "love" for research. She considered pursuing a doctorate but realized that she believes more in the application of research and scholarship. "I believe in working in communities and making changes to systems. I like studying systems to see how they work," she said. 
One of the challenges of working in a large university system is the bifurcation of employee roles and the potential confusion over expectations. Jennifer identifies as administrative faculty but acknowledges how this can be confusing:

It's always really hard to explain my position. I don't feel like a staff member at all because I'm working in theoretical work, in pedagogy, working in program building and relationship building in the community. There's definitely staff and administrative aspects to what I do, but a lot of it is putting theory into practice, which I think is a step above just being a staff paper pusher. It's also that gray area where we don't get any incentives to do scholarly work.

She does not think that job descriptions for these kinds of professions allot the time to pursue scholarship. "It's not built in; there's not time for it, which means anything you do is on your own time," she said.

I still question how professional faculty fit writing and publishing into hectic schedules that neither accommodate nor award writing/publishing. However, to really do the work that many of us are doing well is to be really involved in scholarship and to be very aware of scholarship in our area and participate in some way, but it's not rewarded. It's not part of our job description yet it's an expectation to do our job well.

Jennifer agrees that professionals who work in student services are the people who "are on the ground and figuring out what's wrong and how to strategically fix, solve, and build, and we rarely get credit for that even with people we work with internally." To earn this credit, she feels the need to publish about her work so that she can merit the recognition she feels she deserves. However, Jennifer rhetorically asked, "At the end of the day, will it really matter? Will it give you a pay raise? Will it give you more respect from colleagues?" Her tone suggested that, no, publishing as non-faculty may not garner much.

Jennifer was very open to the ideas I had about her work and where it could go. She had no qualms about changing the direction of her writing. Because action research 
SCHOLARSHIP IN STUDENT AFFAIRS

allows for change upon reflection and is a collaborative process, we were given permission, so to speak, to alter our plans for our sessions as we took Jennifer's health issues into account. Her feelings of being overwhelmed, in addition to her health, made working on this project difficult for her; this also underscored her concerns about the missing expectation in her job description of researching and writing for publication even though it may benefit the programs she administers. Her point of the gray area of her job classification echoes both Logan's and Lou's feelings of those who work in student services.

\section{Bruce}

Bruce identifies as a White male and has worked in student services for seven years. He has a law degree as well as a master's degree in intellectual property. During the study, Bruce was concurrently completing his last course for a certificate in student affairs in higher education. A few years ago, Bruce set a goal of writing "one something per year, even if it's a blog post." Since then, he has published a few short pieces through various student affairs organizations; however, "on the spectrum of 'back of a church bulletin' to 'academic journal,' I'd say these were closer to the church bulletin."

We met nine times individually, and Bruce attended all four group meetings. For my study, Bruce wanted to adapt a presentation that he had given at a regional conference and create an article for publication. He gave the presentation mid-way during our time together. His topic was about hiring student affairs professionals, and he wanted to submit this piece to a human resources publication that specializes in higher education. Bruce described his writing as lacking style; although he acknowledged that writing for a more academic journal does not necessarily involve "flowery" or creative language per 
se, he wanted to write with a bit more flair. Perhaps his background in legal writing prompted such an attitude about his current writing. At the end of our study, Bruce had a revised draft that he was ready to submit. He had contacted the publication and was awaiting word on when he should submit the piece. His goal was to make the article "very practical/useful for the reader and not too heavy on theory."

It was important for Bruce to pursue writing for publication because "it's something that is very positive to get your name out there. I'm at the point where I'm trying to look to advance to the next stage," he said. "To have something out there to the greater field of student affairs is important. It's logical if you want to move on, move ahead in this field or in any fields." Showing how one contributes to one's profession is an asset when looking for promotions or more challenging work. "It will hopefully bolster the resume; there's some self-interest reasons why I'm doing this," he said, adding that publications help raise the profile of his division and institution. Another reason Bruce feels the need to write for publication is that he feels as if student affairs professionals are often viewed as people "who plan dances and people who do quoteunquote less important work. I think by publishing we show, hey, we're smart too. We know things that contribute to the greater good and to academia."

Throughout this study, Bruce commented regularly that this is a "strange" and "unsure" time for his division due to changes in leadership and organizational structures. He was concerned that this may be impacting his work and production:

We're at work at a very interesting time, a stressful time. I wonder how this project would look a year ago or a year from now. My productivity is definitely not where it's been in the past. I'm not slacking, but I feel like I used to put in a lot more hours. We're at a weird time at this university. 
This sense of impending and thus unknown change contributed to his feeling of unease.

We had to reschedule two individual meetings because of family visiting from out of town. Also, a grandparent died, and Bruce had to fly to the East Coast for the funeral. However, Bruce continually shared his drafts using Google Docs, even during these times. This may have been due to, in part, how he felt about the people involved in this study: "In this project having a group and Lisa to which/whom I was accountable helped me complete assignments - mainly because I did not want to let others down," he said.

\section{Effective Writing Strategies}

Bruce and I developed a system where he saved all his drafts and notes in one running Google Doc to which I had access and could edit and comment. He noted on the document the days and times he started his writing and when he ended. He set weekly goals with me that he would work on during the week and email me Sunday nights with his progress. He seemed to work best when he had fairly long uninterrupted stretches of time. For example, Bruce wrote for three hours one Sunday afternoon. He said this worked well for him because it would take a long time to get back into the writing if he had written in short spurts. He had "laser focus" during these times, which meant he was offline completely. He did admit, however, that he did not actually start writing one particular Sunday until he had done everything else he could to avoid writing. Bruce wrote mostly at home or in his office during the weekends, largely because he said if his door opens, he is in trouble. It is common practice in many student affairs offices to leave office doors open; also, his office is situated off the main reception area, and so students and staff often come in to his office to say hi, catch up, or ask work-related 
questions. Because of this, a tension exists between the need to be available to students and the need to meet personal and professional goals that do not directly involve students.

In addition to the steady barrage of visitors to his office, Bruce also struggled at times with motivation to write. Although he often put off his writing, he did understand the need to start, and once he began, he was successful. "Once I stopped procrastinating, I actually enjoyed myself," he said. After returning from his grandfather's funeral, Bruce said, "I haven't written for this assignment in about a week, but I have somewhat of a first draft. I spent about 90 minutes just writing last time I sat down to write and was able to chug out several pages. It felt good!"

One writing strategy that forced Bruce to write was free writing. I had participants engage in free writing for 10 minutes during each of the large group meetings. "I liked being forced to write [in the big meetings] even if it was about anything you wanted," he said. "Having to put your pen to paper or fingers to the keyboard has a lot of use ... It helps clear out any garbage that's in your head a little bit." Bruce wrote about his presentation during one free write, and that served as the basis for the paper that he ultimately planned to submit for publication.

During our individual sessions, I had Bruce try various writing strategies such as having him read his work out loud for word choice and sentence fluency; I also read his work out loud to him one time to point out areas where he needed evidence to support his assertions. He realized a few times that he was making generalizations that could not be supported. However, we also discussed the effectiveness of anecdotal and personal experience as valid forms of evidence as long as there is support in the larger context in the literature. Bruce also had questions about using the library website as he had not used 
this rich resource before, including using article databases and Google Scholar. The sources he did have were from websites such as Inside Higher Ed as well as a policy paper from the Aspen Institute.

Interestingly, Bruce discovered that though his presentation and paper topic were the same, not all elements of the former worked effectively in the latter. During the presentation, Bruce had shared with his audience the story of a woman who had worked at one institution for decades. He struggled to incorporate this same story into his paper, but it just did not seem to fit the tone of his writing. When he decided to omit the story, which had drawn lots of laughs in the presentation and seemed to be a hit, Bruce said he felt "liberated," adding that "even though a personal narrative can bring readers in, it didn't work for this article, which was just fine."

In response to the background questions I asked before the study began, Bruce wrote, "I relish feedback. The more constructive criticism, the better." He looked forward to bringing his work to the larger group to receive feedback; however, he also considered receiving feedback as a bit "scary" because one's writing is an extension of oneself. Thus criticism of one's words can easily translate into a critique of oneself. To ease some of this fear, we often looked at my comments one by one during individual sessions. I sent him my comments before our meetings so he would have time to digest them, and then we went over them together so that I could clarify any confusing points. He had this to say about receiving feedback:

The feedback you gave me on the last draft was very helpful. You made an interesting comment about formality of my language changing two or three different times. It was very much because I stopped writing and picked it back up ... As a writer, you're living it. You're very close to it, so getting different perspectives is very good ... I feel that my first drafts are usually poor, but much 
needed. Without anything on paper, there is a nothing to revise and I would say that I am a much better reviser than writer.

In addition, Bruce appreciated the comments he received from another participant during one large group meeting. He said he responded more positively to these comments when he returned to his office to re-read them. Perhaps the physical distance of time and space away from the group meeting gave him a different perspective on his work. In addition to feedback, Bruce enjoyed the large group meetings overall because "I think it's fun to hear about the successes that other people have. This is now motivating for me to do something as well ... We're not just meeting to meet."

Bruce said he felt a common purpose with the members of the large group as well as with me as we were all trying to help him achieve his goals, which indirectly impacted his moving forward in the profession. Similar to other participants, Bruce also credited having mentors as helping him to develop professionally. "It's been people who have encouraged me and brought me along," he said, recalling previous supervisors who encouraged him to attend and then present at conferences. Being part of national organizations "was very eye-opening and gave me a very broad picture of things [in student affairs]. In turn, I'm trying to instill that in people I have influence over whether they report to me or whether I know them," he said. As with other mentors, he trusted our coaching relationship. "I trust you and whatever you want me to do," he said. "I know it's not for a bad reason."

\section{Scholarly Identity Formation}

Bruce clearly identified as a practitioner throughout our entire time together. "Who I am is more of a doer and not a thinker," he said during our first interview 
protocol. 'It's not that I can't be scholarly, but I'm more of 'let's get something done' rather than spend 10 years thinking." His last comment suggests that he perceives scholars as almost inert in their ability to apply their thinking to actual practice. During our last individual session, Bruce said, "I am a practitioner at my core - my function is to serve students and work in [my division], not to achieve scholarly pursuits."

Bruce raised an interesting view of the student affairs profession and its emphasis more recently on scholarship and research:

Sometimes in student affairs land, historically or presently, we're not as valued. Sometimes we've added research, scholarship, assessment to pad things to look better than they are. There are some things we do because they need to be done, and that's ok. We don't need evidence to show that it's important. I understand why we do, and so I don't even know if I like the scholar-practitioner framework ... Certainly, there are best practices. Is it really scholarship or is it practical advice? It's more like how to do this well, not so much theoretical frameworks.

These comments are reminiscent of Lou's initial thoughts about his practice not being undergirded by theoretical frameworks. The practical nature of many functions in student affairs, such as processing a transcript or disbursing financial aid, can still be informed by best practices, many of which can be based in theoretical frameworks. For example, a registrar who has studied student development theories may create different systems than one who comes from a management model.

Although Bruce did not consider himself a scholar, he did advocate that expectations of sharing knowledge be a requirement of many student affairs positions:

When social media first came out, everybody was saying how are we going to do this [use social media]. I heard at a conference someone saying for every job description going forward, just put in it $5 \%$ of your job involves social media. If we did something like that for writing where part of your position description was to do some scholarly work whether it's presenting, presenting on campus about what you're doing even, this has value. 
Bruce suggested even one to two hours devoted to scholarship per week would be enough to produce quite a bit to share with others in the profession. This was the average amount of time he dedicated to the paper he wrote for this study. Similar to Lou's thoughts about seeing the end product of one's work, perhaps the greatest reason Bruce had for writing, however, was to produce something. "I like having an end product. Writing is tangible. I wrote this. I have this," he said. "I have been an influencer to many students, but that is not anything quantifiable ... [Writing] is right there."

It seems that Bruce would see himself in the management community of practice that Blimling (2001) wrote about regarding frameworks of how student affairs professionals do their work. He clearly saw the need to provide good service to students. However, as I asked him to reflect on student affairs as a profession, Bruce concluded that time allotted to scholarly endeavors could be valuable for some positions and could add to improvement of such services. Through our coaching relationship and using action research as a method, Bruce learned not only to feel more competent in his writing but also to consider movement along the scholar-practitioner continuum.

\section{Diana}

Diana has worked in student services for 12 years, the longest of all the participants, identifies as a White female, and has a master's degree in social work. Although she has presented numerous times at local and national conferences, it had been more than a decade since she had done any "significant" writing (this was in graduate school). Diana wrote about changes to models in her own department and used it as basis for a case study; she selected a practitioner's journal that focused on student unions. Diana contacted her journal's editor for submission guidelines, submitted two drafts to 
the editor and received feedback on the first draft from her, and ultimately had her paper accepted for a spring issue of the journal. We met during eight individual sessions, and she attended all four group meetings. We rescheduled one meeting due to a conflict in her work schedule; we also missed one meeting because of a grandfather's death when she needed to travel out of state for his service.

"I want to challenge myself and add a layer or component to my work and practice. I have been in my position for long enough that sometimes I am in auto-pilot," Diana said as to why she wanted to be a part of my study. "I had been thinking about writing and publishing for a few years. I always included it in my professional development goals," she said. She had not acted on this goal, however. Diana said she was excited work on something that was "cerebral and focused" rather than the more administrative work she does daily, which tended to center around problem solving, making decisions, or navigating politics.

Although Diana considers herself an extrovert, she wanted to work on a project that she could do by herself. "Sometimes I just want to slow down, focus, and get a chance to think - and to work on something alone. I hope that doesn't sound selfish or negative," she said, adding:

In my current job, everything I do is so collaborative. I make decisions, but before this, there's lots of group thinking, multiple committees, and so on. It would be nice to do something where I get to do something that's by myself, even if it's something like I close the door for one hour or go to the library where I just get to think about something by myself ... There is no time in my day where I'm not with other people, talking to a million people. Even for a super extrovert like me, it gets old after a while. 
This time to reflect and thus grow was important to Diana both professionally and personally. "Instead of just doing the work," she said, "I want to have a practice of reflection and learning ... This project may help kick start a practice."

Unlike other participants, Diana's main motivation to write for publication was not to advance professionally or educationally but rather to carve out time to reflect on her professional and personal goals:

I would like to develop a practice to integrate writing into my work, whether that is simply for reflection or as intensive as publishing ... I'm in this transition phase in my career. I don't necessarily want to move or to move jobs or try to strive to get a promotion. But I want to be challenged. I want to do something to feel like I'm moving ahead in the profession or in my career without necessarily having to change jobs.

Without this reflective practice, she said, she would not be able "go deeper" into her work, a position that she enjoys and does not necessarily want to change.

Diana felt she has the autonomy to write for publication but that time was the biggest barrier to doing so. "Time. That's it," she said when asked about writing challenges. "I don't feel I'm discouraged by the environment or my supervisors. It's not my own innate feelings of inadequacy." She felt great responsibility as the leader of her department to contribute to the unit, and so she said she would feel irresponsible if she spent time during the workday doing something that, to her, feels personal even if she is contributing to the profession. "[Scholarship] is a pretty individual practice, and my job is to lead a team," she said. Her greatest concern was then making time to write at home, which she anticipated to be challenging because she has two young children, a partner, and a house to maintain. "It is hard to prioritize non-family focused projects in the limited time I have outside of work," she said. "Home is no longer a place for studying. 
Even if it's quiet, I'm thinking about doing the dishes or the laundry. I've compartmentalized my life." In other words, when she is home, she focuses on her family and all that is associated with that.

Interestingly, Diana conceded at the end of my study that she did most of her writing during work hours. She said this occurred because the time she did have at work can be fairly flexible (she skipped one work meeting so she could write). Modeling ideal employee behavior was important to Diana, and so if she wanted to promote scholarship in her department, then she would need to model that behavior, she said. However, she had not talked with her department about such expectations nor was she sure if she wanted to create such expectations.

At the beginning of her project, Diana worried that she may not appear knowledgeable about the publication process. For example, when I suggested she write an abstract, she said did not know what one was exactly. "I suppose that since this is new to me, I worry that I will show how much of a novice I am in what I submit," she said. "Will my outline look too much like an English essay? Will they think I don't know what I am doing? For example, I want to have a thesis statement. If I call it that in my outline, will they see that as me 'acting like a student'?" This discomfort with roles (a student versus a professional) as well as her competence in producing an article suitable for publication eased as she continued with the process, especially once she received positive feedback from the journal's editor on her ideas.

\section{Effective Writing Strategies}

Diana found most helpful from the first group session our discussion about the various kinds of journals that exist, which range from those that accept only original 
research to others that publish more practitioner-based or applied articles. She did not want to do original research and did not think this was feasible during our finite time of this project. After spending some time researching publications, she settled on one that focused on student unions on university campuses. She inquired about submission guidelines and received a prompt response from the publication. The journal did not have style guidelines per se and so she reviewed previous issues for content, writing style (tone, word choice), and layout. The latter made her think of the possibility of creating a sidebar to her paper. Her topic had to do with the changed paradigm of how the university pays its student leaders, which is a common topic of concern among student union professionals. Her institution underwent this change four years ago and she had enough data and assessment to show that the change had been effective.

After initially contacting the publication's editor to gauge interest, Diana wrote in her journal that she was "excited and proud" that she will be working toward publishing. “Now, it isn't just something I am putting in my annual reviews as a professional development goal but something I will actually be working on," she wrote. Knowing that a journal existed that was interested in her work was extremely helpful for Diana as she now had a sense of what was expected of her in terms of lengths, style, and type of stories accepted. "If it was, I'll just get something ready or I don't have anywhere to send it, it would have been much harder to get it done," she said.

For her article, Diana thought it would be wise to learn how other institutions pay its students. I suggested that she interview three or possibly four people due to how much time it would take. Together, we created five interview questions. I also suggested she conduct member checks after she had written up the interview notes, which she 
agreed to. We did discuss when it was necessary to include human subjects approval but decided this was not necessary due to the nature of this paper; also, the publication did not require it. Diana eventually interviewed three people at a variety of institutions (twoyear, four-year, and private). During her first interview, which was via phone, she realized that she could type faster than she could write, and so for subsequent interviews she placed the subject on speaker phone. Before Diana had written any drafts of her paper, she said, "I feel good about my topic and what I want to write. I need to work out the logical transitions between points a bit more, but I feel confident."

During individual sessions, I regularly asked participants what would be most helpful for them in terms of how we spent our time together. Because Diana was so reflective, we spent one entire session discussing her biases on her topic and how she tried to compensate for that by not leading the people she interviewed who had their own models (and reasons behind them) regarding student pay. She said it was extremely useful to talk her ideas through with me because it clarified her thinking. Also helpful in organizing her thinking were visual outlines. Before creating a linear traditional outline, Diana created visual maps, much like Lou, to help put on paper not only how her paper could be organized but also how to compare topics that needed to be explained in her paper (Appendix J).

Diana first submitted an outline to the journal's editor and then, after positive comments from her, worked on the actual paper with my feedback. She said our discussion in the large group about writing "without worrying about greatness" was helpful to her. When she was ready to submit her article to the publication's editor, she said regarding feedback: 
I am trying to get mentally prepared. I keep reminding myself that it is a draft and to be in a place to welcome feedback. I like what I have written and I always want things to be perfect, but I am trying to have a different attitude. I want to prepare myself to have it torn apart and reworded so that my feelings don't get hurt.

She received positive feedback, including praise for her connection to theory and effective use of a case study, as well as a handful of suggestions that made the paper stronger: adding a student voice, integrating more sources, and revising the introduction and conclusion. Diana agreed with all of the recommendations, revised her work, and resubmitted it even before the deadline she was given. The article will be published in an upcoming issue.

In addition to the feedback itself, Diana strategically knew when it was best to process comments on her writing. She wrote to me in an email, "Thank you for getting back to me so quickly. Great feedback. I am going to let this sit for today and come back to it tomorrow with fresh eyes." Not only was the feedback itself important but so was knowing the time of day when one is in the best frame of mind to receive it.

Another strategy that worked well for Diana was that of constantly reading. An avid reader, Diana felt that this was something she could do at home or on the bus. "Reading sparks all sorts of thinking. The more you hear other people's style, the more you develop your own writing voice, vocabulary, sentence structure," she said. This includes reading fiction, non-fiction, journal articles, blogs, and other genres. Re-reading her own work also helped when she simply did not feel like writing. "Sometimes I have set aside time [to write], but I don't particularly feel inspired," she said. "But if I just get started by reading through what I've written, I will find something to tinker with. Tinkering leads to ideas and ideas lead to writing." 
In addition to our regularly scheduled weekly meetings, Diana also scheduled one hour per week to go to the library. True, this could have been to conduct some research, but technology easily allowed her to do that at her office desk. Rather, she wanted to get away from her work environment so that she could surround herself in a physical space that was naturally conducive to studying. The library has hundreds, if not thousands of students, who use it daily. It has far more traffic than a typical office. However, the perception is that work gets done in a library; it is for studying and focused work. One week, even though she had blocked out the time as usual, she said too many students "kept coming in" for her to leave. Fires, albeit small ones, often deter even the best laid plans. That week, Diana used the library's databases from her computer to find articles relevant to her topic. Diana also took reading notes in her journal rather than simply note marginalia in the articles she read.

Diana said she appreciated the coaching relationship as it provided opportunities to "bounce ideas off somebody" as well as "a little bit of the external motivation to stay on track." Coaching "has been great for encouraging and mentoring me through the next steps," she said. Without the structured time frame of my study, Diana said she would not have been initially motivated to do the work. Perhaps knowing there is an end when a product is expected, rather than a seemingly infinite amount of time to finish a project because one is simply interested in it, prompted her to participate in my study.

Diana appreciated the group members not only because she felt accountable to them, but because they also alleviated the self-doubt she had experienced at the beginning of her writing project. She also appreciated what we did in the group, such as the free writes, and that these activities were appropriate for all group members regardless of 
where they were in the writing process. It was important to Diana that she not let the group down. "I care if I show up and I don't have something prepared and to show other people," she said. "I want to feel I'm doing a good job." Most importantly, she felt connected to the group professionally. "Engaging in another level of the profession has been motivating," she said, referring to the act of writing. "Writing is a way to connect and communicate. Creating a practice of writing is a wonderful way for me to grow and reflect, and sharing it with others is a way to create bonds and dialogue with others."

In addition to the relationship she felt with the other group members, Diana liked having the process of publishing demystified a bit, which we did during the first group meeting. "I also took away more about the process of submitting an article, especially the suggestion to research the publication before writing the article," she said. "That helps to answer the daunting question 'where do I start?"' She also enjoyed free writing during the group sessions, which complemented the practice she had started of journaling in a notebook; however, she said, she was clearly not used to it. "My arm and hand cramp easily and it goes so slow," she said of writing with a pen. "I can type much faster. Handwriting slows my thinking down noticeably. That might be good."

\section{Scholarly Identity Formation}

At the beginning of my study, Diana did not identity as a scholar. Rather, she saw herself as a good administrator because she is collaborative and a problem solver. "A lot of times, I'm the fixer," she said, referring to helping solve problems within her department. She described herself as systematic in processes, adding, "It's almost like I can visualize a policy or procedure or steps in a system.” Diana envisions scholars, on the other hand, as reading, reflecting, and writing more than she does now. She said she 
did, however, identify as a scholar while in graduate school, and so the identity can be intermittent to her. 'It's not like I don't think I could or if I've never been a scholar. It's that it's not my regular practice," she said.

During our second interview protocol, Diana said she was moving on the scholarpractitioner continuum. "I think this process is helping me get closer to that identity," she said. "I don't know that I can call myself a scholar completely but I feel that I could continue on this path, it could be part of my professional identity." For Diana, a scholar is a person who continually incorporates writing and research into her work, much like a faculty member who is expected to produce scholarship regularly. If she completes this one article and she is published, then she would have completed a task; however, if the work "prompts me to do a scholarly article or even keeping a blog based on reading and reflection, I would feel more like a scholar." She confirmed that it is possible that one day, she would reply "yes" to my question about identifying as a scholar, adding:

If I have a practice of connecting research to practice and theory, thinking of all of those things and connecting it to practice, to me that would be a scholar ... I think I just feel like I need to build that practice in more to have that label. I think it having it be more of a routine practice, more embedded in what I do.

At the end of my study, Diana said that going through this process has made her feel more confident and thus competent in her writing abilities. It has also helped her to create that habit of practice that she desired at the beginning of this study as she has been writing more in her journal as well as writing letters. She was even considering starting a blog. Diana also found another surprise in researching her topic, which discussed student motivation for participating in certain activities:

All of the stuff I just researched about drive and motivation resonated with me unexpectedly. I wasn't trying to make it about me ... It was the mastery and 
autonomy that resonated with me right now of having something that I can do, my project, that I'm excited about doing rather than the things I have to do for work that I've been doing for the past seven years, the same routine, and then trying to master something new that I like but haven't mastered yet.

At the end of our time together, Diana said she felt "accomplished ... I am feeling inspired to write more."

Diana emphasized reflection regularly throughout the entire study. Perhaps because she had worked in the profession the longest, she did not feel she had to prove or justify her work, and so she had been thinking a great deal about her personal goals, which included writing for publication. Diana's was internally motivated to do this work. Like all participants, Diana wanted feedback, but, like Bruce, she recognized that receiving criticism about one's writing can be difficult.

\section{Limitations of Study}

Although working with five participants allowed me to gain in-depth knowledge about them, their writing strategies, and their scholarly identity formation, having so few participants was a limit of my study. If I had worked with more participants, I may have found other categories and patterns across them. Also, not all participants attended all nine sessions or all four group meetings, which may have impacted my data collection. In addition, if we had met for a longer period of time, I may have gained more insights in response to my research questions. For example, I wonder how different my study would have been if participants chose to take a longer time to conduct and then write about original research. Would that have made a difference in how they viewed themselves professionally or in what they did to complete those manuscripts? 
I chose mid-level professionals so that participants would have some similarity in length and perhaps breadth of experiences; the range, however, was broad as the years of experience ranged from five to 12 . Such a broad range may have allowed for a wider variety of insights about professional identity formation; if my participants were more similar in years of professional experience, I may have found more common patterns. Also, because some participants were further removed from graduate studies than others, this may also have provided for more variance in both identity formation and use of effective writing strategies. Another limitation was confining my study to mid-level professionals and so missing are voices and experiences of new professionals as well as senior administrators. 


\section{CHAPTER 5: DISCUSSION AND IMPLICATIONS}

The purpose of my study was to explore participants' identities as scholars as well as their effective strategies for writing. My research questions were: (a) What writing strategies do student affairs professionals find effective when producing manuscripts to submit for publication in academic or practitioner journals? and (b) How does scholarly identity change during a structured writing program specifically intended to foster professional writing? I used case study as one method of research because I wanted to gain an in-depth understanding of my participants' professional identity formation and perceptions of effective writing strategies. I addition to case study, I also used as a method action research, which is a participatory process that seeks to generate knowledge that then is given back to the setting (our coaching sessions and large group meetings in this case). I answer my research questions in the next section when I look at my findings across all five participants. Because of the two methodologies I chose to use, I expected that each participant's experience would be different. However, they also shared common experiences and feelings throughout our time together. I write about my participants' collective experience in the interpretation of findings section.

\section{Interpretation of Findings across Participants}

All participants were motivated to write a manuscript intended for publication about good practices in their work that would directly or indirectly help students by sharing such practices. Logan wanted to shed light on how the college environment impacts the success of African-American students; Lou believed his department's ability to use current data would help improve student programs; Jennifer wanted to share information about her programs that address inequities among students; Bruce thought 
that hiring well would positively impact an organization's culture and thus how it serves its students; and Diana absolutely believed in the developmental appropriateness of how her department pays student leaders. However, all participants had other reasons for wanting to participate in my study, ranging from easing workload by sharing how programs got started to adding to one's curriculum vitae to a great desire to do something personally gratifying. It did not seem to matter what the motivation was in terms of actual production of an article. Rather, this motivation, along with a myriad of other factors, seemed to have impacted the creation of a final product.

To the person, time was the greatest concern that all participants had about completing this project as well as why they had not written regularly before. The theme of lacking time, or perhaps prioritizing other activities for a variety of reasons, came up constantly during my study. Many factors contributed to prioritizing writing below other activities including time with family, responsibilities at work, lack of expectations for writing professionally and lack of reward for doing so, adhering to firm and consequential deadlines for other priorities, and desire for community involvement. Everyone had various strategies to make this work; however, a common one was to work during the time we had scheduled together. Spending part of our hour actually writing or researching an article seemed to promote autonomy because it moved the participant a little further along the writing process. Also, as part of participatory action research, I had each participant set weekly goals that were specific to their individual projects such as which two sections did one want to write and how many articles could a person download and read. Meeting these incremental goals, just as our spending incremental time together, ultimately helped create the larger manuscript. 
Because it was difficult for many people to write at work, though some certainly did, finding time and space away from work was key to producing writing. The physical environment, in particular, greatly impacted my participants' abilities to focus on their writing. These physical spaces were created with their positions and department's organizational structures in mind. Logan, Lou, and Bruce all work in offices that open to main areas where anyone — students, faculty, staff, community members—can roam. These individuals' offices literally are in direct sight-lines from entering the main reception areas. Because of this, they are easily accessible to the students with whom they work. All of my participants closed their doors when we met to deter students and colleagues from waking in. Unfortunately for Lou and Logan, that did not matter because students walked in anyway. Also, for Lou, his office's walls do not extend to the ceiling, which means he can hear anything and everything going on in his colleagues' offices as well as any conversations in the main area adjacent to his office.

It seems the only quantifiable connection I could draw in my study had to do with the number of relatives who died. During the 13 weeks that my participants and I worked together, three grandparents (including one of a spouse) died and one mother became seriously ill and required prolonged hospitalization. Three participants $(60 \%)$ had to fly thousands of miles unexpectedly during my study to tend to these family concerns. The good news is that one participant did welcome the birth of a son. All this suggests that life, or in our case death, simply happens, and people have to work through the vicissitudes of their lives. As these circumstances show, it is not only one's specific job description or lack of time during the day to write that temporarily hinders progress in the 
publication process. It is important to note, however, that all these participants moved forward in their writing projects even after such life-changing events.

\section{Effective Writing Strategies}

All participants had at least a master's degree and had written substantial amounts in their respective graduate programs. Logan was the most recent graduate, having been out of his master's program only one year, and Diana had been out the longest at 12 years. Although all participants felt they could write well to a certain level, all participants except for Jennifer lacked confidence at some points about their writing skills.

The most important writing strategy overall was to create a habit of practice that fostered writing. How my participants did this was through coaching, regular journal writing, scheduling writing and research time as they would any other meeting, and seeking weekly (and sometimes daily) accountability. Their ability to create this habit hinged on their feelings of competence in terms of their writing, relatedness with me as their writing coach and with their peers in the writing group, and their perception of autonomy in being able to do so. Unfortunately, this last component of Ryan and Deci's Self-Determination Theory (SDT) (2000a) was the most problematic. To review, autonomy is defined as the feeling of volition to act on a task; competence is one's perceived ability to be able to accomplish a task; and relatedness has to do with a sense of belongingness and connectedness to a person or group (Ryan \& Deci, 2000a).

All participants felt they did have the autonomy to write for publication - to a point. They felt they could participate in the project without having to solely work on it outside of work, and their supervisors were supportive of any scholarship they pursued. 
However, because writing for publication is not in any of their job descriptions, participants felt a tension as to how much time they could devote during the work-day to this project even if a direct supervisor was not checking in on them. In other words, some participants felt allotting a lunch hour or something comparable was all right; allocating a full afternoon or morning, however, was not even though the topics they were pursuing could enhance the institution's reputation, share student voices, and positively impact similar programs and thus students at other institutions. However, many participants said that once they determined which journal to write toward, they felt the project was more manageable. This selection, then, also impacted their belief that they could act on their writing.

What everyone could act upon was his or her own time outside of work. All participants worked on their articles outside of the work-day either in long afternoon stretches or short morning spurts. They used weekends, evenings, and early mornings to research and write and took advantage of partners and other family members' help so they could do so. Because no one had explicit expectations of writing and researching in their professional roles, participants needed to spend time outside of work to do work that they believed would benefit students.

As noted previously, all participants felt they could write reasonably well, and they used several strategies to move their writing forward. For example, all participants created linear, traditional outlines that helped them organize their thoughts. Two people, Lou and Diana, used visual mind maps to categorize their topics. These two participants also commented on how helpful it was to have a publication to write toward rather and how that alone gave them structure because they knew the submission and stylistic 
SCHOLARSHIP IN STUDENT AFFAIRS

guidelines. All participants considered themselves readers in general and of scholarship, and two felt they were solid researchers. However, three participants wanted to become more competent researchers. Lastly, all participants liked free writing during our group or individual sessions. Being "forced" to write created time for reflection and planning as well as a tangible representation of progress because of actual words on paper.

To address the last component of SDT, I wanted to look at relatedness of participants to an intrusive writing coach and their fellow participants. All participants cited the positive relationship among all of these people. Coaching allowed for individual communication and help. I did not have a prescriptive plan in mind before beginning the study where all participants would follow the same plan of action. Because I had collected background information about all participants as well as talked with them about the study beforehand, I had some idea of where we could start. However, because each participant had individual preferences to work certain ways, I tailored each coaching session to each person's needs. I also approached the large group meetings in this way. I created the content as I went along rather than all at the beginning because I wanted to know what participants wanted to talk about during these sessions. Participants were appreciative of these tailored approaches to their work.

Another key component of relatedness in coaching and in large group was accountability. All participants had wanted to write or had been encouraged to write; however, they had never had one person whom they needed to tell weekly what they had done. Also, they did not want to be the person in the large group who did not follow through with what they said they would do. This level of accountability was extremely important to all the participants, and they all noted this. 
All participants valued feedback from their peers in the study and from me, and they felt comfortable giving and receiving such feedback; they understood that other people's perspectives, questions, and comments only improved writing. This mirrors the commonly accepted practice of peer review among faculty who write for publication though our experience certainly did not involve a blind review process as we all knew who was commenting.

Interestingly, four of the participants noted the importance of mentoring outside of our project. Diana, who has been working in student affairs the longest of everyone, did not mention mentors. The others, who have all been working in the profession five to seven years, talked of how vital mentoring has been to them; perhaps this suggests that mentors are more desired to those with less professional experience. Without the faculty who encouraged Jennifer in academia, without the supervisors who advocated for Bruce to attend national conferences, they may not be where they are today. Even the lack of mentoring Logan has encountered here in the Pacific Northwest seemed to have an impact on his professional goals.

Because mentoring and coaching are individualistic experiences, applying the same strategy across all participants was not effective. For example, I knew that when I met with Logan, I would be there the entire hour because my physical presence provided a level of accountability. However, Jennifer specifically said she prefers to write alone and did not have materials that she needed to work on because her writing was on a computer at home. This last point speaks to what the coach and participant could agree upon before sessions begin - that the participant would have materials available during the coaching sessions. I did not explicitly do this with my participants. Because of 
SCHOLARSHIP IN STUDENT AFFAIRS

online sharing technology, the coach and participant may even agree to have all documents shared such as Bruce did via Google Docs.

\section{Scholarly Identity Formation}

Participants felt that a goal of their day-to-day work was to be effective practitioners, whether that entailed direct contact with students in advising roles or supervision of other professionals to maintain university services and programs. These responsibilities were spelled out in their respective job descriptions. However, three participants felt they were moving along the scholar-practitioner continuum as they identified as becoming more of a scholar due to our work together. Even Bruce, who declared himself a practitioner solely and questioned why student affairs professional may even need to consider theoretical frameworks or assessment of our work, said he can do scholarly work and so could play that role. Bruce seems to follow Blimling's (2001) taxonomy of a management view of the student affairs professional; interestingly, Bruce wanted to publish in a human resources journal, a subject area that largely has to do with management and supervision. Two participants, Jennifer and Logan, felt very much like scholars because of their curiosity, love of research, and theoretical groundings even though neither of these participants produced manuscripts at the end of my study. Their work, according to Blimling (2001), would be through a learning lens, which includes their own learning and not necessarily always that of a student's development.

All participants shared their frustrations as to the ambiguous role scholarship plays in their respective positions. It is not expected of any of them to publish in journals or present at conferences; however, it is expected that they seek to grow professionally. They are caught in what Jennifer called the gray area of professionals who are neither 
SCHOLARSHIP IN STUDENT AFFAIRS

administrative staff nor faculty. To do their jobs well and to advance professionally, they are encouraged by their professional organizations and mentors to pursue work outside of their job descriptions. However, they are neither given the time to do this nor are rewarded if they do just that. As Bruce noted, allotting time to write would not work for every student affairs position; however, for many, it would validate what is tacitly being promoted in their profession. For faculty, this is an explicit part of their work, and they are rewarded for it. For student affairs professionals, they can pursue scholarly activities but reap no immediate financial or career-impacting benefit. This can be especially problematic for people like Lou who feel an enormous weight of financial responsibility in supporting his family. As he said, Lou feels he needs to perform his job responsibilities extremely well to maintain his position and thus an income. Activities that are not rewarded are lower priorities.

Did participants accept the label enough to desire it in their job descriptions? Even the staunchest practitioner of the group, Bruce, suggested that it would not be a bad idea if scholarship were expected of certain positions in student affairs. There seemed to be an acceptance that people who hold certain jobs (perhaps the "support staff" to whom Lou referred) may not feel the need to read, research, and write about their work. However, those in supervisory, mid-level, and even senior administrative positions should spend part of their time pursuing and advocating for scholarship.

The label of scholar is itself interesting. Lou suggested this identity is achieved at a certain milestone, such as when one earns a doctoral degree. However, Logan suggested that students can be scholars as this is how he felt through his experience working with faculty. Diana implied that scholarly identity is transitory depending on 
SCHOLARSHIP IN STUDENT AFFAIRS

one's writing production. This implies that a faculty member may not consider herself a scholar simply because she had not published in a while. Conversely, this suggests that faculty consider themselves practitioners when they teach or create businesses that promote their patented research. Some participants felt discomfort with the label of scholar. This may be because some professionals enter the work of student affairs solely because they enjoy working directly with students and not because they desire to write or research; others, such as Lou, feel uncomfortable with how one's upbringing conflicts with the perceptions of academia. The image of the scholar can seem elitist, especially if it is defined by the doctorate, when juxtaposed with that of the common person, the $68 \%$ of U.S. adults over 25 who do not hold at least a bachelor's degree (U.S. Census Bureau, 2014). Ultimately, all participants were eager to or at least willing to accept the label as a part of their professional selves.

\section{Synthesis of Findings in Relation to}

\section{Conceptual Frameworks and Literature}

Self Determination Theory (SDT) is often associated with motivation; however, I posited in Chapter 2 that the theory also can be extended to identity because if a person is motivated to work toward a goal of creating scholarly writing and successfully uses writing strategies to meet this goal, that person may view himself or herself differently for having gone through an intervention such as facilitated writing coaching. In my study, the three participants who did meet the goal of producing a paper for publication (Lou, Bruce, and Diana) did not view themselves drastically differently than at the study's beginning. However, all three participants could see how writing, researching, and pursuing scholarship could be a part of who they are even if they felt uncomfortable 
SCHOLARSHIP IN STUDENT AFFAIRS

or did not want to use the label of scholar to identify themselves. Although participants' perceived competence in their current positions in student services made them feel more of a practitioner rather than scholar, they were all willing to fall somewhere on the scholar-practitioner continuum.

Participants, overall, felt competent about their writing, especially at the end of our time together. This was due to their creation of an entire article for publication or at least progress toward an article. Those who completed manuscripts also had written several drafts of their papers and could see improvement with each draft after receiving and incorporating feedback from their fellow participants, various other people, and me. Although all participants felt positive about their writing abilities, to a point, many lacked confidence in certain areas, such as researching or organization; some felt this way partly due to their being out of graduate programs for a number of years. This supports the literature shared earlier (Abbate-Vaughn, 2012; Saunders et al, 2000; Schroeder \& Pike, 2001).

Coaching has been defined as a professional relationship in which coaches and clients work together with the former facilitating experiential learning often in the context of working toward the latter's specific goals (Biswas-Diener, 2009). In Chapter 2, I posited that coaching can foster the relatedness component of SDT because it can facilitate motivation as participants may feel connected to me as a coach. According to Ryan and Deci (2000b), perceived competence can be supported through offering optimal challenges and appropriate feedback. Both of these are offered in coaching models. Using coaching, I created enough scaffolding that participants worked in their zones of proximal development (Vygotsky, 1978), with three producing completed papers and all 
SCHOLARSHIP IN STUDENT AFFAIRS

producing some writing. All participants stated they felt connected to me as a coach as well as to their peers in the study, and that this model was effective in moving them through the process of working toward their writing goals.

Although many participants felt they had some autonomy in producing their articles, all felt their professional roles inhibited them to an extent from producing scholarship during the work-day. In this sense, participants were more control oriented in their autonomy, which Gagnè \& Deci (2005) defined as a general tendency to experience social contexts as controlling, the social context here being the workplace. I could impact productivity during the time my participants and I had together by suggesting they work during the hour we shared; however, I could not impact their autonomy in how they spent their time at work. Fortunately, I could promote participants' autonomy in the sense of volition to create a manuscript through encouragement, accountability, and feedback.

This lack of autonomy speaks to the difficulty in heeding Carpenter's (2001) call for student affairs practitioners to use theory and scholarship in their everyday work. Although participants wanted to continually improve their practice through research and writing, the ability to do so was difficult because they are considered by many as "streetlevel bureaucrats" (Marshall \& Gerstl-Pepin, 2005, p. 53) due to their daily interaction with students. The regular interruption by students caused consternation among my participants in terms of time and environment. Also, as Carpenter and Stimpson (2007) suggested, scholarship is then viewed not as a priority due to all the other responsibilities that are expected of student affairs professionals, many of which are ostensibly written in their job descriptions and, perhaps, rewarded in annual reviews. 


\section{Reflections of Action Research}

A component of action research is reflection on one's own practice (McNiff, 1991). I set aside time after each session to complete my notes and reflect on the day's interaction. One of the unexpected realizations I experienced had to do with how a scholar is defined. As I learned my participants' varying viewpoints of what it means to be a scholar, I realized that my own definition fits somewhere along the middle of the extremes of Logan's notion that a scholar is anyone who is curious and Lou's idea of a scholar as someone who has worked and researched in a specific field for several years. I consider a scholar as someone who researches and studies topics that are personally gratifying and then contributes to a particular field with new knowledge, typically through publication of an article. I had not thought about the myriad of ways the identity could be defined. I realized clearly that this was one assumption I had to forego. This is one example of the multiple realities that qualitative research methods, such as action research, allow (Lincoln \& Guba, 1985).

For each participant, I wrote in my researcher's journal what participants and I did during each session and what we planned to do for the next session dependent on our previous work. This cycle of action, reflection, and then new action along with my intervention of coaching prompted me to think regularly about the student affairs profession and my role in it. As I listened to my participants' stories, successes, frustrations, and challenges as they attempted to write manuscripts, I reflected on the need for advocacy. I wondered what would happen to this particular writing group once my study ended, and I thought regularly of how I could promote this work in the future. In the next section, I give recommendations of what institutions, graduate programs, and 
SCHOLARSHIP IN STUDENT AFFAIRS

national organizations can do to promote this work. I realize that through my work in this study, I desire to be that advocate across these groups.

\section{Implications and Recommendations}

My study has implications for the profession of student affairs, its national organizations, and for graduate programs in higher education. Leaders of student affairs divisions can foster scholarship, which may positively impact not only those working in the division but also those faculty and administrators from faculty ranks in understanding how both student affairs and academic affairs can work together to help students succeed in higher education. Also, if higher education programs focused on scholarly identity and encouraged continued writing, new student affairs professionals would expect to engage in scholarship within their positions. If more people seek to engage in scholarship, professional organizations may offer more sessions and institutes about scholarship production.

\section{Student Affairs Divisions}

Student affairs leaders have great impact on the culture of their divisions. What a vice president envisions as important will largely determine what employees of that division deem as important. Employees will spend their time working toward what is valued by leadership. As noted previously, Sriram and Oster (2012) wrote that lack of engagement in scholarship by student affairs professionals could be more an issue of culture rather than lack of time or access. In this sense, leadership can do a great deal to create a culture of valuing scholarship should they do so. I offer several recommendations. 
Create organizational expectations and supportive structures. As all the participants clearly stated, the organization in which they work does not specifically advocate writing and pursuing scholarship. No one's job description explicitly allocated time for scholarship. However, senior student affairs administrators can create organizational changes that positively impact autonomy to produce scholarship. This, in turn, could create an organizational culture that values scholarship. To do this, administrators should clearly outline expectations of contributing to the field in the position descriptions of many jobs in student affairs. This expectation may not be appropriate for every position; however, they would be applicable to many job descriptions from program coordinators to senior-level officers. If Senior Student Affairs Officers (SSAO) not only encourage but expect this from their staff, professionals have even more motivation to publish. In addition to explicit expectations, leaders will need to provide time on the job to read, research, and write. One or two hours a week, as Bruce suggested, may be enough to create this habit within a division. This time should not be expected to be during a lunch hour as this may breed resentment rather than autonomy.

In addition to offering flexible schedules when staff can engage with reading, writing, or researching, leaders can implement other organizational frameworks to promote these activities such as convening a group to promote such professional development; this group can offer workshops and trainings so staff in publishing. This group, or perhaps an individual, can also be tasked with fostering scholarship through individual coaching. Because of the possible difficulty of scaling such a system, a coach can work with a small group of participants at a time, such as I have done in my study. 
One common way to promote reading is the book club concept, where everyone on a leadership team or within an entire division is encouraged or expected to read a common book. Discussions can be held then at meetings, in person or virtual. NASPA, the large national student affairs organization, promotes an online book club at a regional level (NASPA, 2015). Another take on this is for a department or division to have a common set of questions that create a focus for a unit. For example, Residence Life and Housing at the University of Delaware studies six topics over the course of a year (Hatfield \& Wise, 2015). Staff members there research these topics and consider how best practices in association with these topics will inform their strategic planning process in the subsequent year. Topics have included gender violence and alcohol use, the sophomore experience, underrepresented students' experiences, and retention issues on college campuses. Lastly, one simple professional development opportunity is to engage the university library. Student affairs leaders can provide their staff time and resources to learn how their campus libraries work, what services they offer, and how to conduct research using such services. As Lou's and Bruce's comments show, the more familiarity with libraries, the more one may feel competent with producing scholarship.

In addition to considering the different ways to foster scholarship, leaders should also consider when this should start. It is often believed that new professionals need time to become grounded in their functional areas—let them learn how residence life works before adding the expectation of scholarship, for example. However, if student affairs leaders want people to view themselves as scholar practitioners, then this identity should be fostered from the beginning of their professional careers. According to one SSAO (Hatfield \& Wise, 2015), our patterns in what we do are based on what we are taught to 
value early on in our graduate programs and our careers. These patterns and habits then become the way in which we operate in our careers. In this sense, the very first job one has in the profession is crucial to developing a pattern of scholarship. If a new professional were given two or three hours per week to be curious, read journal articles, and conduct research, the profession may look vastly different in how our work is approached. Also, if new professionals move on to another institution, they may expect or even demand this in their new positions.

If organizational systems are in place to foster scholarship, student affairs professionals should also then be rewarded for the scholarship they produce. This would address the concerns that Jennifer had regarding her frustrations with no pay or other rewards tied to production of scholarship. If certain positions expect scholarship, then evaluations of these positions should note and reward such production. Faculty are awarded with tenure if they successfully meet the criteria of their positions, which includes scholarship production; from personal experience and conversations with many student affairs colleagues at various institutions across the country, I know that tenure is not a common process in student affairs divisions. However, this model does exist at the University of Hawai' $i$ - Manoa where its student affairs professionals are known as assistant, associate, and full specialists; this mirrors the faculty titles of assistant, associate, and full professors (Hatfield \& Wise, 2015). Professionals merit these titles through criteria created by the institution. Another way that scholarship can be rewarded is monetary support in terms of travel to conferences to share what one has written; other financial support is to pay for memberships to professional organizations, especially those that produce journals so that professionals can keep reading the literature. As 
Bruce noted, being given the financial support to attend and present at conferences went a long way toward his professional development and commitment to the profession. Regardless, such rewards must be meaningful to the professional and appropriate for a division's culture and ethos.

Naysayers may lament that creating a cultural shift will be difficult because student affairs professionals are so busy with the practicalities of serving students. Tight budgets and the subsequent emphasis on efficiency may preclude such a shift, they may argue. However, if student affairs leaders value learning, particularly about student experiences and development, and seek to help their staffs succeed in their own work advocating for students, then they must create environments that foster such professional growth. Prioritizing scholarship means other, less important tasks may not be fulfilled, just as my participants realized during my study. A good leader recognizes this and owns it.

Model and mentor. As noted previously, student affairs professionals are not pursuing scholarship (Carpenter, 2011; Fey \& Carpenter, 1996; Saunders \& Cooper, 1999; Semersheim \& Keim, 2005). This is true even though $85 \%$ of chief or senior student affairs officers (SSAOs) have terminal degrees (Kimbrough, 2007), which ostensibly required research and writing dissertations to earn. It could be, then, that SSAOs are not modeling or prioritizing scholarship in their own practice. If such leaders value scholarship and want their staff also to value it, then they need to also work toward this themselves. Certainly, SSAOs can submit papers to any appropriate journal; however, specific publications exist just for this group of leaders such as Leadership Exchange (NASPA, 2015b), and so this suggests that an audience does exist for leaders at 
this level to share their work and research. Modeling valued behavior is one way to promote scholarship within a student affairs division.

Another way to foster valued behavior is to mentor others. Four of the five participants referred to the positive influence of mentors, whether in a graduate program or in one's current work. Organizationally, SSAOs can create mentoring structures, pairing a new professional with a mid-level employee, for example. A division can create a formal mentoring program and offer expectations of what these relationships could entail. Natural mentoring relationships often do arise out of similar interests; however, an organized program would intentionally promote relatedness throughout an organization.

Mentoring can also occur across divisions. If certain professionals want to learn more about a faculty member's research or how certain faculty go about their research practices, SSAOs can partner with department chairs and deans to create programs where this would be encouraged. This would be a natural relationship for schools or colleges of education that have higher education programs; however, it can occur with any discipline. My participants, for example, may benefit from mentoring by faculty in sociology, psychology, public administration, or women's studies. Not only would this increase relatedness outside a student affairs division, but it also may increase feelings of competence in research and writing. This may also be helpful in bridging student/academic affairs bifurcation experienced by some of my participants as well as noted in the literature (Brubacher \& Rudy, 1997; Carpenter \& Stimpson, 2007; Dungy \& Gordon, 2011; Love \& Love, 1995). 
SCHOLARSHIP IN STUDENT AFFAIRS

Graduate Programs in Higher Education

If student affairs practitioners were expected to publish, more emphasis should be placed on the research and writing process in graduate programs in higher education thus promoting writing competence. Faculty in masters' programs should foster the research process by familiarizing students with not only academic conventions such as style and language but also by demystifying the university library and its myriad of resources. Conversely, the research that practitioners do can inform the curriculum that faculty create for the classroom.

The stronger the partnership between divisions of student affairs and graduate programs, the more collaboration and exposure to each other can occur. Faculty within graduate programs can partner with student affairs professionals to pursue scholarship. This may help address the lack of mentoring that Logan has experienced since moving to the Northwest. This relationship can be a powerful one as the daily work of practitioners can be informed by the theoretical work of scholars and vice versa. Another example of such partnerships is to create mentoring structures between graduate students in higher education programs and the campus's professional staff. The mentor and student can also collaborate in writing a paper for publication and learn from each other's strengths and experiences. Thus, both student and professional can work toward a scholarly identity.

\section{National Student Affairs Organizations}

The two largest student affairs organizations, NASPA and ACPA, have the potential to impact greatly how scholarship is perceived in the profession. They both currently publish a wide variety of journals that publish practitioner-based articles and peer-reviewed original research. These organizations can promote opportunities to write 
and create spaces to do so at conferences and in the virtual world. For example, About Campus, a journal published by ACPA, is offering its inaugural writer's retreat in June 2015 (About Campus Writers Retreat, 2015). It will be held at Virginia Tech, and participants will live on campus and work with each other to produce articles that may be published in the journal. My participants would thrive in such a focused experience, and knowing that they would be writing toward a specific publication, as Diana and Lou noted, may also provide motivation. This could easily be an alternative option to attending a regional or national conference for professional development.

Student affairs organizations can prioritize scholarship to its younger professionals as well as its more seasoned ones. Both NASPA and ACPA offer weeklong specialized institutes for new, mid-level, and senior-level professionals. They also both offer assessment institutes and other conferences that specialize in areas such as higher education legal issues, residential education, and women in the profession. Each of these events provides an opportunity for these organizations to encourage scholarship, particularly in the topics that are the focus of these gatherings. Also, these and other student affairs organizations can offer institutes solely dedicated to scholarship, much like the About Campus writers' retreat but on a broader scale.

\section{Conclusion}

Student affairs professionals have a great deal to offer through scholarship if given the opportunities to pursue research and writing. In my study, five student affairs practitioners were given a structured environment to produce papers for publication, and three of my participants did just that; this process also impacted how participants viewed themselves professionally along the scholar-practitioner continuum. 
All participants viewed creating a habit of practice that fostered writing to be the most effective writing strategy. Their ability to create this habit hinged on their feelings of competence in terms of their writing, relatedness with me as their writing coach and with their peers in the writing group, and their perception of autonomy in being able to write for publication. Specific strategies to create this habit involved using time outside of the work-day, setting specific and incremental goals, and free writing to get ideas and words on paper. Also, all participants valued feedback from their peers in the study and from me, and they felt comfortable giving and receiving such feedback. Interestingly, four of the five participants noted the importance of mentoring outside of our project as positively impacting their writing and their professional identities. Mentoring, through a writing coach or other professional, provides accountability and community.

Participants varied in how they viewed themselves professionally along the scholar-practitioner continuum. All participants understood their day-to-day work was to be effective practitioners, whether that entailed direct contact with students in advising roles or supervision of other professionals to maintain university services and programs. However, three participants felt they were moving along the scholar-practitioner continuum as they identified as becoming more of a scholar due to our work together. The other two participants already viewed themselves as scholars because of their curious natures and love of research. Participants had varying definitions of what constitutes a scholar, including a transitory nature of the role and obtaining the title of scholar only after a certain degree earned or years of studying finished. Two participants felt a scholar was anyone who actively engaged in research, which suggests students can be scholars and so can student affairs professionals. 
Regardless of how a scholar is defined, promoting scholarship can improve the work student affairs professionals do and thus positively impact the students they serve. University leaders can cultivate scholarship by expecting scholarship from their staff. With such expectations should come support, including time and physical space, to pursue such endeavors. If leaders truly prioritized scholarship, they should also model this behavior themselves. National student affairs organizations are working toward this goal though this is not always clearly identified at conferences or other professional development opportunities. However, the profession is evolving as it works across the academy with faculty and with each other outside of departmental silos. Ultimately, the students whom student affairs professionals serve will be the beneficiaries of this shared and collective wisdom.

Further research may include the efficacy of long-term or more systematic programs intended to foster scholarship. For example, the About Campus writing retreat noted earlier will provide more insights into how a focused retreat experience impacts scholarly identity formation and what writing strategies participants find useful. Research can also look across institutions that have practices that foster scholarship in place whether these practices are disparate or similar. Other research could involve faculty and professional staff collaborations and how this impacts practice, teaching, and student success. This study looked at effective writing strategies for people in student services; a future study may compare these strategies with those that faculty find effective. In addition to studying different groups such as faculty, research can also look at how professionals of different age groups and professional experiences respond to a structured writing program (for example, younger and/or newer professionals). A 
quantitative study specifically looking at the kinds of session topics at conferences, including those involving scholarship, would be informative. Also, the efficacy of online models, including the use of social media, in coaching and scholarly development can be studied as well. Regardless of how the student affairs profession develops, I look forward to being part of these continuing conversations. 
SCHOLARSHIP IN STUDENT AFFAIRS

References

ACPA. (2013). Donna M. Bourassa mid-level management institute. Retrieved from http://www2.myacpa.org/professional-development/donna-m-bourassa-mid-levelmanagement-institute

ACPA. (2014). Documents. Retrieved from http://www.myacpa.org/documents?field_audience_tid=2\&field_subject_tid=All \&og_group_ref_target_id=All\&fid=\#/page $/ 1$

ACPA. (2015). ACPA Tampa program book. Washington, DC: Author . Retrieved from http://convention.myacpa.org/tampa2015/wp-content/uploads/2015/02/ProgramBook-FINAL-no-printer-marks-smaller.pdf

ACPA \& NASPA. (2010). Professional competency areas for student affairs practitioners. Washington, DC: Author. Retrieved from http://www.naspa.org/images/uploads/main/Professional_Competencies.pdf

Abbate-Vaughn, J. (2012). The graduate writing challenge: A perspective from an urban teacher education program. Action in Teacher Education, 29(2), 51-60.

About Campus Writers Retreat. (2015). The inaugural About Campus writers retreat. [Web blog comment]. Retrieved from http://blogs.lt.vt.edu/abcretreat/

Ackerman, R. L. (Ed.). (2007). The mid-level manager in student affairs. Washington, DC: NASPA.

Allen, K. E. (2002). The purpose of scholarship, redefining meaning for student affairs. NASPA Journal, 39(2), 147-157.

Appleton, J. (2010). NASPA leadership exchange: A new paradigm. Retrieved from http://www.1 eadershipexchange- 
SCHOLARSHIP IN STUDENT AFFAIRS

digital.com/leadershipexchange/2010summer?pg=9\#pg9

Baard, P. P., Deci, E. L., \& Ryan, R. M. (2004). Intrinsic need satisfaction: A motivational basis of performance and well-being in two work settings. Journal of Applied School Psychology, 34(10), 2045-2068.

Bair, M. A., \& Mader, C. Y. (2013). Academic writing at the graduate level: Improving the curriculum through faculty collaboration. Journal of University Teaching \& Learning Practices, 10(3), 1-14.

Bandura, A. (1986). Self-efficacy mechanism in human agency. American Psychologist, $37,122-147$.

Bargal, D. (2008). Action research: A paradigm for achieving social change. Small Group Research, 39(17), 17-27. doi:10.1177/1046496407313407

Belcher, W. L. (2009). Reflections on ten years of teaching writing for publication to graduate students and junior faculty. Journal of Scholarly Publishing, 40(2), 184200. doi: $10.3138 /$ jsp.40.2.184

Bettinger, E., \& Baker, R. (2011). The effects of student coaching in college: An evaluation of a randomized experiment in student mentoring (No. w16881). National Bureau of Economic Research.

Biswas-Diener, R. (2009). Personal coaching as a positive intervention. Journal of Clinical Psychology: In Session, 65(5), 544-553. doi:10.1002/jclp.20589

Blimling, G. S. (2001). Uniting scholarship and communities of practice in student affairs. Journal of College Student Development, 42(4), 381-396. 
Borda, O. F. (2006). Participatory (action) research in social theory: Origins and challenges. In P. Reason \& H. Bradbury (Eds.), Handbook of action research (pp. 27-37). London, England: Sage.

Boyer, E. L. (1990). Scholarship reconsidered: Priorities of the professoriate. Princeton, NJ: The Carnegie Foundation for the Advancement of Teaching.

Bresciani, D. (2012). Time for an honest look in the mirror. NASPA Leadership Exchange, Fall, 40.

Brown, J. S., \& Duguid P. (2000). The social life of information. Boston, MA: Harvard Business School Press.

Brubacher, J. S., \& Rudy, W. (1997). Higher education in transition: A history of American colleges and universities $\left(4^{\text {th }}\right.$ ed.). New Brunswick, NJ: Transaction Publishers.

Bruning, R. H., Schraw, G.J., \& Ronning, R. R. (1995). Cognitive psychology and instruction ( $2^{\text {nd }}$ ed.). Englewood Cliffs, NJ: Prentice Hall.

Caffarella, R. S., \& Barnett, B. G. (2000). Teaching doctoral students to become scholarly writers: The importance of giving and receiving critiques. Studies in Higher Education, 25(1), 39-52.

Carpenter, S. (2001). Student affairs scholarship (re?)considered: Toward a scholarship of practice. Journal of College Student Development, 42(4), 301-318.

Carpenter, S., \& Stimpson, M. T. (2007). Professionalism, scholarly practice, and professional development in student affairs. NASPA Journal, 44(2), 265-284.

Carter, N. (2012). Action research: Improving graduate-level writing. Educational Action Research, 20(3), 407-421. 
SCHOLARSHIP IN STUDENT AFFAIRS

Colbeck, C. L. (2008). Professional identity development theory and doctoral education. New Directions for Teaching and Learning, 113, 9-16. doi:10.1002/t1.304

Creswell, J. (2013). Qualitative inquiry \& research design: Choosing among five approaches (3rd ed.). Los Angeles, CA: Sage.

Davis, M. M., \& Berdrow, I. (2008). Service science: Catalyst for change in business school curricula. IBM Systems Journal, 41(1), 29-39.

Deci, E. L., \& Ryan, R. M. (2002). Self-determination research: Reflections and future directions. In E. L. Deci \& R. M. Ryan (Eds.), Handbook of self-determination research (pp. 431-441). Rochester, NY: University of Rochester Press.

Dedoose . (2013). Dedoose user guide. Los Angeles, CA: Author. Retrieved from http://userguide.dedoose.com/UserGuidePDFVersion

Dewey, J. (1902). Child and the curriculum. Chicago, IL: University of Chicago Press. Dungy, G., \& Gordon, S. A. (2011). The development of student affairs. In J. H. Schuh, S. R. Jones, \& S. R. Harper (Eds.), Student services: A handbook for the profession ( $5^{\text {th }}$ ed.) (pp. 61-79). San Francisco, CA: Jossey-Bass.

Elbow, P. (1998). Writing without teachers ( $2^{\text {nd }}$ ed.). New York, NY: Oxford University Press.

Ellemers, N., De Gilder, D., \& Haslam, S. A. (2004). Motivating individuals and groups at work: A social identity perspective on leadership and group performance. Academy of Management Review, 29(3), 459-478.

Emerson, R. M., Fretz, R. I., \& Shaw, L. L. (1995). Writing ethnographic fieldnotes. Chicago, IL: University of Chicago Press. 
SCHOLARSHIP IN STUDENT AFFAIRS

Ferguson, T. (2009). The 'write' skills and more: A thesis writing group for doctoral students. Journal of Geography in Higher Education, 33(2), 285-297. doi:10.1080/03098260902734968

Fey, C. J., \& Carpenter, D. S. (1996). Mid-level student affairs administrators: Management skills and professional development needs. NASPA Journal, 33(3), $218-231$

Gagnè, M., \& Deci, E. L. (2005). Self-Determination Theory and work motivation. Journal of Organizational Behavior, 26, 331-262. doi:10.1002/job.322

Gardiner, M., \& Kearns, H. (2012). The ABCDE of writing: Coaching high-quality high quantity writing. International Coaching Psychology Review, 7(2), 247-259.

Goldman, E., Wesner, M., \& Karnchanomai, O. (2013). Reciprocal peer coaching: A critical contributor to implementing individual leadership plans. Human Resources Development Quarterly, 24(1), 63-87. doi:10.1002/hrdq.21153

Hardré, P. L. (2013). Teaching assistant development through a fresh lens: A selfdetermination framework. Journal of Faculty Development, 27(2), 52-61.

Hatfield, L. J., \& Wise, V. L. (2015). A guide to becoming a scholarly practitioner in student affairs. Sterling, VA: Stylus.

Herdlein, III, R. J. (2004). Survey of chief student affairs officers regarding relevance of graduate preparation of new professionals. NASPA Journal, 42(1), 51-71.

Herr, K., \& Anderson, G. L. (2005). The action research dissertation: A guide for students and faculty. Thousand Oaks, CA: Sage. 
SCHOLARSHIP IN STUDENT AFFAIRS

Hobson, E. H. (2001). Writing center pedagogy. In G. Tate, A. Rupiper, \& Schick, K. (Eds.), A guide to composition studies (pp. 165-182). New York, NY: Oxford University Press.

International Coach Federation. (2014). ICF: International coach federation. Retrieved from http://www.coachfederation.org/

Jablonski, M. A., Mena, S. B., Manning, K., Carpenter, S. \& Siko, K. L. (2006). Scholarship in student affairs revisited: The summit on scholarship, March 2006. NASPA Journal, 43(4), 182-201.

Kellogg, K. (1999). Collaboration: Student affairs and academic affairs working together to promote student learning. ERIC Clearinghouse on Higher Education. Washington, DC: George Washington University, Graduate School of Education and Human Development.

Kemmis, S. (2006). Exploring the relevance of critical theory for action research: Emancipatory action research in the footsteps of Jürgen Habermas. In P. Reason \& H. Bradbury (Eds.), Handbook of action research (pp. 94-105). London, England: Sage.

Kemmis, S., \& McTaggart, R. (2000). Participatory action research. In N. K. Denzin \& Y. S. Lincoln (Eds.), Handbook of qualitative research (pp. 567-605). Thousand Oaks, CA: Sage.

Kidder, R. (2010, Spring). Part 1: The scholar practitioner: Administrators engaging in the research process. Developments. Retrieved from http://www.myacpa.org/publications/developments/volume-8-issue-1 
SCHOLARSHIP IN STUDENT AFFAIRS

Kimbrough, W. M. (2007). How did I end up here? A reflection on advancement in student affairs. In R. L. Ackerman \& L. D. Roper (Eds.), The mid-level manager in student affairs (pp. 275-293). Washington, DC: NASPA.

Knight, J. (2006). Instructional coaching: Eight factors for realizing better classroom teaching through support, feedback and intensive, individualized professional learning. School Administrator, 63(4), 36.

Knight, J. (2007). Instructional coaching: A partnership approach to improving instruction. Thousand Oaks, CA: Corwin Press.

Kram, K. E., Wasserman, I. C., \& Yip, J. (2012). Metaphors of identity and professional practice: Learning from the scholar-practitioner. The Journal of Applied Behavioral Sciences, 48(3), 304-341.

Kuh, G. D., \& Banta, T. W. (2000). Faculty-student affairs collaborations on assessment: Lessons from the field. About Campus, 4(6), 4-11.

Lechuga, V. M. (2011). Faculty-graduate student mentoring relationships: Mentors' perceived roles and responsibilities. Higher Education, 62(6), 757-771.

Lee, A., \& Boud, D. (2003). Writing groups, change and academic identity: Research development as local practice. Studies in Higher Education, 28(2), 187-200. doi:10.1080/0307507032000058109

Lewin, K. (1948). Action research and minority problems. In K. Lewin (Ed.), Resolving social conflicts (pp. 201-216). New York, NY: Harper \& Brothers.

Lincoln, Y. S., \& Guba, E. G. (1985). Naturalistic inquiry. Beverly Hills, CA: Sage.

Love, P. G., \& Love, A. G. (1995). Enhancing student learning: Intellectual, social, and emotional integration. ASHE-ERIC Higher Education Report, No. 4. Washington, 
DC: The George Washington University, Graduate School of Education and Human Development.

Lynch, M., \& Engle, J. (2010a). Big gaps, small gaps: Some colleges and universities do better than others in graduating African-American students. College Results Online. Washington, DC: The Education Trust. Retrieved from http://www.edtrust.org/sites/edtrust.org/files/publications/files/CRO\%20BriefAfricanAmerican.pdf

Lynch, M., \& Engle, J. (2010b). Big gaps, small gaps: Some colleges and universities do better than others in graduating Hispanic students. College Results Online. Washington, DC: The Education Trust. Retrieved from http://www.edtrust.org/sites/edtrust.org/files/publications/files/CRO BriefHispanic.pdf

Maher, D., Seaton, L., McMullen, C., Fitzgerald, T., Otsuji, E., \& Lee, A. (2008). Becoming and being writers: The experiences of doctoral students in writing groups. Studies in Continuing Education, 30(3), 263-275. doi: $10.1080 / 01580370802439870$

Marshall, C., \& Gerstl-Pepin, C. (2005). Re-framing educational politics for social justice. Boston, MA: Pearson.

Maxwell, J. A. (2013). Qualitative research design: An interactive approach $\left(3^{\text {rd }}\right.$ ed.). Los Angeles, CA: Sage.

McNiff, J. (1991). Action research: Principles and practice. New York, NY: Routledge. Merriam, S. B. (1998). Qualitative research and case study applications in education. San Francisco, CA: Jossey-Bass. 
SCHOLARSHIP IN STUDENT AFFAIRS

NASPA. (2013). Mid level professionals institute. Retrieved from

http://naspawrc.com/institutes/mid-level-professional-institute/

NASPA. (2014a). RPI reports \& issue briefs. Retrieved from

http://www.naspa.org/rpi/reports

NASPA. (2014b). NASPA 2014 annual conference schedule. Retrieved from http://apps.naspa.org/sch/sch.cfm

NASPA. (2015a). Check out our first virtual book club chat. Retrieved from http://www.naspa.org/constituent-groups/posts/check-out-our-first-virtual-bookclub-chat

NASPA. (2015b). Leadership Exchange Magazine. Retrieved from http://www.naspa.org/publications/leadership-exchange

National Center for Education Statistics. (n.d.). Fast facts. Retrieved from http://nces.ed.gov/fastfacts/display.asp?id=98

National Commission on Asian American and Pacific Islander Research in Education and Asian Pacific Islander American Scholarship Fund. (2011). The relevance of Asian Americans \& Pacific Islanders in the college completion agenda. Retrieved from http://www.nyu.edu/projects/care/docs/2011_CARE_Report.pdf

Nuss, E. M. (2003). The development of student affairs. In S. R. Komives, \& D. B. Woodward, Jr. (Eds.), Student services: A handbook for the profession ( $4^{\text {th }}$ ed.) (pp. 65-88). San Francisco, CA: Jossey-Bass.

O'Connor, J. S. (2012). Factors that support or inhibit academic affairs and student affairs from working collaboratively to better support holistic students' experiences: A 
SCHOLARSHIP IN STUDENT AFFAIRS

phenomenological study. (Doctoral dissertation, Drexel University). ProQuest Dissertations and Theses, 1282645303.

Oregon Council of Student Services Administrators. (2014). Schedule and session materials. Retrieved from https://sites.google.com/site/studentsuccess2014/home/conference-schedule

Parker, S. K. (1998). Enhancing role breadth self-efficacy: The roles of job enrichment and other organizational interventions. Journal of Applied Psychology, 83(6), $835-852$.

Patton, M. Q. (1990). Qualitative evaluation and research methods (2nd ed.). Newbury Park, CA: Sage.

Poverjuc, O., Brooks, V., \& Wray, D. (2012). Using peer feedback in a master's programme: A multiple case study. Teaching in Higher Education, 17(4), 465477.

Reason, P., \& Bradbuy, H. (2006). Introduction: Inquiry and participation in search of a world worthy of human aspiration. In P. Reason \& H. Bradbury (Eds.), Handbook of action research (pp. 1-14). London, England: Sage.

Reeve, J. (2002). Self-Determination Theory applied to educational settings. In E. L. Deci R. M. \& Ryan (Eds.), Handbook of self-determination research (pp. 183-204). Rochester, NY: University of Rochester Press.

Reiss, K. (2007). Leadership coaching for educators: Bringing out the best in school administrators. Thousand Oaks, CA: Corwin Press. 
SCHOLARSHIP IN STUDENT AFFAIRS

Rhodes, C. (2006). The impact of leadership and management on the construction of professional identity in school learning mentors. Educational Studies, 32(2), 157169. doi:10.1080/03055690600631051

Rose, M., \& McClafferty, K. A. (2001). A call for the teaching of writing in graduate education. Educational Researcher, 30(27), 27-33. doi:10.3102/0013189X030002027

Ryan, R. M., \& Deci, E. L. (2000a). Intrinsic and extrinsic motivations: Classic definitions and new directions. Contemporary Educational Psychology, 25, 54-67.

Ryan, R. M., \& Deci, E. L. (2000b). Self-Determination Theory and the facilitation of intrinsic motivation, social development, and well-being. American Psychologist, 55(1), 68-79. doi:10.1037/0003-066X.55.1.68

Ryan, R. M., \& Deci, E. L. (2002). Overview of Self-Determination Theory: An organismic dialectical perspective. In E. L. Deci \& R. M. Ryan (Eds.), Handbook of self-determination research (pp. 3-33). Rochester, NY: University of Rochester Press.

Sallee, M., Hallett, R., \& Tierney, W. (2011). Teaching writing in graduate school. College Teaching, 59, 66-72. doi:10.1080/87567555.2010.511315

Sanchez, C. L. (2013). Involvement in a first-year experience course: What impact does it have on the collaboration between academic and student affairs professionals? (Doctoral dissertation, University of Texas at San Antonio. ProQuest Dissertations and Theses, 3563240.

Saunders, S. A., Register, M. D., Cooper, D. L., Bates, J. M., \& Daddona, M. F. (2000). Who is writing research articles in student affairs journals? Practitioner 


\section{SCHOLARSHIP IN STUDENT AFFAIRS}

involvement and collaboration. Journal of College Student Development, 41(6), 609-615.

Saunders, S. A., \& Cooper, D. L. (1999). The doctorate in student affairs: Essential skills and competencies for midmanagement. Journal of College Student Development, 40(2), 185-191.

Schroeder, C. C., \& Pike, G. R. (2001). The scholarship of application in student affairs. Journal of College Student Development, 42(4), 342-355.

Seidman, I. (2013). Interviewing as qualitative research: A guide for researchers in education \& the social sciences $\left(4^{\text {th }}\right.$ ed. $)$. New York, NY: Teachers College.

Semersheim, K. L., \& Keim, M. C. (2005). Mid-level student affairs managers: Skill importance and need for continued professional development. The College Student Affairs Journal, 25(1), 36-49.

Shaver, L., Bowles, S., \& Beemer, C. (2009). Making the rhetorical sell: Entrepreneurial consultancy as a WAC model. Pedagogy: Critical Approaches to Teaching Literature, Language, Composition, and Culture, 9(1), 61-76. doi:10.1215/15314200-2008-017

Smith, B. (2013). Mentoring at-risk students through the hidden curriculum of higher education. Lanham, MD: Lexington Books.

Smith, L. T. (2005). On tricky ground: Researching the native in the age of uncertainty. In Denzin, N. K., \& Lincoln, Y. S. (Eds.), The SAGE handbook of qualitative research (pp. 85-107). Thousand Oaks, CA: Sage. 
SCHOLARSHIP IN STUDENT AFFAIRS

Sriram, R. (2011). Engaging research as a student affairs professional. Netresults. Retrieved from http:/www.naspa.org/membership/mem/pubs/nr/PrinterFriendly.cfm?ld=1810

Sriram, R., \& Oster, M. (2012). Reclaiming the "scholar" in scholar-practitioner. Journal of Student Affairs Research and Practice, 49(4), 377-396. doi:10.1515/jsarp$2012-6432$

Stake, R. E. (2006). Multiple case study analysis. New York, NY: Guilford Press.

Sutherland, L., \& Markauskaite, L. (2012). Examining the role of authenticity in supporting the development of professional identity: An example from teacher education. Higher Education, 64, 747-766. doi:10.1007/s10734-012-9522-7

Taylor, S. J., \& Bogdan, R. (1984). Introduction to qualitative research: The search for meanings ( $2^{\text {nd }}$ ed.). New York, NY: Wiley.

Upcraft, M. L., \& Schuh, J. H. (1996). Assessment in student affairs: A guide for practitioners. San Francisco, CA: Jossey-Bass.

U.S. Census Bureau (2014). Educational attainment in the United States: 2014-detailed tables. Retrieved from http://www.census.gov/hhes/socdemo/education/data/cps/2014/tables.html

U.S. Department of Education (2014). Federal TRIO programs home page. Retrieved from http://www2.ed.gov/about/offices/list/ope/trio/index.html

Vallerand, R. J., \& Ratelle, C. F. (2002). Intrinsic and extrinsic motivation: A hierarchical model. In Deci, E. L., \& Ryan, R. M. (Eds.), Handbook of selfdetermination research (pp. 37-64). Rochester, NY: University of Rochester Press. 
Vansteenkiste, M., Lens, W., \& Deci, E. D. (2006). Intrinsic versus extrinsic goal contents in Self-Determination Theory: Another look at the quality of academic motivation. Educational Psychologist, 41(1), 19-31.

Vansteenkiste, M., Williams, G. C., Y Resnicow, K. (2012). Toward systematic integration between Self-Determination Theory and Motivational Interviewing as examples of top-down and bottom-up intervention development: Autonomy or volition as a fundamental theoretical principle. International Journal of Nutrition and Physical Activity, 9(23), 1-11.

Vygotsky, L. S. (1978). Mind in society: The development of higher psychological process. M. Cole, V. John-Steiner, S. Scribner, \& E. Souberman (Eds.). Cambridge, MA: Harvard University Press.

Wadsworth, J., Halfman, A. H., \& Upton, T. (2002). Strategies to improve the writing of graduate students. Rehabilitation Education, 16(3), 295-305.

Wiggins, G. P. (1998). Educative assessment: Designing assessments to inform and improve student performance. San Francisco: CA: Jossey-Bass.

Yin, R. K. (2014). Case study research: Design and methods (5th ed.). Thousand Oaks, CA: Sage.

Yin, R. K., Bateman, P. G., \& Moore, G. B. (1983). Case studies and organizational innovations: Strengthening the connection. Washington, DC: Cosmos Corporation. 
SCHOLARSHIP IN STUDENT AFFAIRS

Appendix A

\section{Informed Consent Form}

Lisa J. Hatfield

Informed Consent Form

Submitted with IRB Application for Exempt Review

August 6, 2014

Scholarship of Student Affairs Professionals: Professional Identity and Writing Strategies Explored through a Coaching Model

You are invited to participate in a research study conducted by Lisa Hatfield, a doctoral student in the Curriculum and Instruction department in Portland State University's Graduate School of Education. As a result of the study, the researcher expects to learn about participants' identity as scholars as well as effective strategies for writing when they engage in a structured writing program. If you decide to participate, data from your participation will be analyzed for inclusion in the study. Though you will not receive any direct benefit from taking part in the study, your participation will increase what is known about student affairs professionals who engage in scholarship.

Information that is obtained in connection with this study and that can be linked to you or identity will be kept confidential. To maintain confidentiality, pseudonyms will be used and specific titles and departments of the participants will not be given. Data will be kept secure on the researcher's computer, which is password protected; printed data will be kept secure in the researcher's locked office on campus.

Your participation is voluntary. You do not have to take part in this study. You may withdraw from this study at any time without affecting your relationship with the researcher, the Graduate School of Education, or Portland State University.

If you have questions or concerns about your participation in this study, contact Lisa Hatfield at lisa.hatfield@pdx,edu, 503-725-2952. If you have concerns about your rights as a research subject, please contact Research and Strategic Partnerships, Market Center Building 6th floor, Portland State University, (503) 725 4288. Your signing below indicates that you have read and understand the above information and agree to take part in this study. 
Appendix B

\author{
Background Questions \\ (sent via Google forms before initial group meeting)
}

Thank you for your willingness to participate in my dissertation research. As you know, I will be exploring professional identity formation as well as effective writing strategies. We will be working together to help you create a manuscript intended for publication in a practitioner or academic journal.

To help me become more familiar with your writing experience, attitudes, and goals, please respond to these questions by Friday, Oct. 3. Thank you.

1. Please share your experience with writing both professionally and academically.

2. What writing project would you like to complete by the end of our work together? (Choices are: new research you would like to conduct, revision or adaptation of current writing project, new article on practice, adaptation of presentation topic, and other, which allows for the participant to type in a response.)

3. Please talk about the commitment you have to this process.

4. What is your experience with writing for publication? Include any publications, including digital media.

5. What five words and/or phrases best describe your current professional and/or personal writing practices?

6. Please share your views about with feedback on your written work.

7. Have you presented at conferences? If so, please share the topic (or a few recent topics) and at what conference(s).

8. What are your two greatest strengths in terms of your writing that you can bring to this group? This can include anything from strategies you use to the actual writing itself or perhaps a characteristic you possess.

9. What are two concerns you have with your writing that you would like discussed in our work together?

10. Is there anything else you would like to share? 
Appendix C

Interview Protocol: Guiding Questions and Rationales

\begin{tabular}{|l|l|}
\hline Question & Rationale \\
\hline $\begin{array}{l}\text { 1. Why do you want to publish } \\
\text { scholarship? }\end{array}$ & Explores and honors experience and story \\
\hline $\begin{array}{l}\text { 2. How do you identify yourself } \\
\text { professionally? }\end{array}$ & $\begin{array}{l}\text { Explores identity, feelings of competence } \\
\text { and autonomy }\end{array}$ \\
\hline $\begin{array}{l}\text { 3. Do you identify yourself as a scholar? } \\
\text { Why or why not? }\end{array}$ & $\begin{array}{l}\text { Explores identity, perceptions of role in } \\
\text { higher education, feelings of competence }\end{array}$ \\
\hline $\begin{array}{l}\text { 4. What has or has not supported you in } \\
\text { your pursuit of scholarship? }\end{array}$ & $\begin{array}{l}\text { Explores competence, relatedness, } \\
\text { autonomy; explores writing strategies }\end{array}$ \\
\hline $\begin{array}{l}\text { 5. Beginning of study: What do you think } \\
\text { of coaching as a model to be used in our } \\
\text { study? }\end{array}$ & $\begin{array}{l}\text { Explores competence, relatedness, } \\
\text { autonomy; asks participants to reflect on } \\
\text { process (middle and end of study } \\
\text { questions); provides insights into roles of } \\
\text { relationship working for you? } \\
\text { relationship worked for you? }\end{array}$
\end{tabular} \begin{tabular}{l} 
writing strategies \\
\hline
\end{tabular}


Appendix D

Parent, Children, and Grandchildren Codes in Alphabetical Order

Autonomy (Parent level)

Competence

Creating habit

Journals

Finding one problematic (Child level)

Reading past issues/familiarity

Lack of time

Community work/volunteer

Family

Health

Too much work

Missed meeting

Family emergency

No reason

Transportation

Work

Motivations

Contribution to profession

Economic

Helping students

Personal goal

Prestige of publishing

Professional advancement

Not expected of profession (scholarship)

Inferiority

Wants expectation

Professional identity

Becoming more of a scholar

Doesn't fit in in higher education

Practitioner

Scholar practitioner

Relatedness

To coach

To large group

To mentor

Writing challenges

Distracted with other priorities

Environment

Researching

Writing perception

Likes to write 
SCHOLARSHIP IN STUDENT AFFAIRS

Not faithful to background

Not strong writer

Strong writer

Unfamiliar with expectations

Writing preferences

Seek feedback

Write alone

Writing strategies

Change plans in some way

Free writing

Goal setting

Just getting something down

Outlining

Linear (Grandchild level)

Visual

Physical organization

Reflecting

Revising

Support from family/partner

Talking through ideas

Write in long chunks of time

Write in short chunks of time 
Appendix E

Group Slides Session 1

\section{Welcome!}

Writing Group 1, Oct. 8, 2014

Lisa J. Hatfield, Portland State University

\section{Gratitude}

Participants names here; intentionally left blank for publication 


\section{Today ...}

- Overview of my research

- The submission process

- Journal selection

\section{Future writing group sessions}

Citation management systems (Zotero, Mendeley, etc.)? Style (APA, etc.)?

Checking in with colleagues ...

Lisa J. Hatfield, Portland State University

\section{Research Questions}

(a) How do student affairs professionals respond to various writing strategies in producing manuscripts to submit for publication in academic or practitioner journals?

(b) How does professional identity change during a structured writing program specifically intended to foster professional writing? 


\section{Methods, Theoretical Frameworks}

Multi-case study \& action research

Self-determination theory \& coaching

\section{Confidentiality Thoughts}

Pseudonyms will be used

Departments not named though brief description of work, years working with students, gender identity, and age range will be used 


\section{Methods, Theoretical Frameworks}

Multi-case study \& action research

Self-determination theory \& coaching

\section{Confidentiality Thoughts}

Pseudonyms will be used

Departments not named though brief description of work, years working with students, gender identity, and age range will be used 


\section{Data Sources}

Background questions

Interview protocol

Researcher's journal

Participants' journals (collected, digital and/or paper)

Writing drafts, outlines, doodles, etc.

Session interactions (recorded?)

Other communication (emails, etc.)

Lisa J. Hatfield, Portland State University

\section{Schedule}

Writing Group 1: Oct. 8 Individual sessions 1-3 Writing Group 2: Nov. 5 Individual sessions 4-6 Writing Group 3: Dec. 10 Individual sessions 7-9 Writing Group 4: Jan. 21 


\section{Processes \& Journals}

\section{Typical Publication Process}

Solicit paper or receive invitation to write Submịt paper

Wait, wait, wait some more (peer review)

Accept Reject

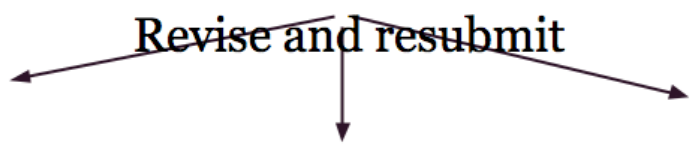




\section{Feedback}

I believe the topic of academic coaching is of interest to our readers and would be a good fit for our audience; however, I have a number of revision requests before it is ready for a second review. I have written some of the broader suggestions here and I have also attached suggested revisions on your article. ...

I recommend following a more traditional format for this article--provide an abstract, introduction, and new headings (I have offered those revisions in the article as well)...

A word of caution before you open the attachment--the article is heavily edited, but do not be discouraged by that. I think you would need to invest a good deal of time into revising this piece, although I hope what I have already done for you in terms of editing will significantly cut down on the amount of time you would need to dedicate.

Again, I want to emphasize that the overall concepts you have presented are worthy of publication-with a bit of revision, your main ideas will more clearly reach your audience.

\section{Top Reason an Article is Rejected}

\section{Sent to wrong journal, does not fit the journal's aims and scope/fails to engage with the issues addressed by the journal.}

Graham Hobbes, Editorial Director, Routledge (UK), AERA conference, April 2103 


\section{Reasons 2-10}

2. Not a proper journal article (too journalistic or clearly a thesis chapter)

3. Too long or too short (ignoring word limits or minimums)

4. Poor regard to journal's conventions or academic writing generally

5. Bad style, grammar, punctuation

6. Fails to say anything of significance or states the obvious at tedious length

7. Not properly contextualized (ignores needs of wider readership)

8. Poor theoretical framework (including references to relevant literature)

9. Scrappily presented and clearly not proofread

10. Libellous, unethical, rude

\section{Journal Types Schema}

From Dannelle Stevens, GSE

\begin{tabular}{|l|l|l|l|l|}
\hline Generation & Definition & Text Structure Elements & References & Examples of Journals \\
\hline First & $\begin{array}{l}\text { Peer reviewed, qualitative, } \\
\text { quantitative, mixed } \\
\text { methods }\end{array}$ & $\begin{array}{l}\text { Abstract, detailed title, common } \\
\text { research format, pages numbered } \\
\text { across issues in one volume (year), } \\
\text { results often numerically } \\
\text { represented in tables } \\
\text { Audience: researcher }\end{array}$ & $\begin{array}{l}\text { Numerous } \\
\text { Used to find other } \\
\text { sources }\end{array}$ & $\begin{array}{l}\text { Journal of Student Affairs } \\
\text { Research and Practice } \\
\text { Journal of College } \\
\text { Student Development }\end{array}$ \\
\hline Second & $\begin{array}{l}\text { Peer reviewed, qualitative, } \\
\text { quantitative, mixed } \\
\text { methods }\end{array}$ & $\begin{array}{l}\text { Abstract sometimes, often a review } \\
\text { article, often summarizes a series of } \\
\text { research, pages numbered across } \\
\text { issues in one volume (year), can be } \\
\text { action research, sometimes photos } \\
\text { Audience: researcher, informed } \\
\text { practitioner }\end{array}$ & $\begin{array}{l}\text { Numerous, especially if } \\
\text { a review article }\end{array}$ & $\begin{array}{l}\text { Review of Educational } \\
\text { Research }\end{array}$ \\
\hline
\end{tabular}




\section{Journal Types Schema}

\begin{tabular}{l} 
Slide 15 From Dannelle Stevens, GSE \\
\begin{tabular}{|l|l|l|l|l|}
\hline Generation & Definition & Text Structure Elements & References & Examples of Journals \\
\hline & & & & \\
Third & $\begin{array}{l}\text { Not necessarily peer } \\
\text { reviewed } \\
\text { Editor or editorial board } \\
\text { review }\end{array}$ & $\begin{array}{l}\text { No abstract } \\
\text { Can have catchy title } \\
\text { Little attention to methods } \\
\text { Summary of findings } \\
\text { Quick read, user friendly } \\
\text { Photos, advertisements } \\
\text { Audience: informed practitioner }\end{array}$ & $\begin{array}{l}\text { Few } \\
\text { Usually no references } \\
\text { within text }\end{array}$ & $\begin{array}{l}\text { Leadership Exchange } \\
\text { About Campus }\end{array}$ \\
Lisa J. Hatfield, Portland State University
\end{tabular} \\
\hline
\end{tabular}

\section{Journals ...}

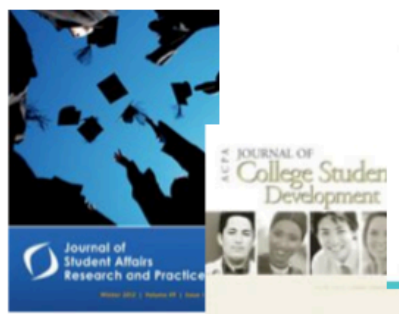

\section{IBOUTCAMPUS}
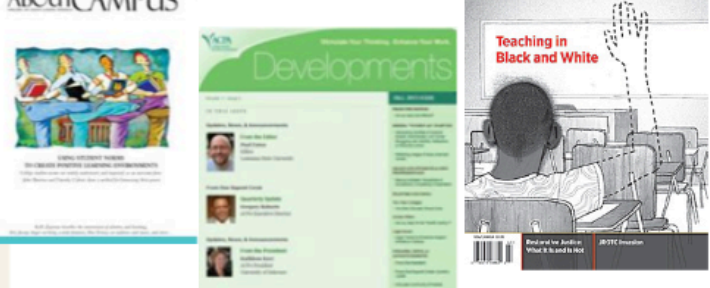

rom

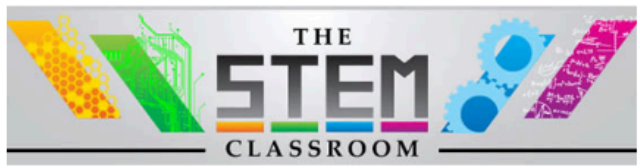




\section{Selecting a Journal}

Find several issues and look through them

What kinds of articles? Topics? Length?

Who gets published?

What is the review process?

What is the tone of articles?

Are there abstracts, tables, figures?

How many references?

\section{For Next Time}




\section{Goal-Setting}

Create two goals for yourself

1. One to be accomplished by Dec. 10 (writing group meeting \#3)

2. One having to do with journals to be done by first 1:1 session next week

3. Email me these by the day before our 1:1

\section{SMARTer Goal-Setting}

15 SAECIFIC

M MEASURABLE

9 A AGREED

R REALISTIC

IT TPME-BOUND

E ETHICAL

बR RECOROED 


\section{Concluding Thoughts}

What are your take-aways for today?

What questions do you still have?

How do you feel about what you're getting yourself into? 
Appendix F

Group Slides Session 2

\section{Welcome!}

\section{Writing Group Meeting 2}

Nov. 5, 2014

\section{Freewrite}

\section{Your project ...}




\section{Share Progress}

How's it going? What's happened?

What strategies have/have not worked for you?

\section{Strategies (Silvia, 2008)}

- Instead of finding time, allot time

- The secret is regularity (I call it habit) rather than binging

- It isn't enough to set a goal and make it a priority; we must monitor our progress toward our goal 


\section{The Power of Habit}

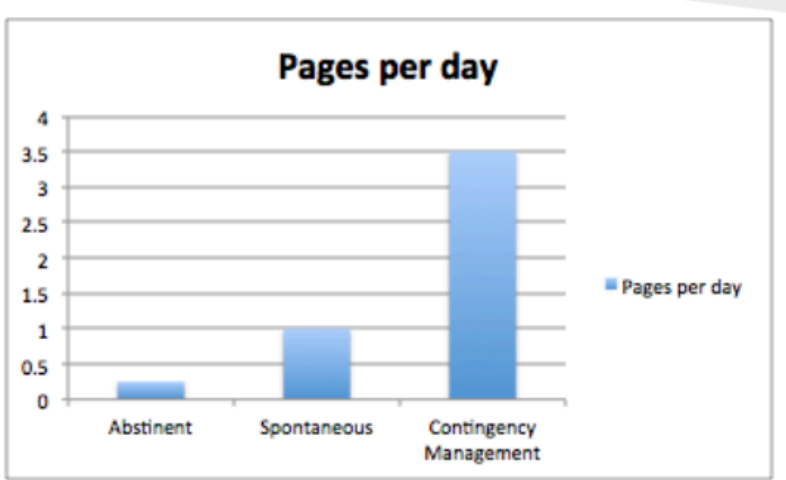

Boice, 1990

\section{Observation: Environment}

\section{Doors \& Windows}

"We want to be accessible to students (and be safe for all sorts of reasons) and so our offices and doors are covered with windows. But this is not always the best to be productive. Perhaps having a place where people can go away? Physically removing oneself is key ..." 


\section{The Abstract}

\section{Clarifies PURPOSE even if not required in} submission guidelines

- Provides context

- States the problem

- States why the problem matters

- Provides a summary of employed methods/approach to research

- Gives brief description of results

Suggests what literature needs to be used

\section{What else?}




\section{By Next 1:1}

$\rightarrow$ Email today's freewrite (typed or scanned)

$\rightarrow$ Email your CV/resume

$\rightarrow$ Review your goals

$\rightarrow$ Keep writing in your journals! 
Appendix G

Slides from Group Session 3

\section{Welcome!}

\section{Writing Group Meeting 3}

Dec. 10, 2014

On stage, Jack Kornfield asked about my writing process. A trick question! Butt in chair. Just DO it. Shitty 1st drafts. Short assignments. 
Slide 3

\section{Freewrite ...}

Response to Lamott quote

How your writing is coming along

How you're feeling about your writing so far

How you're feeling about the process so far

A pictorial timeline of your process

Something else about your writing?

\section{Rubrics}

Ideas and content

Organization

Word choice

Voice

Sentence fluency

Conventions

Citing sources

http://www.ode.state.or.us/wma/teachlearn/testing/scoring/guides/2011-12/wriscorguide eng no-dates.pdf 


\section{Writers' Workshop}

Give brief context

Share your specific questions regarding

feedback

Preferences for how to mark text?

Read and comment with focus on questions

\section{Resource}

They Say, I say:

The Moves That Matter in Academic Writing

by Gerald Graff and Cathy Birkenstein (and Russel Durst on some editions)

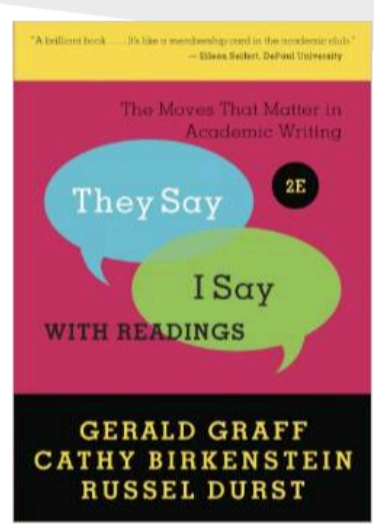




\section{By Monday, Dec. 15}

Please send me freewrite

REMINDERS:

Save your commented drafts!!

Save your drafts as separate documents!!

\section{You're Almost There!}

- Last series of individual meetings

- Last group meeting Wednesday, Jan. 21

Come prepared to share what you have

What would be helpful for you for the last group meeting?

- Submit all documents (drafts, doodles, notes, etc.) or give me access to them by Jan. 21 
Appendix $\mathrm{H}$

Slides from Group Session 4

\section{Welcome!}

Writing Group Meeting 4

Jan. 21, 2015

\section{Congratulations! We Made It!}




\section{Freewrite}

Autonomy: "the feeling of volition that can accompany any act, whether dependent or independent, collectivist or individual"; not necessarily that one is independent*

Competence: another term for efficacy or the perceived ability to be able to accomplish a task** Relatedness: has to do with a sense of belongingness and connectedness to persons, group, or culture disseminating a goal**

... and other final thoughts.

${ }^{*}$ Ryan \& Deci, $2000 b$

**Ryan \& Deci, 2000

\section{Etc.}

- Create pseudonyms or use Participants A-E?

- "pseudonyms will be used and specific titles and departments of the participants will not be given" (consent form)

Departments not named though brief description of work, years working with students, gender identity, and age range will be used (slide from writing group 1 meeting)

- PSU described as large urban institution in the Northwest (will check with my adviser -- PSU may be named) 


\section{Today ...}

1. Share current successes

2. Focused freewrite

3. Pseudonyms, data deadline

4. What's next

\section{Research Questions}

(a) How do student affairs professionals respond to various writing strategies in producing manuscripts to submit for publication in academic or practitioner journals?

(b) How does professional identity change during a structured writing program specifically intended to foster professional writing? 


\section{The End of Data}

Please give me any lingering documents no later than Monday, Jan. 26, 2015, so I can begin the analysis portion of my dissertation.

Question: May I contact you if I have questions about the data?

Request: Please let me know once you submit and if you hear anything.

\section{My (tentative) Timeline}

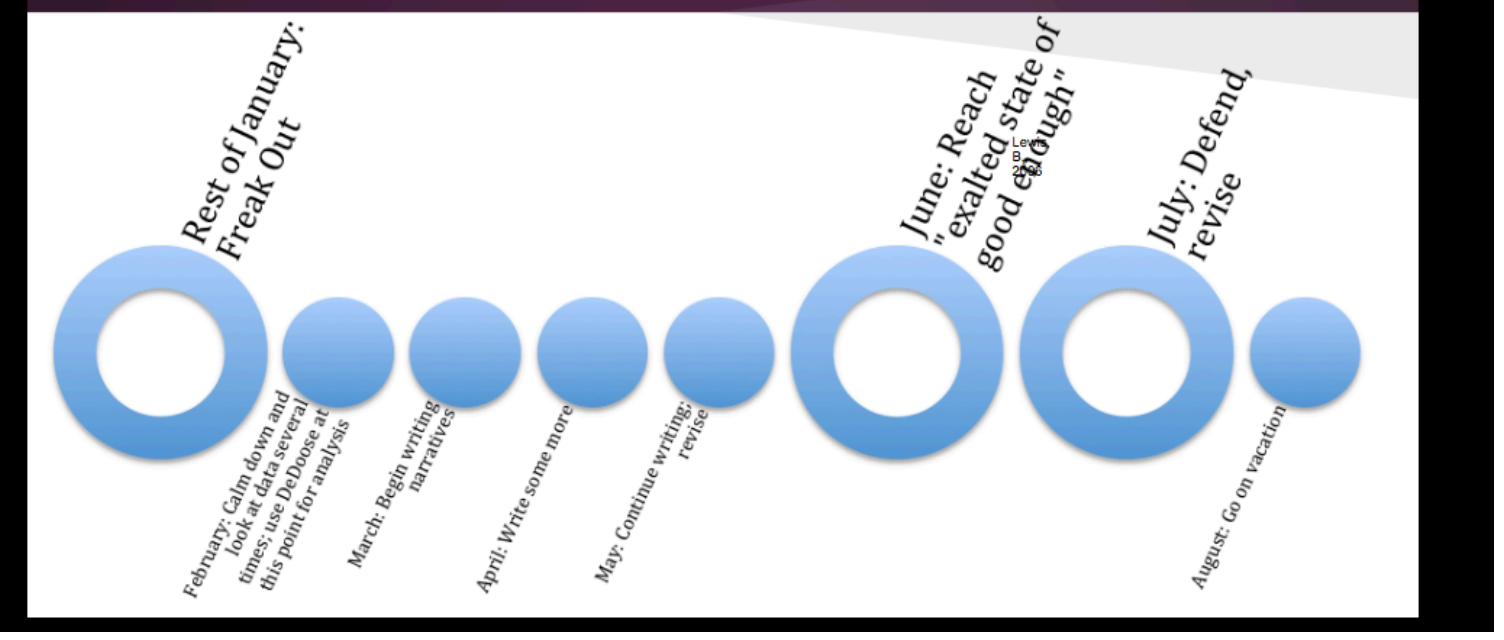




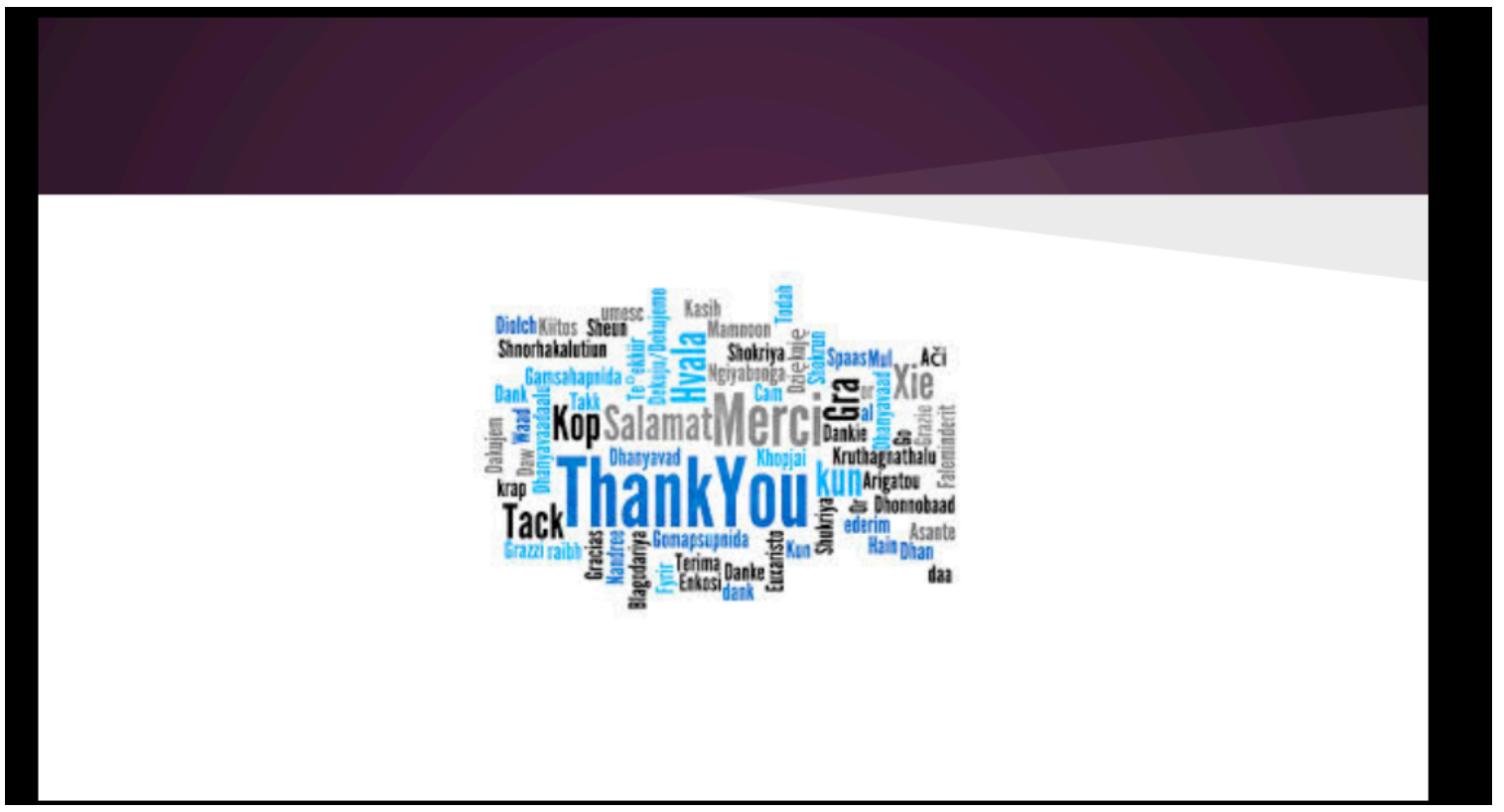


Appendix I

\section{Lou's Organizational Mind Map}

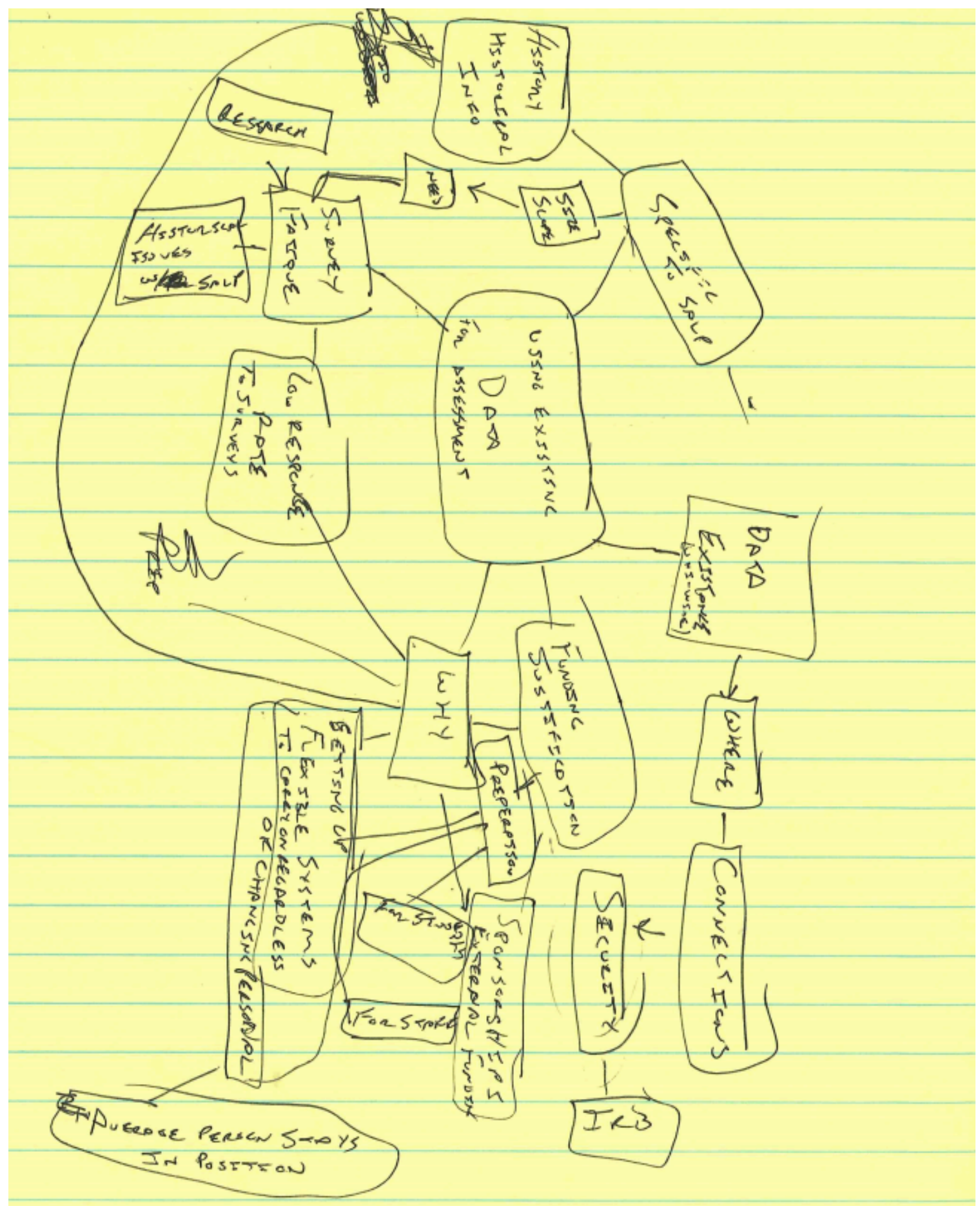

Appendix $\mathbf{J}$ 
SCHOLARSHIP IN STUDENT AFFAIRS

174

Diana's Visual Organization

out history of C.F., all the 3 - what people said we could nit do.

making the chang: ext on paperwork I no time for der.

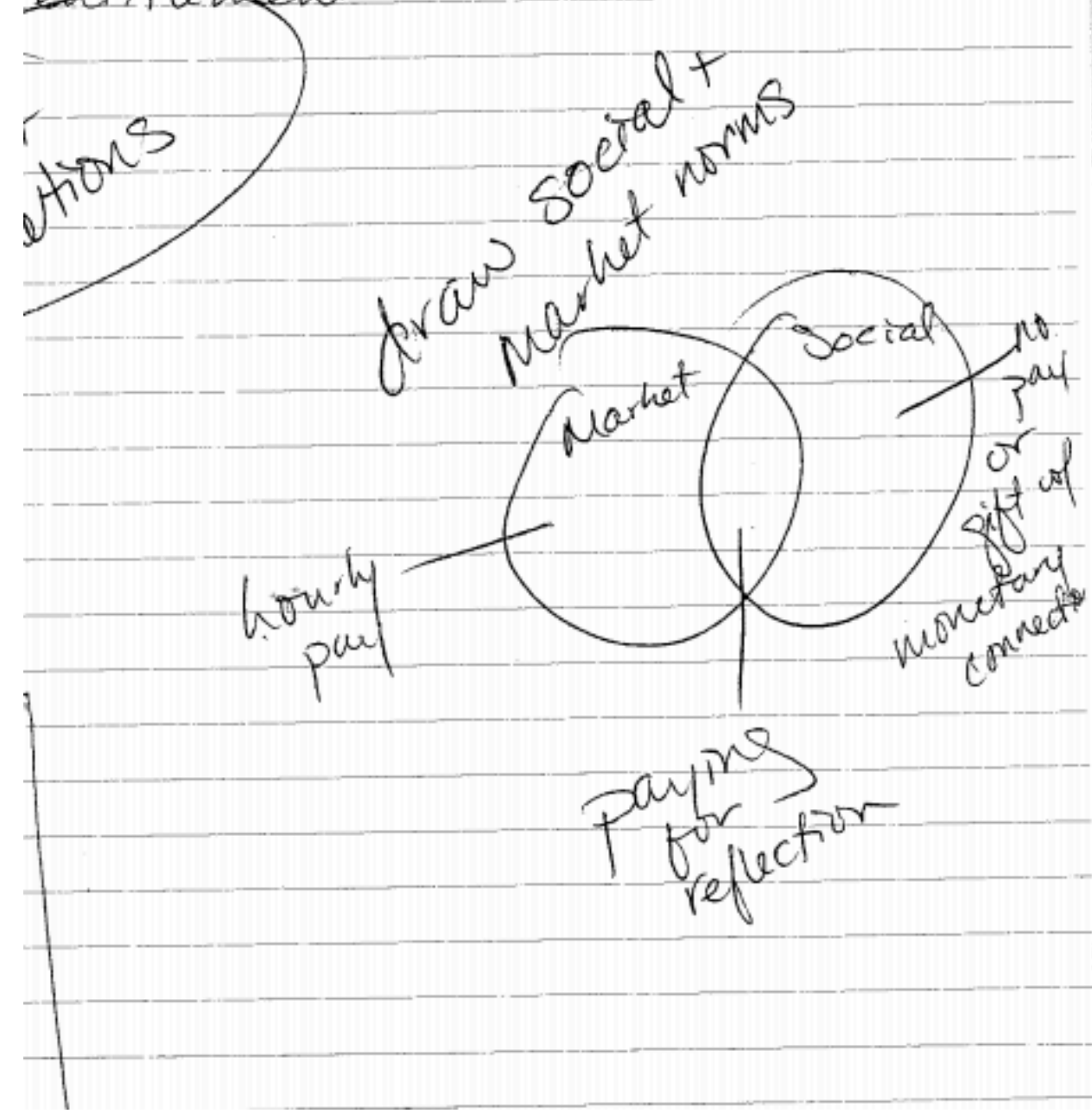

